مجلة الاسكندرية للبحوث المحاسبية قسم المحاسبة - كلية التجارة جامعة الإسكندرية

د/ السيد أحمد محمود فودة مدرس المحاسبة

وهيكل التكلةة خلال دورة حياة الشركة "دراسة إختبارية"

\title{
ملخـص البحث
}

استهدف البحث دراسـة العلاقة بين حالـة عدم التأكد حول الطلب واختبار هيكل التكلفة، بالإضافة إلى اختبار أثز توجه المدراء نحو المخاطرة على طبيعة هذه العلاقة خلال المراحل هله

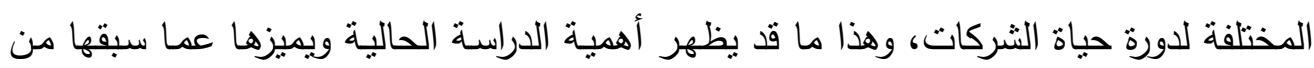

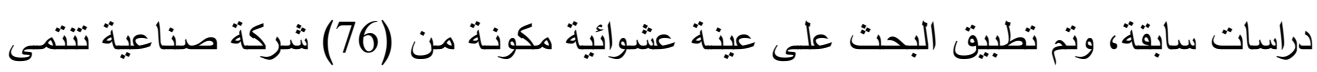

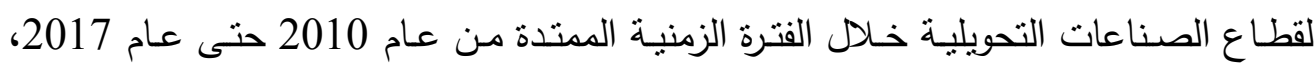

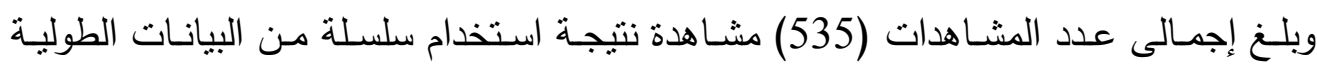

الغير منوازنة (Unbalanced Panel Data).

واعتمدت الدراسة على تطوير نموذج (Banker et al, 2014 "b") لقياس العلاقة بين حالة عدم التأكد حول الطلب ومرونـة هيكل التكلفة، بالإضـافة إلى اختبار أثر توجـه المدراء نحو المخاطرة على طبيعة هذه العلاقة خلال المراحل المختلفة لدورة حياة الثركات الصناعية محل الدراسة، وذلك باستخدام المتغيرات الوهمية (Least-squares dummy variable

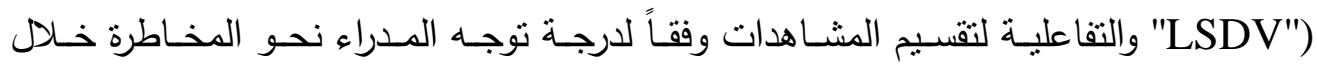
المراحل المختلفة لدورة حياة الثركات الصناعية. كما تم الاعتماد على نموذج (Bo and Sterken, 2007) للتعبير عن توجه المدراء نحو المخاطرة سواء من حيث تجنب المخاطرة أو الإقبال على تحملها، وكذلك تم الاعتماد على نموذج (Dickinson, 2011) 
(EviewsVersion, النقدية التشغيلية والاستثمارية والتمويلية، وتم تشغيل البرنامج الإحصائى (10، واستخدام نموذج الأثار الثابتة (Fixed Effect Model) لاختبار الفرض الأول للبحث، والذى ينص على أنه "لا يوجد اختلاف فى العلافة بين حالـة عدم التأكد حول الطلب وهيكل التكلفة خلال المراحل المختلفة لدورة حياة الثركات الصناعية العاملة فى بيئة الأعمال المصرية".

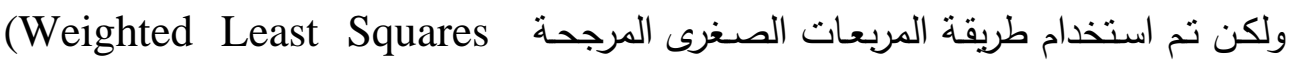
"WLS") توجـه المدراء نحو المخاطرة على العلاقة بين حالة عدم التأكد حول الطلب وهيكل التكلفة خلال المراحل المختلفة لدورة حباة الثركات الصناعية العاملة فى بيئة الأعمال المصرية". وجدير بالذكر أنه تم تقدير نماذج الانحدار المستخدمة فى اختبار فرضى البحث باستخدام أهر (Robust Standard Errors) للتخلص من مشكلتى الارتباط التسلسلى بين البواقى (هي

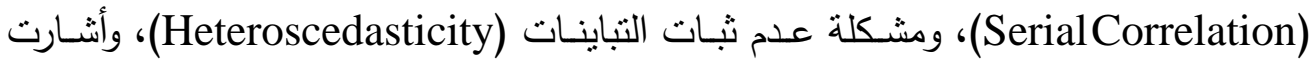
نتائج البحث إلى رفض فرضى البحث؛ نظراً لاختلاف درجة التأثثر السلبى لحالة عدم التأكد حول الطلب على مرونة هيكل التكلفة خلال المراحل المختلفة لدورة حياة الثركات الصناعية محل الدراسـة، وبـالأخص فى مرحلـة النضـج (Maturity) والاهتزاز (Shakeout) والتقديم

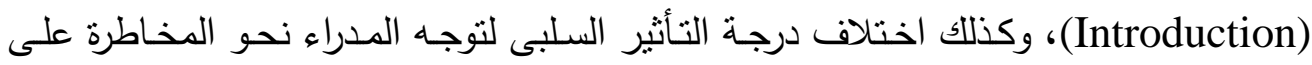
العلاقة بين حالة عدم التأكد حول الطلب ومرونـة هيكل التكلفة خلال المراحل المختلفة لدورة حياة الثـركات الصـناعية محل الدراسـة، وبـالأخص فى الثـركات التى يغلب على مدرائها

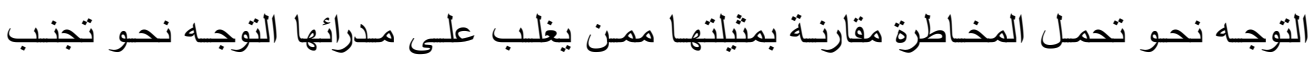

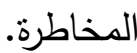

الكلمـات المفتاحيةة: حالة عدم التأكد حول الطلب (Demand Uncertainty)، هيكل التكلفة (Cost Structure)، توجه المدراء نحو المخاطرة (Risk Attitude of Managers)، دورة حياة الثركة (Firm Life Cycle). 


\section{The Effect of Risk Attitude of Managers on the Relationship between Demand Uncertainty and Cost Structure through Firm Life Cycle- An Empirical Study}

\section{Abstract}

This Paper aims to investigate the relationship between demand uncertainty (DU) and cost structure flexibility (CSF), in addition to test the effect of risk attitude of managers (RAM) on that relationship through different stages of firms' life cycle (FLC) and this reflects the importance of the current study and makes it unique from previous studies.

The researcher developed the model of (Banker et al, 2014 "b"), by using number of dummy and interactive variables, to split the observations according to (RAM) through different stages of (FLC).

The current study used the model of (Bo and Sterken, 2007) to distinguish between (RAM) even they are risk averse or risk takers, and used the model of (Dickinson, 2011) to distinguish between different stages of (FLC) by using cash flow from operations, investment and financing.

The researcher used a random sample of (76) industrial firms belonging to the transformational industries sector, during the period from 2010 to 2017 , with a total number of observations (535) using unbalanced panel data.

The study applied the statistical programming of (Eviews version, 10) and (Fixed Effect Model) to test the first hypothesis which states "There are no differences in the relationship between (DU) and cost structure (CS) through different stages of (FLC) in the Egyptian environment". And the method of (Weighted Least Squares "WLS") to test the second hypothesis which states "There are no differences in the effect of (RAM) on the Relationship between (DU) and (CS) through different stages of (FLC) in the Egyptian environment".

Finally, all regression models used in testing the hypotheses were estimated by using (Robust Standard Errors) to get rid of both problems (Serial Correlation, Heteroscedasticity).

The results indicated that, null of both hypotheses of the study have been rejected, due to first: the value difference in the negative effect of (DU) on (CSF) through different stages of (FLC), espesically on maturity, shakeout, and introduction. Second: the value difference in the negative effect of (RAM), on the relationship between (DU) and (CSF), through different stages of (FLC), espesically on firms which managers are higher-risk takers, compared to firms with managers who are risk averse.

Keywords: Demand Uncertainty, Cost Structure, Risk Attitude of Managers, Firm Life Cycle. 


\section{أولاً: مقدمة ومشكلة البحث}

يعـد التغير الذـى شـهـته خصـائص البيئـة الصـناعية الحديثـة - مـن تعقد فـى العمليـات الإنتاجيـة وتتـوع المنتجـات، ومرونـة خطوط الإنتاج، بالإضـافة إلى تزايد حدة المنافسـة بين

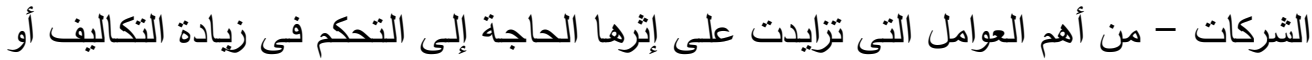
ما يُعرف بإدارة التكلفة، ولعل إدارة التكلفة والتحكم فيها يتطلب بالدرجة الأولى فهماً للعوامل بهل التى قد تؤثر على سلوك وهيكل التكاليف الخاص بالثركة. وفى هذا الإطار اهتمت العديد من الدراسات بالتعرف على سلوك التكلفة وذلك سواء من خلال البحث واختبار محركات التكلفة الغير مرتبطة بالحجم Banker et al, 2008; Chen)

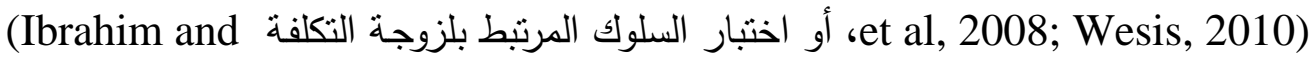
Ezzat, 2017; Balakrishnan et al, 2014; Via and Perego, 2014) (Noreen and Soderstrom, إلى أى مدى تكون الأعباء الصناعية تكاليف ثابتة ومتغيرة 1997; 1994; Raffi and Swamidass, 1987) واختيار هيكل التكلفة (Cost Structuer) بنفس القدر من الأهمية، حيث لم ينل الموضوع الخـاص بمحددات اختيـار هيكل التكلفة على اهتمـام سوى عدد ضـئيل مـن الدراسـات، مـن (Banker et al, 2014 (b); Kallapur and Eldenburg, 2005;

.Balakrishnan et al, 2008)

وبمراجعـة تلك الدراسـات تببين أن هيكل التكلفة يعرف على أنـه التكوين النسبى لعناصـر التكاليف الثابتة والمتغيرة إلى إجمالى تكاليف الثركة، وجدير بالذكر أن هذا الهيكل بختلف

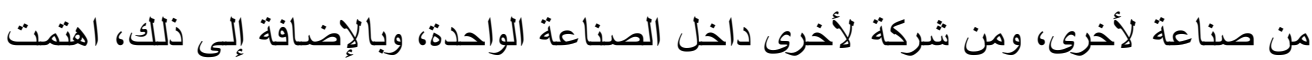
تللك الدراسات باختبار بعض العوامل المؤثرة على اختيار التكوين النسبى لهيكل التكلفة وكان من أهمها: حالة عدم التأكد المرتبطة بالطلب (Demand Uncertainty)، إلا أن نتائج هذه الدراسـات جـاءت متعارضــة مـع بعضــها البعض، وذللك إلـى جانـب تعارضــها مـع الأدبيـات التقليدية المرتبطة بمحاسبة التكاليف والإدارية؛ حيث أثنارت دراسة (b)( إلى أنه فى حالة ارتفاع حالة عدم التأكد المرتبطة بالطلب على منتجات الثركة ستقبل الثركات على اختيار هيكل تكلفة أقل مرونة (أكثر جموداً) وذلك لتجنب تكاليف الازدحام 
(الاختناقات) من خلال زيادة نسبة التكاليف الثابتة فى مقابل تخفيض نسبة التكاليف المتغيرة فى هيكل التكلفة الخاص بالشركة. وعلى النقيض مما سبق، أثنارت دراسة (Kallapur and Eldenburg, 2005) إلى أن الثركات تُفضل عندما تزداد حالة عدم التأكد إلى اختيار هيكل تكلفة أكثر مرونة (أقل جموداً) وذلك من خلال تخفيض نسبة التكاليف الثابتة وزيادة نسبة التكاليف المتغيرة فى هيكل التكلفة، ومـن ثم تصـبح التقنيـات التكنولوجيـة ذات التكـاليف الثابتـة المنخفضـــة والتكـاليف المتغيـرة المرتفعـة أكثر جاذبيـة فى حالـة زيادة حالـة عدم التأكد، وتتفق نتائج هذه الدراسـة مـع وجهة

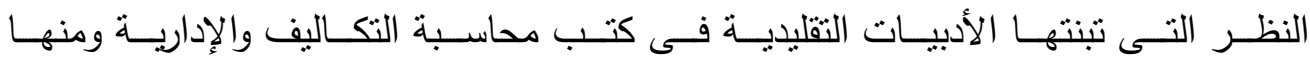
(Balakrishnan et al, 2008) والتى أثنارت إلى أن هيكل التكلفة المرتبط برافعة تشغيلية

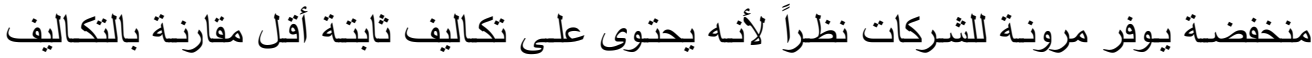
المتغيرة، ومن ثم من المتوقع فى حالة وجود تقلبات فى حجم الطلب على منتجات الثركة بما يثير إلى ارتفاع حالة عدم التأكد حول الطلب- أن تختار الثركات هذه المرونة.

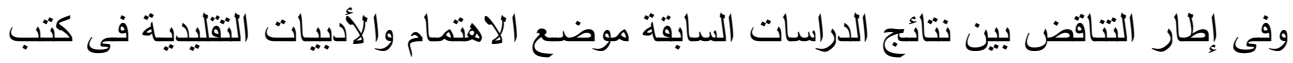
محاسبة التكاليف والإدارية حول أثر حالة عدم التأكد حول الطلب على اختبار التكوين النسبى النى

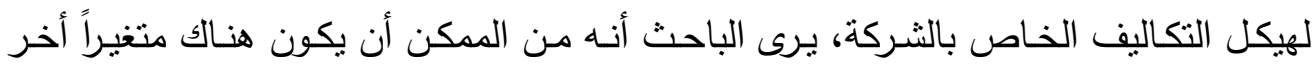

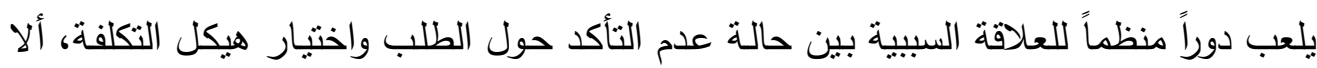
وهو توجه مدراء الثركات نحو المخاطرة (Mangers Attitude Towards Risk)، حيث تجاهلت معظم الدراسات الاختبارية التى اهتمت بدراسـة العلاقة بين حالة عدم التأكد المرتبطة

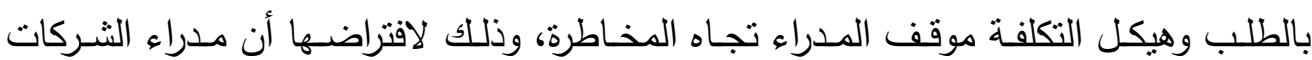
محايدون تجاه المخاطرة (Bo and Sterkin, 2006)، في حين قسمت دراسـة كل مـن توجـه (Brigham and Houston, 2007; Brigham and Erdhard, 2005) المدراء نحو المخـاطرة وفقـاً للأدبيات السـابقة فى مجال الإدارة الماليـة إلى ثـلاث توجهات،

- مدراء محبى للمخاطرة (Risk-Taking)؛ وهم لديهم استعداد مرتقع لتحمل المخاطرة عند صنـع القرارات الماليـة والاستثمارية، حيث يخضـع ميلهم نحو المخـاطرة لقانون تزايـ 
المنفعة الحدية للوحدة الإضافية من العائد، ومن ثم يعطى الأولوية لأثر القرارات التى ينتوى اتخاذها على الربحية.

- مـدراء كـارهى للمخـاطرة (Risk-Aversion)؛ وهم لديهم استعداد منخفض لتحمل المخاطرة عند صنع القرارات المالية والاستثمارية، حيث يخضع ميلهم نحو المخاطرة لقانون تتاقص المنفعـة الحدية للوحدة الإضـافية من العائد، ومن ثم يعطى الأولويـة لأثر القرارات التى ينتوى اتخاذها على مستوى المخاطرة الكلية للشركة.

- مدراء محايدون للمخاطرة (Risk-Netural)؛ وهم لا يهتموا بالمخاطرة عند صنع القرارات

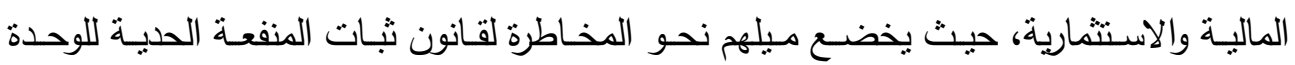
الإضافية من العائد، ومن ثم يوازن هذا النوع من المدراء بين ربحية ومخاطرة القرارات التى ينتوى اتخاذها.

لذا من الغير واقعى افتراض حيادية توجه المدراء نحو المخاطرة فى جميع المواقف وذلك

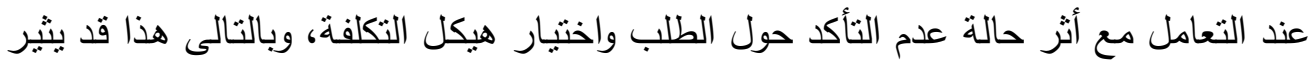
الشكوك حول نتائج الدراسات التى اهتمت بدراسة العلاقة السببية بين حالة عدم التأكد حول هوليجل الطلب واختيـار هيكل التكلفـة وذلـك نتيجـة تجاهلهـا المواقف المختلفـة لتوجـه المـدراء نحسو

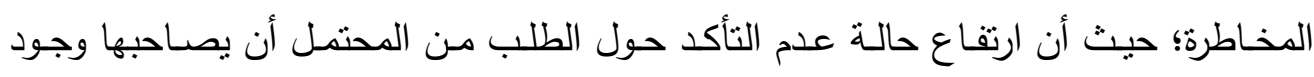
انخفاض أو ارتفاع غير عادى فى الطلب الفعلى المحقق. ومن ثم قد يميل المدراء ممن لديهم رغبة فى تحمل الدخاطرة إلى اختبار هيكل تكلفة أكثر جموداً (أقل مرونـة) من خـلال زيادة التكاليف الثابتة وتخفيض التكاليف المتغيرة فى هيكل التكلفة، من أجل تحقيق الاستفادة القصوى من الفرص التى قد تتيحها حالة عدم التأكد حول الطلب والخاصة باحتمال تحقق ارتفاع غير عادى فى حجم الطلب على منتجات الثركة، بما قد يضطر مدراء الثركات إلى زيادة مستوى الطاقة، وذلك تجنباً لزيادة حدة تكاليف الازدحام

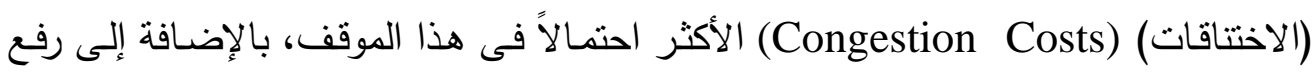
الكفاءة الإنتاجية التى قد تعانى من الانخفاض نتيجة عدم مراعاة زيادة تكاليف الازدحام.

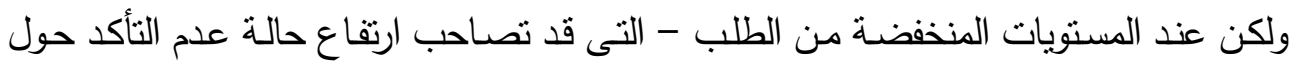
الطلب - قد يسعى المدراء ممن لديهر رغبة فى تجنب المخاطرة إلى اختبار مستوى أقل من الطاقة (Capacity)، ومن ثم تخفيض التكاليف الثابتة الأكثر ارتباطاً بها، بما يؤدى إلى اختيار هيكل 
تكلفة أكثر مرونة (أقل جموداً) من خلال تخفيض التكاليف الثابتة وزيادة التكاليف المتغيرة، وذلك نظراً لأن تكاليف الازدحام تكون أقل خطورة من الوضـع السـابق خاصـة فحى حالة زيادة مخاطر الهبوط (Downside Risk)، ومن ثم فإن وفورات التكاليف الناتجة عن زيادة وحدة إضـافية من لهن المدخلات الثابتة ستككون أكبر عند ارتقاع مستوى الطلب المحقق وذللك مقارنة بانخفاض مستوى ونى الطلب المحقق، وكلا الوضعين بصبح أكثر احتمالاً عند زيادة حالة عدم التأكد حول الطلب.

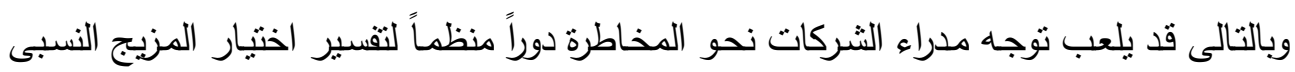
لهيكل التكلفة استجاباً لحالة عدم التأكد حول الطلب، إلا أن العلاقة التفاعلية التى قد نتشـأ بين

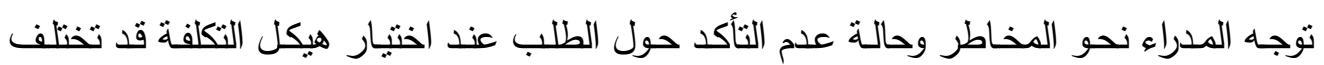

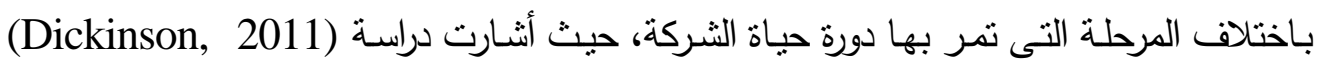

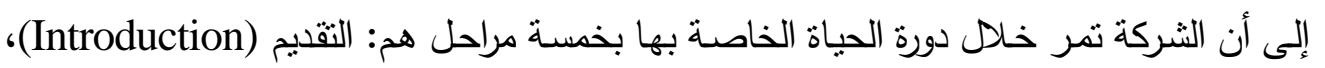

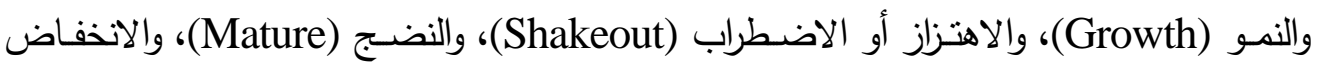

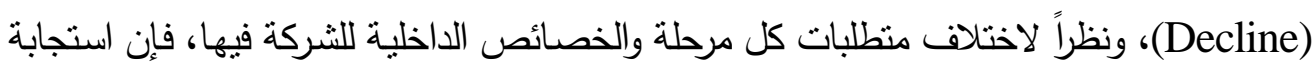
المزيج النسبى لهيكل التكلفة قد يختلف باختلاف كل مرحلة من مراحل دورة حياة الثركة.

\section{ومما سبق، يمكن تلخيص مشكلة البحث فى التساؤلات الرئيسية التالية:}

- - هل تختلف العلاقة بين حالة عدم التأكد حول الطلب وهيكل التكلفة فى الثركات الصناعية التى تعمل فى بيئة الأعمال المصرية خـلال المراحل المختلفة التى تمر بها دورة حياة الشركات؟.

- هل يختلف أثز توجه المدراء نحو المخاطرة على العلاقة بين حالة عدم التأكد حول الطلب وهيكل التكلفة فى الثركات الصناعية التى تعمل فى بيئة الأعمال المصرية خلال المراحل المختلفة التى تمر بها دورة حياة الثركات؟.

\section{ثانياً: أهداف البحث}

تمشياً مع التساؤلات الرئيسية لمشكلة البحث تتمثل أهداف البحث في الهدفين التاليين:

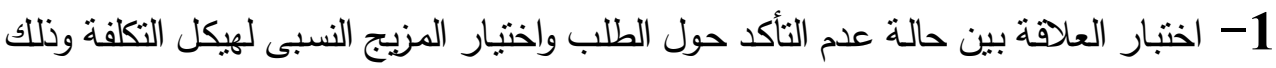
بالتطبيق على الثركات الصناعية التى تعمل فى بيئة الأعمال المصرية خلال المراحل المختلفة

$$
\text { التى تمر بها دورة حياة الثركات. }
$$


2- اختبار أثز توجه المدراء نحو المخاطرة على العلاقة بين حالة عدم التأكد حول الطلب واختيار المزيج النسبى لهيكل التكلفة وذللك بالتطبيق على الثركات الصناعية التى تعمل لهن فى بيئة الأعمال المصرية خلال المراحل المختلفة التى تمر بها دورة حياة الثركات ثالثاً: أهمبة البحث

\section{يستمد هذا البحث أهميته من خلال الأبعاد التالية:}

ندرة الدراسـات - فى حدود علم الباحث - التى تتاولت موضوع محددات اختيار هيكل التكلفة وذللك بالتركيز على حالة عدم التأكد حول الطلب. ندرة الدراسـات - فى حدود علم الباحث - التى نتاولت أثنر توجهـ المدراء نحو المخاطرة على اختبار هيكل التكلفة وذللك استجابة لحالة عدم التأكد حول الطلب. يتوقع أن تسهم نتائج البحث فى الكثف عن التكوين النسبى لهيكل التكلفة خلال المراحل المختلفة لدورة حياة الشركات.

يتوقع أن نسهم نتائج البحث فى توفير فهم أفضل لسلوك التكلفة فى الشركات الصناعية التى تعمل فى بيئة الأعمال المصرية من خلال تقديم الدليل العلمى عن ما إذا كانت حالة

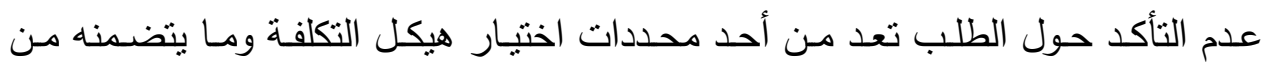
تكاليف ثابتة ومتغيرة، وذلك خلال المراحل المختلفة لدورة حياة الثركات. يتوقع أن تسهم نتائج البحث في الكثف عن توجهات مدراء الثـركات الصناعية نحو المخاطرة خلال المراحل المختلفة لدورة حياة الثركات.

يتوقع أن تسهم نتائج البحث فى حسم الجدل القائم بين الدراسات والأدبيات التقليدية السابقة (Banker et al, 2014 (b); Kallapur and Eldenburg, 2005; Balakrishnan حول ما إذا كان ارتفاع حالة عدم التأكد حول الطلب سيصاحبه اختيار هيكل تكلفة أقل مرونـة (أكثر جموداً) أم العكس، بالإضـافة إلى الكثف عن عن ما عا إذا كان

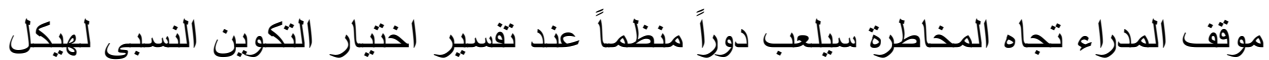
التكلفة استجابة لحالة عدم التأكد حول الطلب فى الثركات التى تعمل في بيئة الأعمال المصرية، وذلك خلال المراحل المختلفة لدورة حياة الثركات. 


\section{رابعاً: الدراسات السابقة واشثتقاق فروض البحث}

تعد دراسة (Kallapur and Eldenburg, 2005) من الدراسات التى اهتمت بالكثف عن

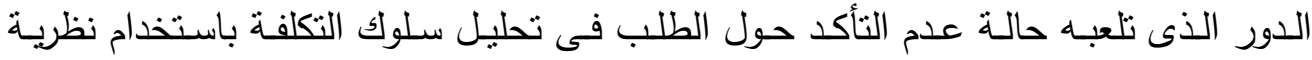
الخيارات الحقيقية (Real Option)، وذلك بالتطبيق على قطاع الرعاية الصحية وبالأخص

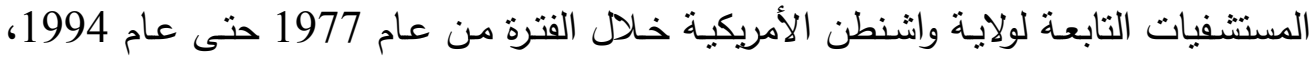

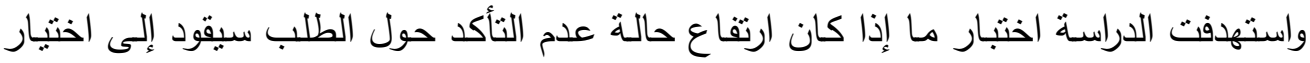
هيكل تكلفة أكثر مرونة وأقل جموداً (Cost Rigidity)، وذلك من خلال تفضيل استخدام الأساليب التكنولوجية النى تتطوى على تكاليف ثابتة منخفضة وتكاليف متغيرة مرتفعة. وأثنارت الدراسة إلى أن المستشفيات التابعة لولاية واشنطن خلال الفترة من عام 1965 حتى الفى عام 1983 كانت تستعيض (Reimbursement) نكاليف الخدمات الطبية المقدمة للمرضى إنى

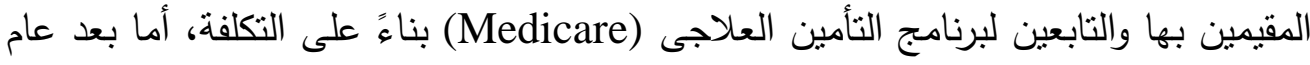

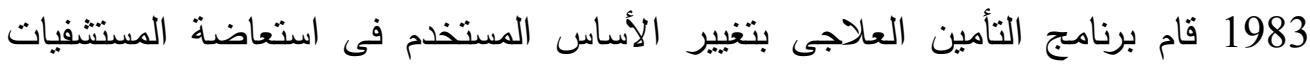
لتكاليف الخدمات الطبية المقدمة للمرضى المقيمين داخلها، وذلك على أساس تحديد معدلات

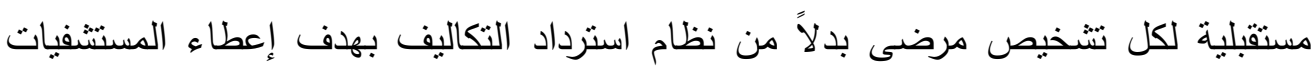
فرصة للسيطرة على (إدارة) التكاليف. وتتميز هذه الدراسة باعتمادها على نظرية الخيارات الحقيقية في تبرير اختيار هيكل تكلفة

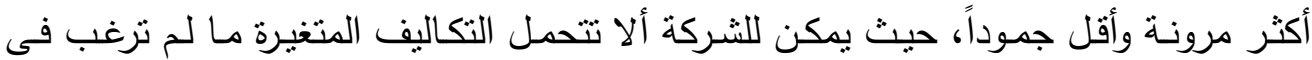

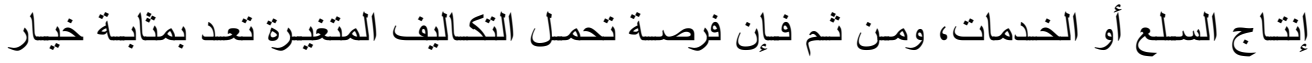
(أوروبى) حقيقى (McDonald and Siegel, 1985)؛ وهى عبارة عن عقود لا يجوز

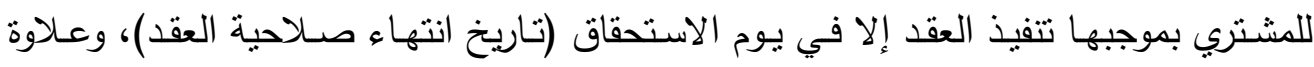

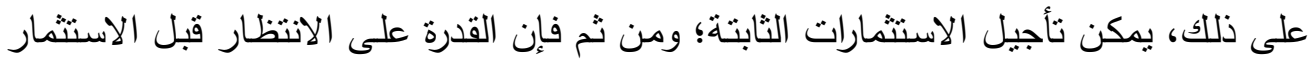

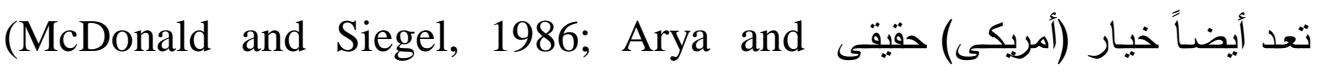
(Glover, 2001) وهي عبارة عن عقود يجوز للمشتري بموجبها تنفيذ العقد في أي وقت

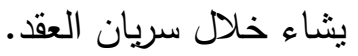

وعادة ما يكون لاى صانعى القرار معلومات مثاحة أكثر دقة عند اختيار تحمل نفقات (تكاليف

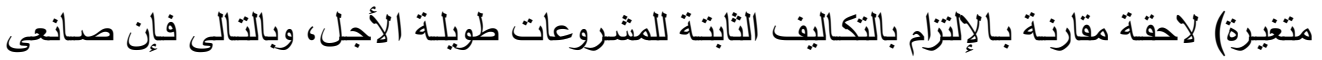


القرار يتمتعون بمرونـة أكبر للاستجابة للتغيرات فـى مخـاطر (ظـروف) الأعمـال عندما تكون التكاليف الثابتة المقدمة منخفضة فيما يتعلق بالنفقات اللاحقة، نظراً لزيادة قيمة المرونـة مع حالة

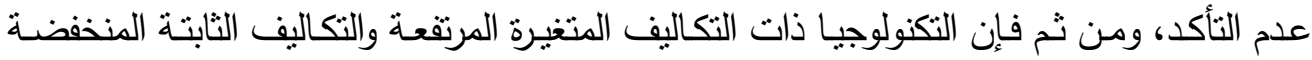
تكون أكثر جاذبية مـع زيادة حالة عدم التأكد، ولذلك فإن نظرية الخيارات الحقبقية تنتبى فكرة أن

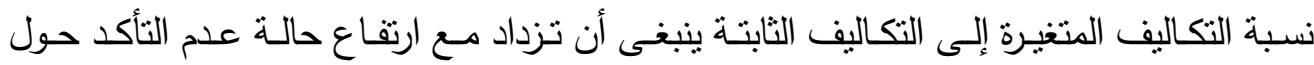
الطلب.

وخلصـت دراسـة (Kallapur and Eldenburg,2005) إلـى تأييد مـا أثنـارت إليـه نظريـة الخيارات الحقيقية حـول تفضيل الأسـاليب التكنولوجيـة ذات التكاليف الثابتة المنخفضـة والتكاليف المتغيرة المرتفعة، وذلك استجاباً لزيادة حالة عدم التأكد حول الطلب، حيث توصلت الدراسة إلى لى لئ ارتقاع نسبة التكاليف المتغيرة إلى إجمالى التكاليف بعد عام 1983، ولا ترجع هذه الزيـادة إلى

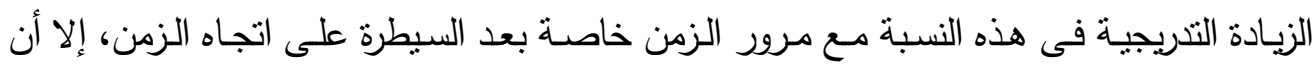
الاراسة أثارت إلى أن هناك عاملان يهددان صحة ما توصلت إليه الدراسة من نتائج هما: -يمكن أن يعزى التغير فى سلوك التكاليف إلى عوامل أخرى متزامنه مع تغيير نظام استعاضـة

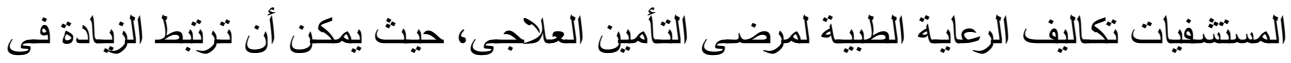
التكاليف المتغيرة ارتباطاً إيجابياً بنسبة الإيرادات المحققة من برنامج التأمين العلاجى. - يمكن أن يؤثز تغيير نظام استعاضة تكاليف الرعاية الطبية على التكاليف لأسباب لا ترجع إلى زيادة حالة عدم التأكد حول الطلب، وبالفعل قام برنامج التأمين العلاجى بتغيير نظام الاستعاضة ليوفر للمستشفيات حافزاً للسبطرة على التكاليف.

وعلى النقيض مما سبق تبنت دراسة (banker et al, 2014 (b) وجهة النظر القائلة بأنه إذا استجاب المدراء على النحو الأمثل لزيادة حالة عدم التأكد حول الطلب فإن اختبارتهم لمستوى الته

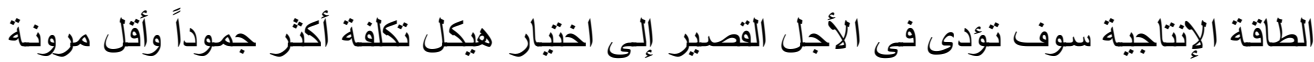

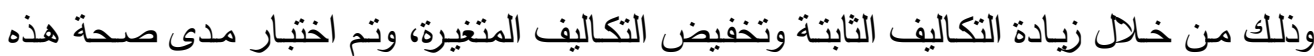

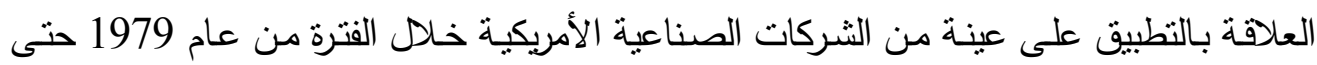
عـام 2008 باســتخدام قاعـدة البيانــات الخاصـة بكـل مـن الثـركات (CompustatData)

والصناعات التى تتنمى إليها الثركات محل الدراسة (NBER-CES).

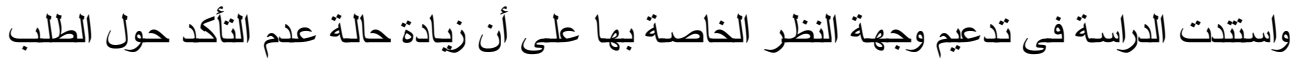
قد يصاحبها تزايد احتمالات تحقيق مستويات غير عادية فى الطلب، بما قد يؤثز على سلوك وهيكل 
التكلفة، وذلك من خـلال قيام الثـركات برفع كفاعتها الإنتاجية وزيادة المدخلات (التكاليف) الثابتة اسـتجابة لزيـادة حالـة عدم التأكد حـول الطلب مـن أجـل تخفيض تكـاليف الاختخاقـات (الازدحـام) "Congestion Costs" فى حال تحقق طلب فعلى على نحو غير عادى. وأثنارت نتائج دراسة (banker et al, 2014 (b) إلى أنه فى الأجل القصير ومع زيادة حالة عدم التأكد حول الطلب تقوم الثـركات باختيار هيكل تكلفة أقل مرونـة وأكثر جموداً وذلك بزيادة التكاليف الثابتة وتخفيض التكاليف المتغيرة، وعلى الرغم من أن نتائج الدراسة تدعم توقعاتها، إلا هردال

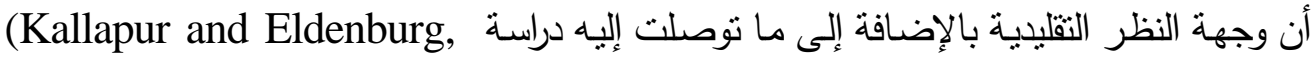
(2005 ومـا تقوم عليهه من اعتمـاد هيكل تكلفة أكثر مرونـة كلمـا زادت درجـة عدم التأكد حول الطلب لها ما ييررها وهو زيادة مخاطر الهبوط (DownsideRisk)؛ حيث تعكس ارتقاع مخاطر الهبوط أن احتمالات انخفاض الطلب هى الأكثر احتمالاً، مما لا يزيد فقط من تباين الطلب بل لبل يخفض أيضاً من متوسط الطلب، وعلى العكس تؤثر حالة عدم التأكد حول الطلب على التباين وليس على المتوسط، ويرجع ذلك إلى أن: -تكاليف الازدحام تكون أقل عند تحقق انخفاض فى الطلب أو أو وجود طلب سلبى، وبالتالى

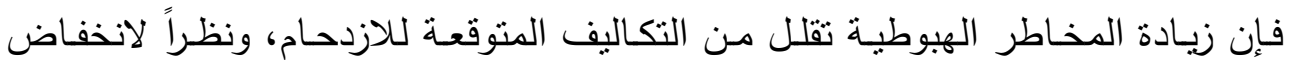
تكاليف الازدحام يختار المدراء مستوى أقل من الطاقة، بما يؤدى إلى اختبار هيكل تكلفة أكثر مرونة وأقل جموداً فى الأجل القصير وذللك فى حالة زيادة مخاطر الهجوط. - وعلى النقيض، فى حالة زيادة حالة عدم التأكد حول الطلب يتوقع أن تنزايد تكاليف الازدحام بما قد يؤدى إلى رفع مستوى الطاقة، بالثكل الذى قد ينعكس على اختبار هيكل تكلفة أكثر جموداً

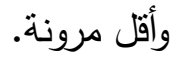
واستكمالاً للجهود المبذولة لتحديد العلاقة بين حالـة عدم التأكد حول الطلب وسلوك التكاليف اهتمت دراسة (Bo and Sterken, 2007) بمناقثـة الجدل القائم حول ما إذا كان توجه المدراء نحو المخاطرة قد يتوقف عليه نوع وطبيعة العلاقة بين حالة عدم التأكد حول الطلب والاستثمار فى الأصول الثابتة، بما قد يؤثر على اختيار هيكل التكلفة وما يتضمنه من تكاليف ثابتة، وطبقت الدراسـة على عينـة من الثركات الهولندية البالغ عددها (68) شركة خـلال الفترة من عام 1985 حتى عام 2000. 
وأنثارت دراسة (Bo and Sterken, 2007) إلى أن سبب اهتمامها بهذا الموضوع يرجع إلى تجاهل معظم الدراسـات السـابقة التى اهتمت باختبار العلاقة بين حالة عدم التأكد حول الطلب والاستثمار فى الأصول الثابتة عاملاً أساسياً فى دالة الهدف الخاصة بالثركة وهو موقف المدراء تجاه المخاطرة، بالإضـافة إلى افتراض معظم هذه الدراسـات حياديـة توجهه المدراء نحو المخاطرة

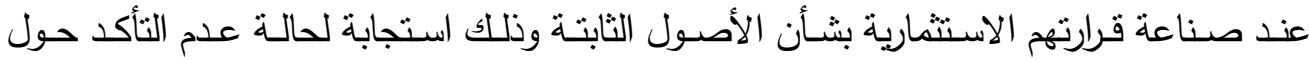
الطلب، وهو ما يعد أمراً غير واقعياً فى الواقع العملى. ومن هذا المنطلق ، شككت دراسـة (Bo and Sterken 2007),فيما توصلت إليـه معظم

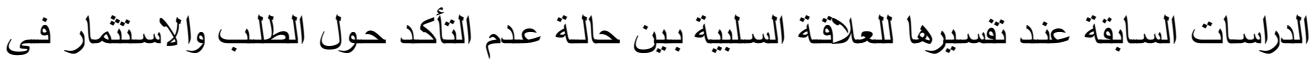
الأصول الثابتة، حيث أثنارت دراسة (Lensink et al, 2001) إلى أنـه من بين (20) دراسـة

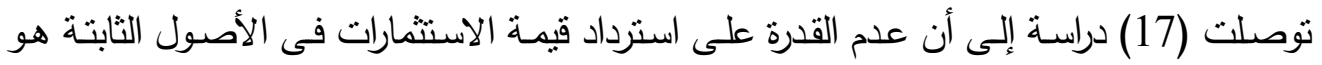
السبب وراء وجود تلكك العلاقة السلبية بين عدم التأكد حول الطلب والاستثمار فى الأصول الثابتة، ومن ثم تجاهل التفسيرات البديلة الأخرى التى قد تتبىء عن أن توجه المدراء نحو المخاطرة بدلاًا

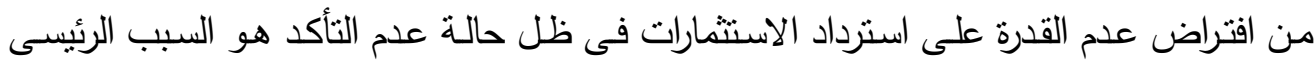
لتفسير العلاقة السلبية بين حالة عدم التأكد والاستثمار . وبصفة عامة أظهرت نتائج دراسة (Bo and Sterken, 2007) إلى أن افتراض حيادية التوجه نحو المخاطرة لا ينطبق على صناعة القرارات الخاصة بالاستثمار فى الأصول الثابتة؛ حيث أن أن إنى

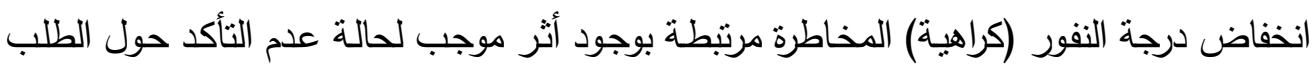

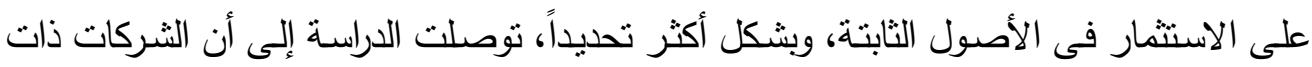

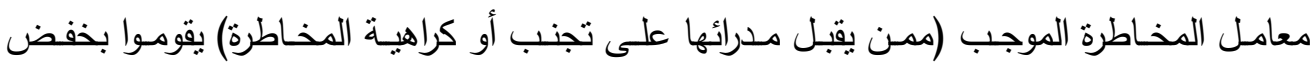
الاستتمارات فى الأصول الثابتة استجابة لحالة عدم التأكد حول الطلب، في حين أن الاستثمار الذى تقوم بـه الثركات المخاطرة استجابة لحالة عدم التأكد حول الطلب يكون موجب، وتتمانثى هذه النتائج مع ما توصل إليه (Nickell, 1978)؛ الذى خلص إلى أنه عندما يكون الطلب غير مؤكد، فإن المدراء ممن لديهم سلوك النفور (كراهية) المخاطرة يقبلوا على تخفيض مستويات الطاقة الإنتاجية، بما يؤدى إلى أن انخفاض مستوى الطاقة الإنتاجية المنلى يصبح دالة فى درجة نفور (كراهية) المخاطرة. 
كمـا استهوفت دراسـة (Indrawati,2017) اختبـار أتثر توجـه المدراء تجـاه المخـاطرة كمتغير منظم للعلاقة بين حالة عدم التأكد حول الطلب والاستثمار فى الأصول الثابتة، وكذلك قياس الأثر

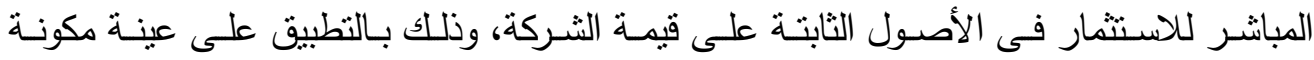
الثركات الصناعية المسجلة ببورصة أندونيسيا، والبالغ عددها (81) شركة صناعية نتتمى لثلاث

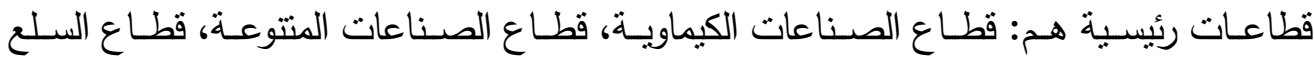
الاستهلاكية، وذلك خـلال الفترة من عام 2010 حتى عام 2011، بإجمالى عدد مشـاهدات قدره (162) مشاهدة خلال فنزة الدراسة. وانتقدت دراسـة كل من (Indrawati, 2017; Bo and Sterken, 2007) تجاهل معظم الدراسـات السابقة توجه المدراء تجاه المخاطرة وذلك من خـلال افتراضـها حياديـة هذا التوجه عند دراسة أثر حالة عدم الثأكد حول الطلب تجاه قرار الاستثمار فى الأصول الثابتة، فى حين أثنارت (Sandmo, 1971; Leland, 1972; Hartman, 1976; Nickel, العديد من الدراسات 1978; Nakamura, 1999)

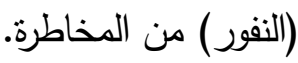
كما أثنارت دراستى (Nickel, 1978; Bo and Sterken, 2007) إلى أنه فى ظل عدم توافر الأسواق المالية الكاملة وحالة التأكد التام - سواء لوجود عوائق اقتصادية، أو ارتقاع تكاليف للوكالة، أو ارتفاع مدفوعات الضرائب - تصبح دالة هدف الثركة تشتهدف تعظيم منافع المدراء، لذا قد يغلب على توجه المدراء الميل نحو تجنب المخاطرة تجنباً للإفلاس، وكذللك حتى لا يتأثز دورهم الرقابى ولا

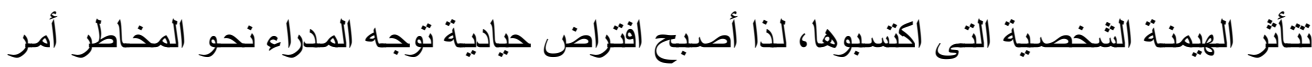
غير واقعى عند صناعة قرارات الاستثمار فى الأصول الثابتة. وبالتـالى شككت دراسـة (Indrawati, 2017) فى صـحة مـا توصلت إليـه دراسـة كل مـن (Leahy and Whited, 1996; Guiso and Parigi, 1999) الطلب أضعفت استجابة الاستثمار فى الأصول الثابتة تجاه الطلب، وذلك انطلاقاً من كون حالة عدم التأكد حول الطلب تعد بمثابة قيداً على السيولة، بالثكل الذى قد يؤدى إلى تباطؤ تراكم رأس الته

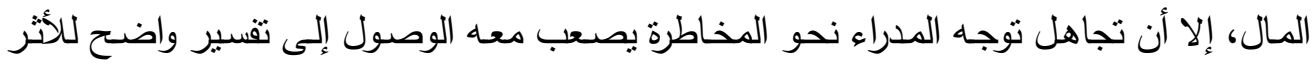
السلبى لحالة عدم التأكد حول الطلب تجاه قرار الاستثمار فى الأصول الثابتة. 
وانطلاقاً من كون قرار الاستثمار فى الأصسول الثابتة ينطلب إنفاق الكثير من الأموال، اهتمت دراسـة (Indrawati, 2017) بتحليل جدوى هذا الاسنثمار لتحديد ما إذا كان له تأثنير إيجابى هونى على أداء الثركة وعلى وجه التحديد قيمة الثركة، وبالاستتاد إلى موازنة النفقات الرأسمالية ينبغى النى أن تلنزم الثـركات الجديدة بالنفقات الرأسمالية بشكل دورى للحفاظ على قيمتها فى المقام الأول، وضمان قدرتها على النمو (Nwaeze, 2004; Chan et al., 1995). حيث أوضحت دراسة (Deshmukh and Voght, 2005) أن النزام الثركة بموازنة النفقات

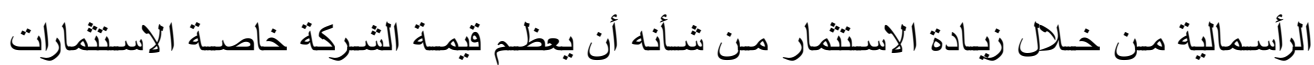

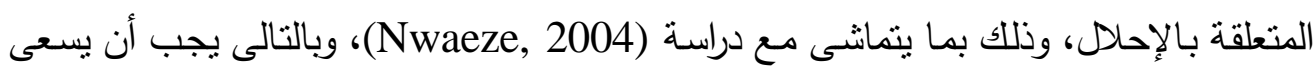
المدراء نحو الحفاظ على الاستتمار فى الأصول الثابتة (Fixed Investment-FI) لتعظيم قيمة الثركة، لذا توقعت دراسة (Indrawati, 2017) وجود علاقة موجبة بين قرار الاستثمار فى الأصول الثابتة وقيمة الثركة معبراً عنها بمقياس (Tobin's Q). وخلصت دراسـة (Indrawati, 2017) إلى أن حالة عدم التأكد حول الطلب لا يوجد لها تأثثير معنوى على قرار الاستثمار فى الأصسول الثابتة، وذلك على عكس ما توصلت إليه دراسة كل من (Hartman, 1972 ; Abel, 1983) بخصوص أن ارتفاع حالة عدم التأكد

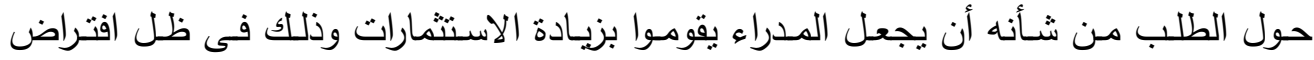

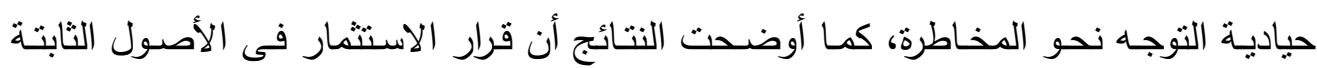
يرتبط بتحسين قيمة الشركة، نظراً لأنها يعكس أن الثركة حققت توسعاً بهدف تحقيق النمو ،

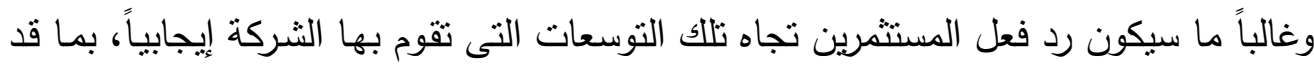

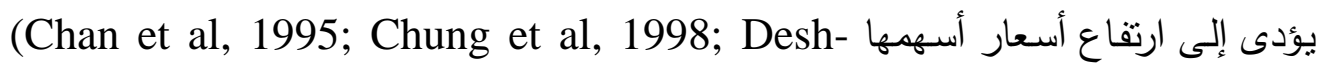
(mukh and Voght, 2005)

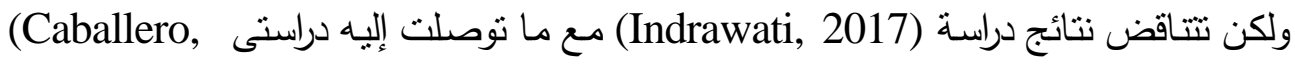
1991; Bo and Sterken, 2007) بشأن وجود علاقة سلبية بين حالة عدم الثأكد حول الطلب وقرار الاستثمار فى الأصسول الثابتة، كما أثنارت دراسـة (Caballero, 1991) إلى أن وجود الأسواق غير الكاملة ونقص تتويع الاستثمارات لـه دور هام فى تقسير العلاقة السليية بين حالـة عدم التأكد حول الطلب وقرار الاستثمار فى الأصول الثابتة. 
وعلى الرغم من ذلك تثمانثى النتائج التى توصلت لها دراسـة (Indrawati, 2017) مـع مـا

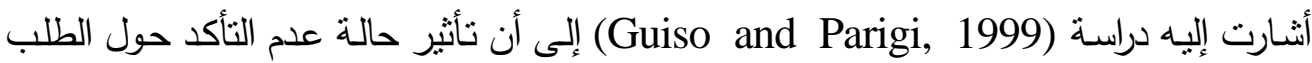

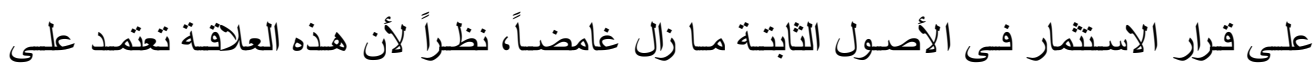
الافتراض الخاص: (بمستوى تكنولوجيا الإنتاج، والمنافسة فى أسواق المنتجات، توجه المدراء تجاه

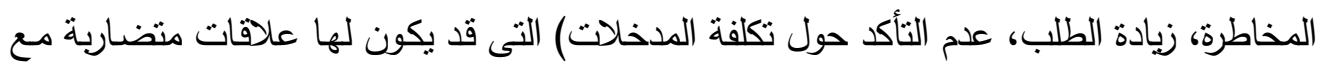
قرار الاستثمار فى الأصول الثابتة.

\section{تقييم الاراسات السابقة واستخلاص الفجوة البحثية:}

بعد مراجعة واستعراض بعض الدراسات السابقة التى اهتمت باختبار العلاقة بين حالة عدم التأكد

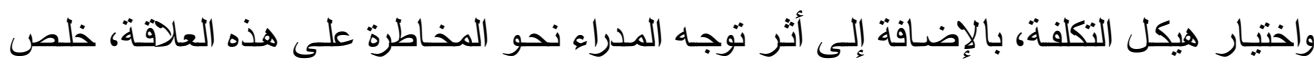

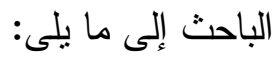

- ندرة الدراسات (خاصة فى البيئة المصرية فى حدود علم الباحث) التى اهتمت باختبار العلاقة بين حالة عدم التأكد حول الطلب واختبار هيكل التكلفة، بالإضافة إلى اختبار أثر الثراني توجه المدراء نحو المخاطرة على هذه العلاقة؛ حيث ارتكز اهتمام دراسة كل من Bo and Sterken, 2007; Indrawati, 2017) المخاطرة على العلاقة بين حالة عدم التأكد حول الطلب والاستثمار فى الأصول الثابتة وليس اختيار هيكل التكلفة. - تتاقض الأدلة البحثية حول طبيعة العلاقة بين حالة عدم التأكد حول الطلب واختيار هيكل التكلفة؛ حيث توصلت دراسة (Kallapur and Eldenburg, 2005) إلى وجود علاقة (Banker et al, سلبية بينهما بالنطبيق على قطاع الرعاية الصحية، بينما توصلت دراسة راست 2014 (b)) إلى تباين النتائج باختلاف القطاعات التى تتتمى إليها الثركات محل الدراسة. - تتاقض الأدلة البحثية حول أثر توجه المدراء نحو المخاطرة على العلاقة بين حالة عدم التأكد حول الطلب والاستثمار فى الأصول الثابتة؛ حيث توصلت دراسة مo and) Sterken, 2007) عدم التأكد حول الطلب والاستثمار فى الأصول الثابتة، وذللك على عكس ما توصلت إليه دراسة (Indrawati, 2017)، ومن ثم توقع تغير التكوين النسبى لهيكل التكلفة وما 
يتضمنه من تكاليف متغيرة وثابتة استجابة للعلاقة التفاعلية المتوقعة بين توجه المدراء نحو المخاطرة وحالة عدم التأكد حول الطلب.

- لم يكن من بين اهتمامات الدراسات السابقة (فى حدود علم الباحث) اختبار العلاقة بين حالة عدم التأكد حول الطلب وهيكل التكلفة خلال مراحل دورة حياة الشركة، وكذلك اختبار أثر توجه المدراء نحو المخاطرة على هذه العلاقة خلال مراحل دورة حياة الثركة، فمن المتوقع أن يختلف التكوين النسبى لهيكل التكلفة خلال المراحل المختلفة لدورة حياة الثركة استجابة للعلاقة التقاعلية المتوقعة بين نوجه المدراء نحو المخاطرة وحالة عدم التأكد حول

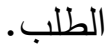

وفى ضـوء مراجعـة وتقيبم بعض الدراسـات السـابقة المتعلقـة بمشكلة البحـث تكمن الفجوة البحثية للبحث الحالى: فى اختبار العلاقة بين حالة عدم التأكد حول الطلب وهيكل التكلفة خلال دورة حياة الشركة، بالإضـافة إلى اختبار أثر توجه المدراء نحو المخاطرة على العلاقة بين حالة عدم التأكد حول الطلب وهيكل التكلفة خلال دورة حياة الثركة، وذلك بالتطبيق على الثركات الصناعية العاملة فى بيئة الأعمال المصرية، وذلك باعنبارها بيئة خصبة لإجراء هذا البحث نظراً لتعرض الثركات خاصة الصناعية للعديد من التغيرات الاقتصادية مثل: (تعويم الجنيه المصرى، انخفاض الاحتياطى من العملة الأجنبيـة خاصـة الدولار الأمريكى، ارتفاع معدلات التضخم) أثناء وبعد الثورات التى مرت بها الدول العربية وخاصة فى جمهورية مصر العربية (كثورتى الخامس والعشرين من يناير عام 2011، والثثلاثون من يونيه عام 2013)،

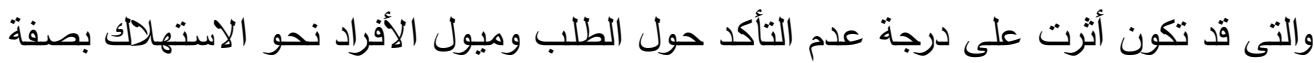
عامة.

\section{فروض البحث}

فى ضوء تقييم الدراسات السابقة واستخلاص الفجوة البحثية يمكن صياغة فرضى البحث الرئيسيين فى صيغة فرض العدم كما يلى فيو: الفرض الأول: "لا يوجد اختلاف فى العلاقة بين حالة عدم التأكد حول الطلب وهيكل التكلفة خلال المراحل المختلفة لدورة حياة الثركات الصناعية العاملة فى بيئة الأعمال المصرية". 
الفرض الثانى: "لا يوجد اختلاف فى أثز توجه المدراء نحو المخاطرة على العلاقة بين حالة عدم التأكد حول الطلب وهيكل التكلفة خلال المراحل المختلفة لدورة حياة الثركات الصناعية العاملة فى بيئة الأعمال المصرية".

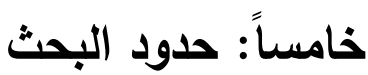
تتمثل حدود البحث فى النقاط التالية: - يعتمـد الباحث على اختيار عينـة مـن الثـركات المسـاهمة الصـناعية التى تتنمى لقطـاع

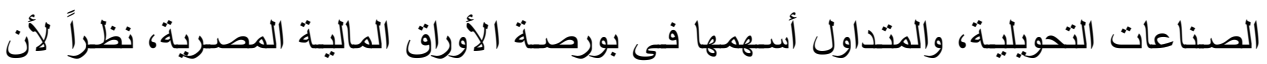
قطاع الصناعات التحويلية يعد المكون الأكبر للاقتصاد القومى؛ حيث بلغت نسبة مساهمة قطاع الصناعات التحويلية غير البترولية 16\% من الناتج المحلى الإجمالى (استراتيجية وزارة التجارة والصناعة 2020/2016)، هذا بالإضـافة إلى الرغبة فى التعرف على هيكل التكلفة فى الثركات الصناعية التى تعمل فى بيئة الأعمال المصرية وذلك من أجل تدعيم القدرة التنافسية لهذا القطاع.

$$
\text { - تمند الفترة الزمنية من عام } 2010 \text { حتى عام } 2017 .
$$

فى ضوء مشكلة وأهداف البحث، يمكن تقبيم البحث إلى الأقسام التالية: القسم الأول: الخلفية النظرية للبحث. القسم الثانى: الدراسة الاختبارية. القسم الثالث: تحليل ومناقثنة النتائج. القسم الرابع: الخلاصة والدراسات المستقبلية. 


\section{القسم الأول \\ الخلفية التظرية للبحث}

يهتم الإطار النظرى للبحث باستعراض القضايا التالية:

أولاً: مفهوم وكيفية اختيار هيكل التكلفة فى الأدبيات المحاسبية.

ثانياً: دور عدم التأكد حول الطلب فى اختيار هيكل التكلفة خلال دورة حياة الثركة.

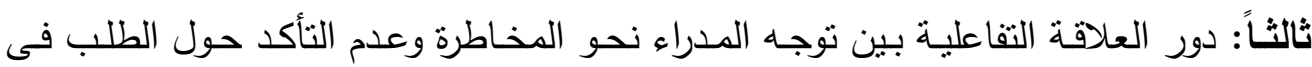
اختبار هيكل التكلفة خلال دورة حياة الثركة.

ويمكن تناول النقاط السابقة كما يلى هئى

\section{أولاً: مفهوم وكيفية اختيار هيكل التكلفة فى الأدبيات المحاسبية}

ركزت الأدبيات المحاسبية عند تتاول مفهوم هيكل التكلفة على أنه التكوين (المزيج) النسبى

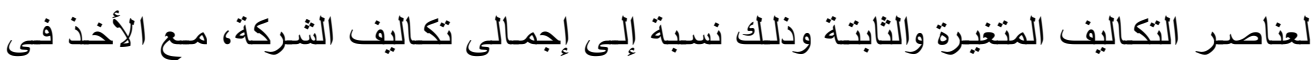
الاعتبار ضرورة اختلاف هيكل التكلفة من صناعة لأخرى، ومن شركة لأخرى Guilding)

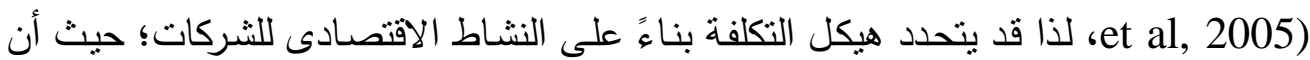
التكاليف الثابتـة تكون منخفضـة نسبياً مقابـل التكاليف المتغيرة فى الثـركات الخدميـة، وذلك على عكس الثركات الصناعية التى تعتمد على نظم التصنيع المتقدمة.

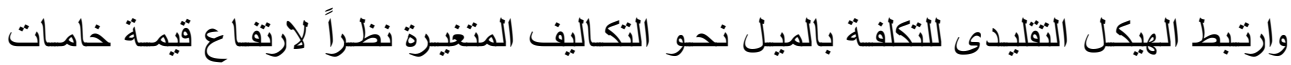

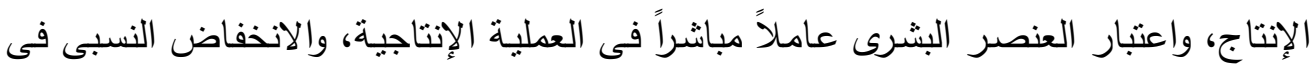
قيمة التكاليف المحملة، ولكن مـع تغير البيئة الصناعية وتزايد التطور التكنولوجى انخفضت أهمية العنصر البشرى وأصبح يعالج كأحد بنود التكاليف الثابتة، وذلك مع زيادة أهمية تكلفة ونية

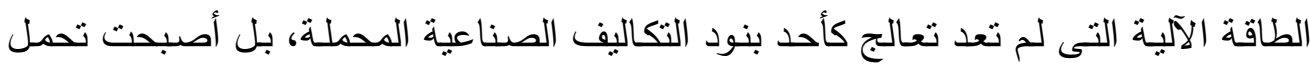
على المنتجات مباشرة بمقدار الاستفادة منها، بما قد يؤثر على هيكل التكلفة لصالح التكاليف الثابتة (Pavlatos, 2011). وفى هذا الإطسار أوضحت دراسـة(Brierley et al, 2007) تأييداً لما خلصت إليه دراسـة بخصوص وجود انخفاض ملحوظ في نسبة تكلفة (Lamminmaki and Drury, 2001) الأجور المباثرة يقابله ارتقاع فى نسبة التكاليف الإضـافية الصناعية وغير الصناعية والتى ينتج 
معظمها عن أنتطة لا تتعلق بالحجم، وإنما تعود إلى زيادة درجة تعقد عمليات الإنتاج والتشويق والتوزيع وأنشطة البحوث والتطوير •

وتعرف التكاليف المتغيرة على أنها عناصر التكاليف التى يتغير مبلغها الإجمالى بتغير حجم

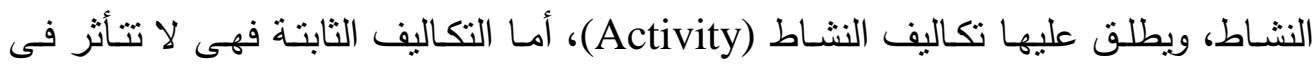
مجموعها بتقلبات حجم النشاط، لذا يطلق عليها بتكاليف الطاقة (Capacity)، أو التكاليف لون الزمنية نظراً لأنها تحدث بصفة دورية منتظمة، وتعد تكاليف النشاط استخداماً لتكاليف الطاقة، وللتفرقـة بـين تكـاليف النشـاط (التكـاليف المتغيـرة) والطاقـة (التكـاليف الثابتـة) يتعـين تحديـ

:(Harris, 2014)

- فترة زمنية يدرس خلالها سلوك التكاليف وعلاقتها بالتقلبات فى حجم النشاط. - ضرورة تعيين حدود مناسبة أو مدى ملائم للنشاط (Relevant Range) وذلك لدراسـة التغير الذى يطرأ على التكاليف نتيجة تغير حجم النشاط داخل هذه الحدود؛ نظراً لأنـه

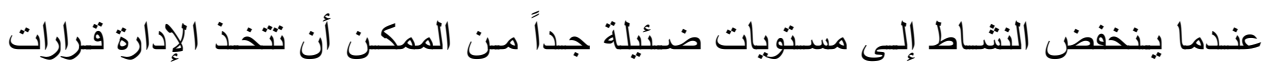
بخفض بعض عناصر التكاليف الثابتة مثل توفير بعض العمالة (المشرفين والملاحظين) وتكاليف الأبحاث والتدريب، والعكس صحيح عندما يزداد حجم النشاط عن المدى الملائم

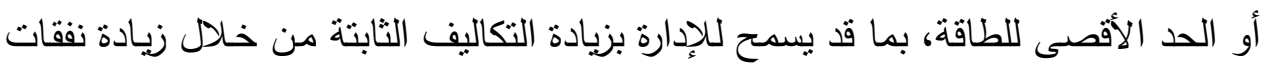

$$
\text { الصيانة وتعيين مشرفين جدد. }
$$

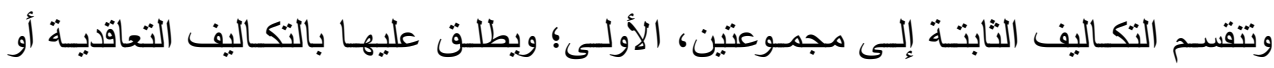
الملزمـة (Committed Fixed Costs) وتنشأ نتيجة تملك الثركة للطاقة خاصة في مجال الإنتاج، ومن أمتلة هذه التكاليف: إهلاك الأصول الثابتة والإيجار والتأمين ومرتبات العمالة الأساسية، وهذه التكاليف تعكس الاحتياجات طويلة الأجل للطاقة وهى أقل تأثراً بتقلبات حجم النشاط، أما المجموعة الثانية؛ بطلق عليها بالتكاليف الاختيارية أو تكاليف السياسات الإدارية وتتشأ عن القرارات التى تتخذها (Managed Costs or Discretionary Fixed Costs) الإدارة لتحقيق أهداف معينة، وعادة ترتبط بتحديد اعتمادات سنوية ينبغى عدم تجاوزها للإنفاق على بنود معينة كالبحوث والتطوير والتدريب، بالإضـافة إلى صعوبة إيجاد علاقة منلى بين

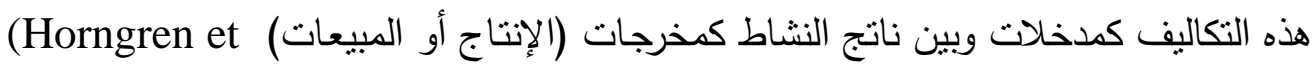


ومن ثم يكون من الصعب خفض التكاليف الثابتة الملزمـة للشركة دون الإضـرار بمركزهـا

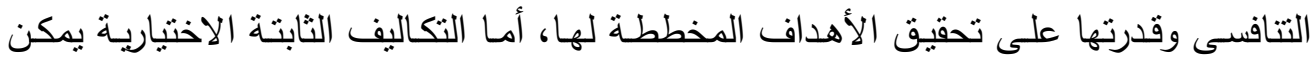

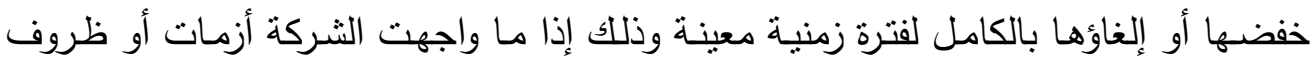

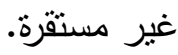
ويجدر الإثـارة إلى أنه يزداد مقدار ما تمنلـه التكاليف الثابتة الملزمة فى هيكل تكاليف الثركة

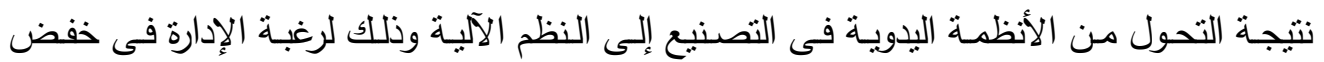

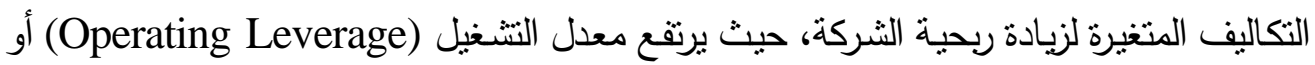

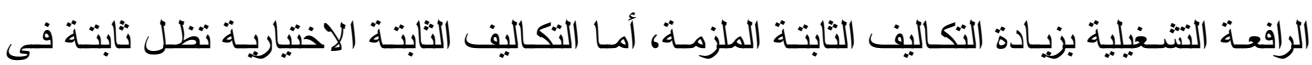

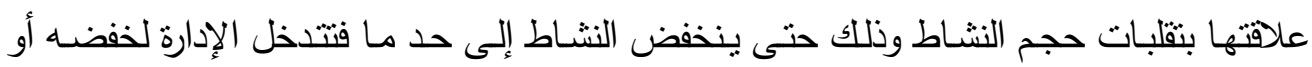
إلغـاؤه، ومن ثم تحتوى التكاليف الثابتة الإجماليـة على جزء ثابت لا يمكن خفضـه حتى حالـة

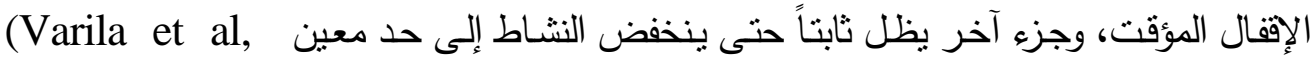

ومما سبق يتضح أن هيكل التكلفة يرتبط ارتباطاً وثثقاً بالرافعة التشغيلية التى تعكس النطاق الذى تشتخدم الثركة فيه التكاليف الثابتة فى هيكل التكاليف، لتعبر الرافعة التشغيلية بذلك عن لتن الجزء الثابت من هيكل تكاليف الثركة، وبالتالى تزداد درجة الرفع التشغيلى كلما كانت الثركة

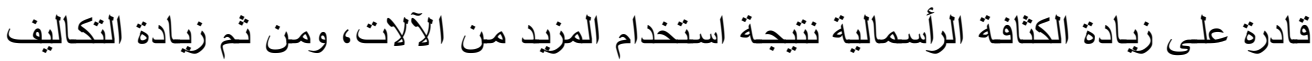
الثابتة مقارنة بالتكاليف المتغيرة وذلك نتيجة الاستغناء عن عدد كبير من العمالة، بالإضـافة

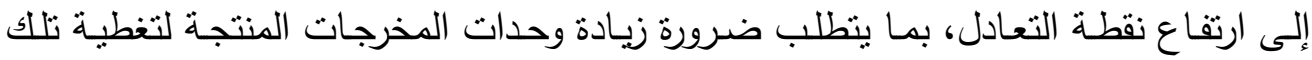
التكاليف (Aboody et al, 2017). وبالتالى قد يترتب على ارتفاع درجة الرفع التشغيلى تحقيق أرباح أكبر نتيجة ارتفاع ربحية

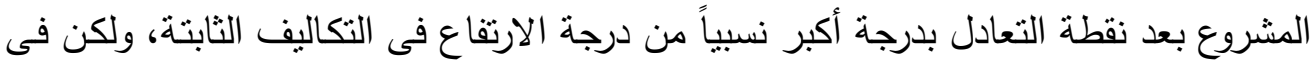
نفس الوقت قد تتعرض الثركة لخسائر أكبر عند نفس مستوى المبيعات مما كانت تحقق قبل اللجوء إلـى الرفـع التشـيللى، بمـا يعكس زيـادة مسـئولية إدارة الثــركة عـن اسـتخلال طاقتهـا الإنتاجية حتى لا تتحقق أية خسائر ، حيث أن وجود طاقة عاطلة قد يسفر عن عدم تحقيق حجم المخرجات التى تسمح بتغطية الانفاق على الموارد مع تحقيق الأرباح التى تحقق النمو لإنى والبقاء للشركة، بالثكل الذى قد يترتب عليه تقليص حجم الأعمال وربما الدخول فى مرحلة 
الانحدار والخروج من مجال الأعمال (Lee and Park, 2014). وعلى النقيض عندما تتخفض الرافعة التشغيلية يميل هيكل التكاليف لصالح التكاليف المتغيرة

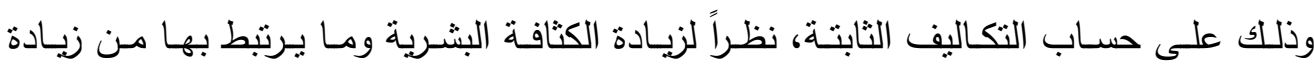
الأجور، وارتفاع قيمة الخامات، بالإضافة إلى انخفاض الآلية والمستوى التكنولوجى السائد.

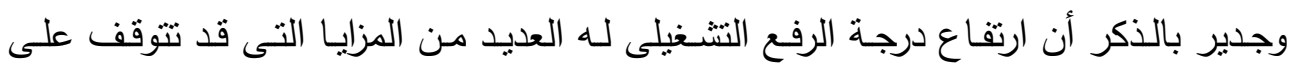
طبيعة الأوضـاع الاقتصادية للثركة والسوق الذى تعمل فيه؛ حيث يعتبر ارتفاع درجة الرفع التشغيلى مؤشراً جيداً لأن كل تغير بسيط فى المبيعات ينتج عنه زيادة كبيرة فى صافى ربح

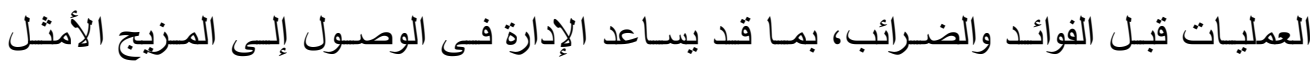
للتكاليف، وذلك بشرط أن تتسم الثركة بوضع تتافسى جيد، وتعمل فى سوق يسوده ازدهار اقتصادى يسمح للشركة بالنوسع (Kiymaz and Hodgin, 2003).

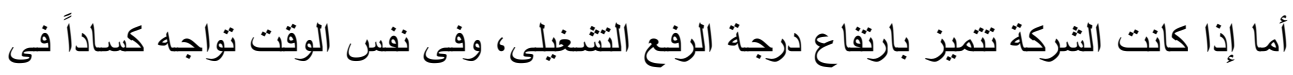

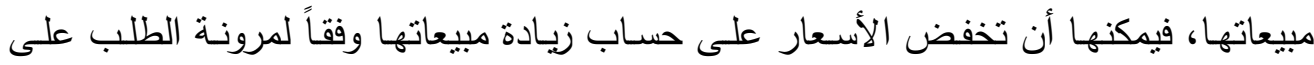

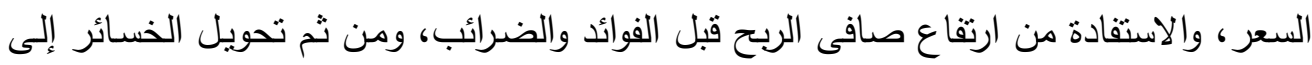
أرباح أو زيادة الأرباح إذا كانت ضئيلة (Horngren et al, 2006).

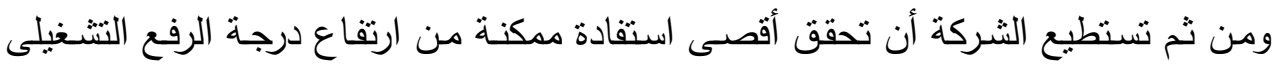

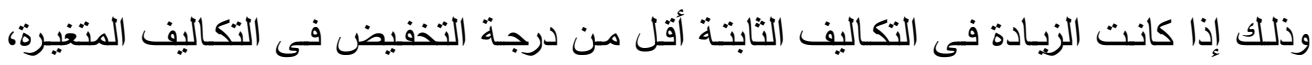

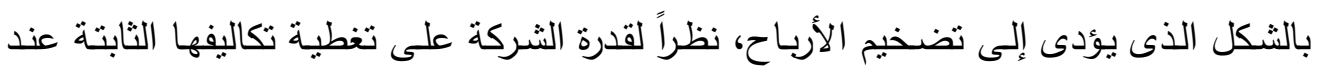

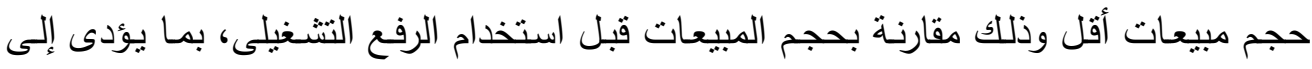
ترحيل نقطة التعادل إلى أسفل ليكون ذلك مؤشراً جيداً للشركة.

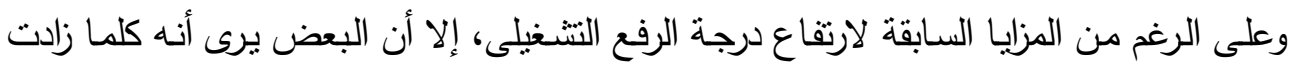

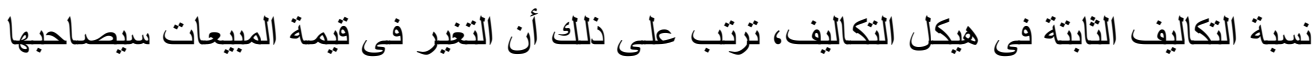

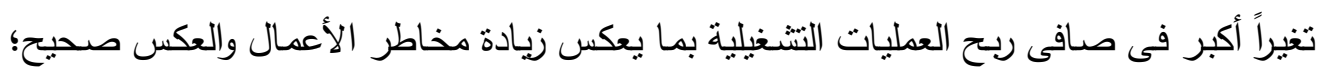
نظراً لأن استخدام الرفع التشغيلى يؤدى إلى رفع نقطة التعادل (زيادة حجم المبيعات اللازم لتغطية

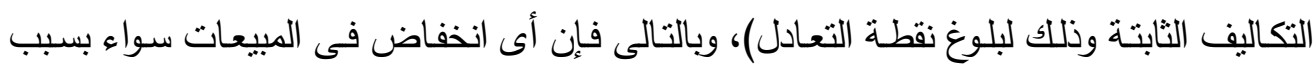

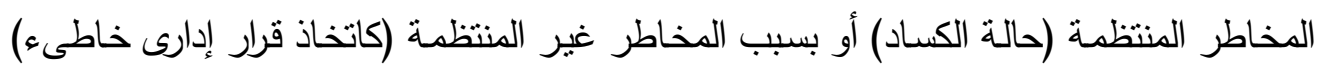
سيزيد من احتمال وقوع المزبد من الخسائر (Guan et al, 2015). 
ومن التحليل السابق يمكن الوقوف على المحددات التى قد تحكم اختبار هيكل التكلفة من

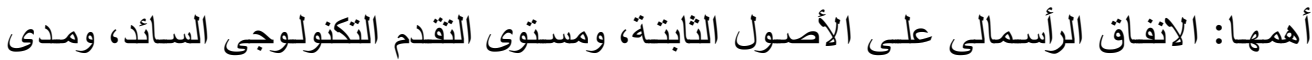

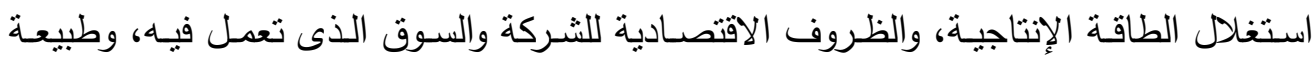
النشـاط الاقتصـادى للشركة؛ حيث أن الثركات التى تتنمى إلى القطاع الصـناعى قد يرتفع لديها التكاليف الثابتة، وذلك على عكس الثركات التى تتنمى إلى القطاع الخدمى، حيث تتخفض لديها التكاليف الثابتة نسبياً مقارنة بالتكاليف المتغيرة. وبالإضـافة لمـا سبق تعد المراحل المختلفة لدورة حياة الثـركة من المحددات التى قد تحكم اختيار هيكل التكلفة لما لها من نأثنير منوقع على اختلاف التكوين النسبى لهيكل التكلفة خلال هذه المراحل، نظراً لوجود العديد من التغيرات الجوهرية في بيئة الإنتاج خلال المراحل المختلفة هئة

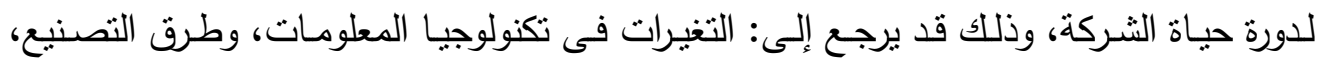

وحدة المنافسة (Oberholzer and Ziemerink, 2004).

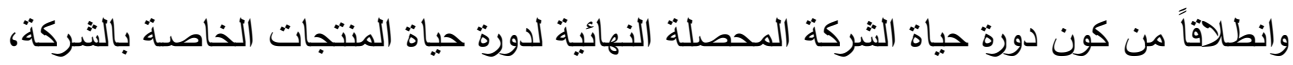
يلاحظ قصر دورة حياة المنتجات نسبياً في البيئة الصناعية الحديثة، وذلك إلى جانب تركز التكاليف الثابتة فى المراحل مـا قبل الإنتاج، ومن ثم ميل هيكل التكاليف لصـالح التكاليف الثابتة فى هذه المراحل، بمـا يستلزم ضـرورة الوصـول بحجم المخرجات إلى المستوى الذى لـى يحقق التغطية الكاملـة لتلك التكاليف مـع تحقيق هدف الربح فى المراحل الخاصـة بـالنمو

والاستقرار (Anderson and Lee, 2016).

وكذللك يعد حجم المبيعات من العوامل التى قد يعزى إليها حدوث تغير فى التكوين النسبى

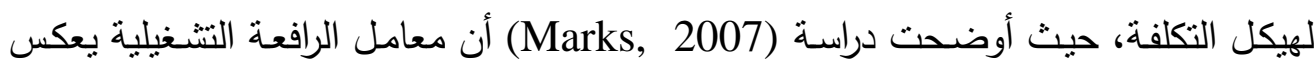
مدى قدرة الثركة على نوليد زيادة فى صافى الدخل نتيجة الزيادة فى إيراد المبيعات، نظراً لأنــه يقـاس بنسـبة حـد المسـاهمة (Contribution Margin) إلى صـافى الــخل Net) .Income) ومن ثم فإن زيـادة الرافعـة التشـيلية سوف تؤُثر مباثـرة فى زيـادة حجم مخرجات التعـادل لتغطية الزيادة فى التكاليف الثابتة، بما قد يزيد من احتمالات المخاطرة التى تواجهها الثركة نتيجة حدة المنافسة فى الأسواق، أو وجود أى تغيرات فى حجم الطلب على منتجات الشركة سواء نتيجة الظروف الاقتصادية (رواج/ كساد)، أو نجاح المنافسين فى تقديم منتجات بديلة الئة 
بشكل بضعف الطلب على منتجات الشركة، بما قد يخلق حالة من عدم التأكد حول الطلب، التى قد تختلف حدة تأثيرها على هيكل التكلفة خلال المراحل المختلفة لدورة حياة الثركة، وهو ما سوف يتتاوله الباحث لاحقاً.

ثانياً: دور عدم التأكد حول الطلب فحى اختيار هيكل التكلفة خلال دورة حياة الشيركة:

يعتبر الطلب على منتجات الثركة حالياً أو مسنقبلاً بمثابة نقطة البدء الرئيسية عند اختبار هيكل التكلفة الخـاص بالثـركة، وذلك لتفـادى وجـود طاقـات عاطلـة غير مستغلة، وتجنب احتمـال تعرض الثـركة لخسائر نتيجـة انخفاض الطلب (المبيعـات) على المنتجات الخاصـة

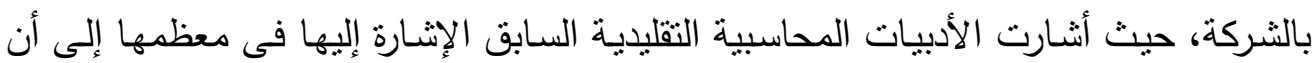

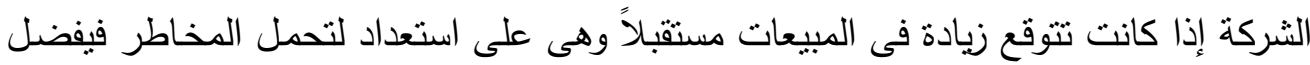
اختيار هيكل تكلفة أكثر جموداً وأقل مرونة، وذلك بزيادة التكاليف الثابتة وتخفيض التكاليف

المتغيرة، ومن ثم زيادة الرافعة التتغيلية (Banker et al, 2006).

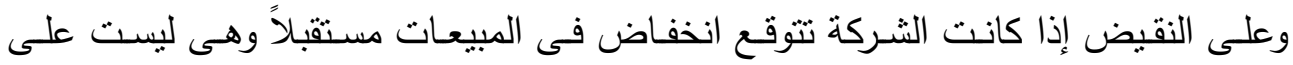
استعداد لتحمل المخاطر فيفضل اختيار هيكل تكلفة أقل جموداً وأكثر مرونة، وذلك بزيادة

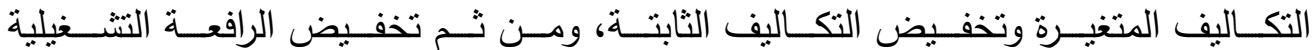

.(Balakrishnan et al, 2008)

وبالتالى أصبحت حالة عدم التأكد المحيطة بالطلب - خاصـة نتيجـة التغير الذى شـهـته البيئة الصـناعية سـواء لتزايد حدة المنافسـة أو تغير الأوضـاع الاقتصـادية للشـركات والسـوق الذى تععل فيه - من العوامل المتوقع أن يكون لها تأثثير على اختبار هيكل تكلفة أكثر جموداً

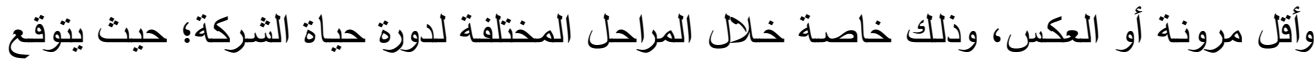

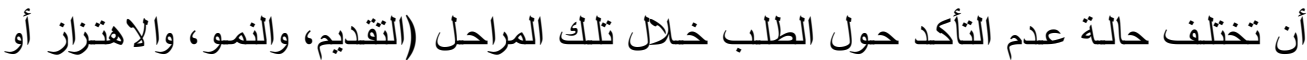
الاضـطراب، والنضـج، والانخفـاض)، حيـث تتميـز الثـركات فـى مرحلـة النمـو بسـرعة نــو

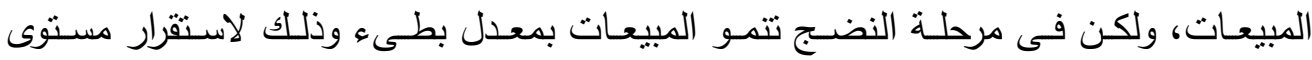
المبيعات، أمـا فى المراحل الخاصـة: بالتقديم، والاهنزاز، والاتخفاض، بتجهـه مستوى المبيعات

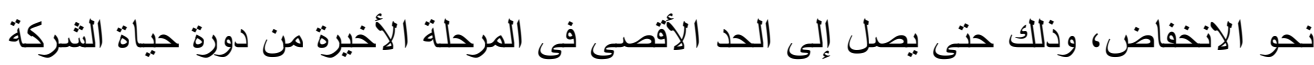
(Vorst and Yohn, 2017)، بما قد ينرك أثنارً مختلفة على هيكل التكلفة الخاص بالثركة 
خلال تلاك المراحل.

وجدير بالذكر أن التقرقة بين حالة عدم التأكد والمخاطرة حول الطلب أمر غير ذات معنى؛

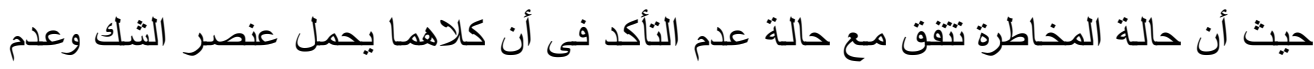
اليقين فى أحداث المستقبل المرتبطـة بالطلب على منتجـات الثـركة، بسبب تغير حـالات

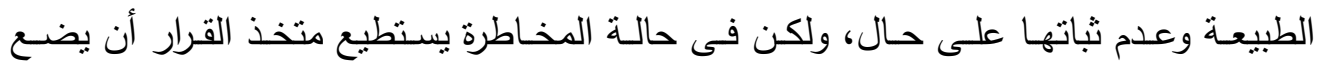

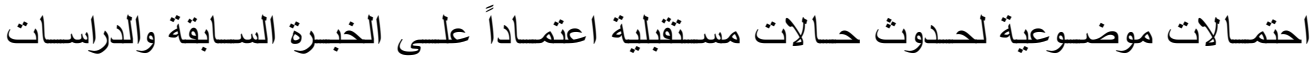
الإحصائية وما إلى ذلك من معلومات تاريخية، بينما فى حالة عدم التأكد يعتمد متخذ القرار

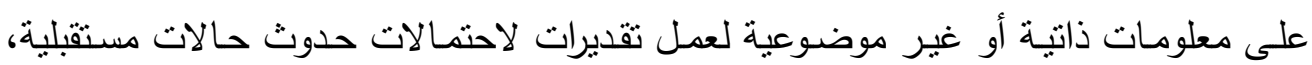
ويـرى الباحـث أن درجـة الموضـوعية لا تعـوق اسـتخدام هذه التقديرات فـى اتخـاذ القـرارات

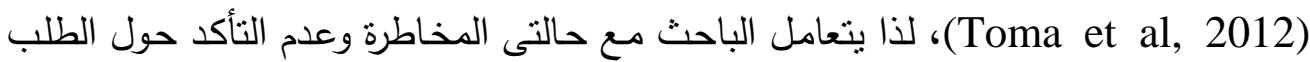
على أنهما مصطلحات مترادفة. وفى إطار اختبار العلاقة بين حالة عدم التأكد حول الطلب وهيكل التكاليف، تتاقضت الأدلة البحثية حول مدى استجابة هيكل التكاليف للتغيرات فى حالة عدم التأكد حول الطلب؛ حيث أثنارت دراسة (Kallapur and Eldenburg, 2005) توافقاً مع الأدبيات المحاسبية النقليديـة إلى ميل هيكل التكلفة لصالح التكاليف المتغيرة على حساب التكاليف الثابتة وذلك التك

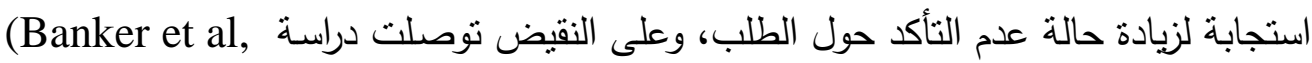
(b) (إلى ميل هيكل التكلفة لصالح التكاليف الثابتة على حساب التكاليف المتغيرة وذلك استجابة لزيادة حالة عدم التأكد حول الطلب، ويمكن التعرف على مبررات تلك العلاقة من خلال استعراض النقاط التالية: 1- دور نظرية الخيارات الحقيقية فى تقسير العلاقة بين عدم التأكد حول الطلب واختيار هيكل التكلفة: تتيح نظريـة الخيارات الحقيقية (Real Option Theory) خصيصاً في ظل حالة عدم التأكد حول الطلب نموذجاً لاتخاذ القرارت التى تتطوى على تحمل المزيد من التكاليف الثابتة

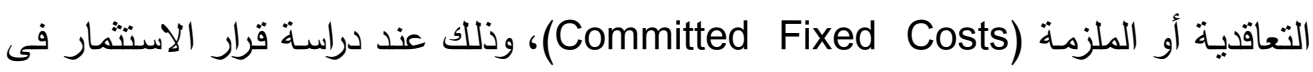
الأصول الثابتة استجابة لحالة عدم التأكد حول الطلب (Driver et al, 2002)، بما قد يؤثز على التكوين النسبى لهيكل التكاليف وما يتضمنه من نكاليف ثابتة ومتغيرة. 
وتوفر نظريـة الخيارات الحقيقية مجموعة من الخيارات الإدارية (Managerial Option) عند دراسـة قرار الاستثمار فى الأصسول الثابتة خاصـة فى ظل حالة عدم التأكد حول الطلب هن

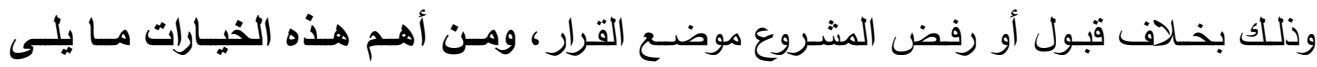
(Schwartz and Trigeorgis, 2001; Knudsen and Scandizzo, 2011; :McDonald and Siegel, 1986)

\section{أ- خيار الانتظار أو التأجيل (Option to Defer)}

ويقصد به إمكانية تأجيل اتخاذ قرار الاستثمار فى الأصول الثابتة فترة من الوقت لتحديد ما ستؤول إليه ظروف عدم التأكد حول الطلب، بما قد يسمح بشكل قاطع إمكانية اتخاذ هذا القرار من عدمهه، وذلك بشرط ألا يؤدى التأجيل إلى ضياع فرص استتمارية، حيث يتم اتخاذ إنه

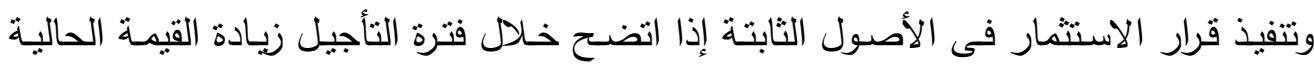
للتدفقات النقديـة للقرار عن التكاليف الاستثمارية الخاصـة بـه، إذ يعد القرار فـى هذه الحالـة

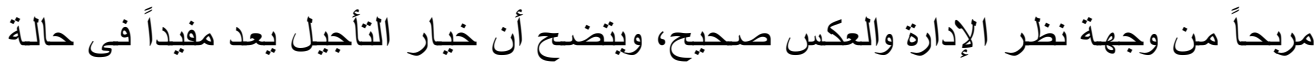
ارتفاع حالة عدم التأكد حول الطلب المحيطة بالقرار المطلوب اتخاذه، بما قد يؤدى إلى تحقيق نتائج عكس ما تم توقعه عند اتخاذ وتتفيذ هذا القرار . ب- خيار التوسع المرحلى (Option to Stage) ويقصد بـه إمكانيـة تقسيم المشروع موضـع القرار (الاستتمار فى الأصـول الثابتـة) المطلوب اتخاذه من قبـل الإدارة إلى مجموعـة من المراحل التى يعتمد بعضـها على بعض، ويتم تتفيذ

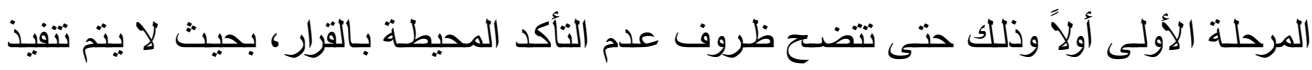

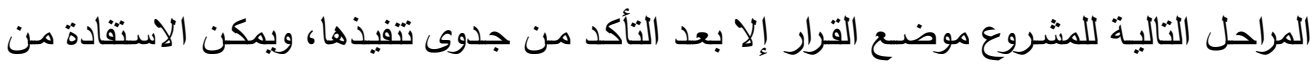
خيار التوسـع المرحلى فى أن تضـع الإدارة حد أقصى للخسائر وهو الخسارة الناتجة عن تتفيذ

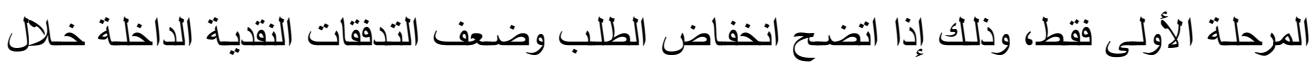
تللك المرحلة، ومن ثم الوقاية حينئذ من تحمل خسارة كافة مراحل المشروع إذا تم تتفيذه بالكامل.

جـ - الخيارات التشغيلية (Operating Options)

ويقصد به تصميم المشروع موضع القرار (الاستثمار فى الأصول الثابتة) بشكل مرن يسمح بالتكيف مع التغيرات التى تحدث فى ظروف عدم التأكد حول الطلب، بما يسهل من إمكانية استبدال الآلات بالأجيال الحديثة بسهولة بما يخفض تكاليف تركيبها، وكذللك تصميم المصنع 
بشكل يستوعب أكثر من مصدر للطاقة.

د -خيار التوقف المؤقت (Shutdown Options)

يمكن الاستفادة من هذا الخيار بعد تتفيذ المشروع موضع القرار (الاستثمار فى الأصول الثابتة)، حيث يمكن إيقاف استمرار التشغيل فترة من الوقت التى يسود فيها حالة عدم التأكد حول الطلب، نظراً لتوقع وجود انخفاض فى التدفقات النقدية الداخلة خـل تللك الفترة، ومن ثم

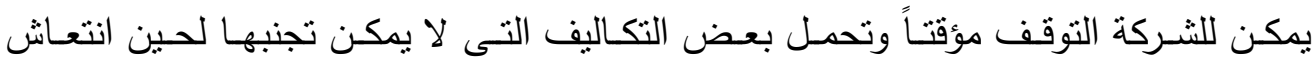
الظروف الاقتصادية للشركة والسوق الذى تعمل فيه.

هـ -خيار الإنهاء أو التصفية (Option to Abandom)

يمثل هذا الخيار أداة للتغطية (التحوط) ضد مخاطر توقع انخفاض القيمة الحالية للتدققات النقديـة للمشـروع موضـع القرار فـى ظل حالـة عدم التأكد حـول الطلب، مـع العلم بـأن الإدارة لديها الحق فى اتخاذ قرار بشـأن عدم تتفيذ المشروع موضـع القرار (الاستشمار فى الأصـول الثابتة) وذللك دون أى إلزام.

وبعد التعرف على الخيارات الإدارية المتاحة بشأن اتخاذ أى قرار استثمارى، نجد أن نظرية

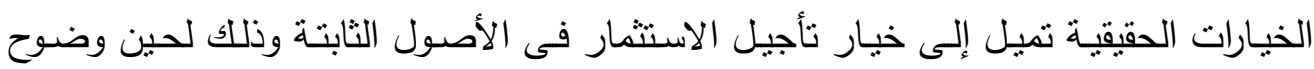
حالة عدم التأكد حول الطلب، ومن ثم اختبار هيكل تكلفة أكثر مرونـة وأقل جموداً، وذلك وضلك بزيادة التكاليف المتغيرة وتخفيض التكاليف الثابتة، وهذا ما أكدته نتائج دراسة Kallapur) (and Eldenburg, 2005) ليشير ذلك إلى إمكانية تأثنر حالة عدم نأكد الطلب على هيكل التكلفة وذلك فى ظل افتراض حياديـة توجه المدراء نحو المخاطرة، إلا أن عدم تتـاول دراسـة هذه العلاقة خلال المراحل المختلفة لدورة حياة الثركة قد ييرز أهمية البحث الحالى. 2- دور اسـتراتيجية الطاقة الإنتاجيـة في تفسير العلاقة بين عدم التأكد حول الطلب واختيار هيكل التكلقة تنتذعى عمليـة التخطيط للطاقة الإنتاجيـة ضـرورة تبنى استراتيجيات معينـة لتلبيـة حجم الطلب

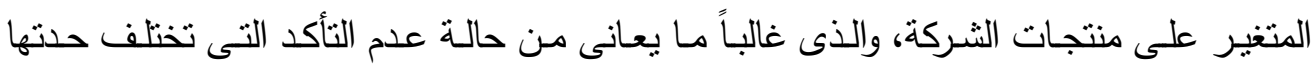
باختلاف مراحل دورة حياة الثركة، ومن ثم يتوقع أن يؤثر مستوى الطاقة الذى يتم اختياره على هيكل التكاليف وسياسات المخزون؛ فإذا كانت الطاقة غير كافية فقد تتعرض الثركة لفقد جزء من عملائها بسبب بطىء الاستجابة بما بسمح للمنافسين بالدخول إلى السوق، أمـا إذا كانت الطاقة 
فائضة فإن الثركة قد تضطر لتخفيض الأسعار لتغير حجم الطلب، والاحتفاظ بمخزون كبير ، أو إضافة منتجات جديدة للبقاء فى السوق (Huang et al, 2008).

وجدير بالذكر أن الثـركة قد نواجـه صـعوبة فى تحديد مقدار الطلب المتوقـع على منتجاتها مستقبلاً بسبب حالة عدم التأكد المحيطة بالطلب وذلك على عكس الطاقة الإتتاجية التى يمكن تحديدها من قبـل الثـركة، لذا تحتاج الثـركة إلى تصميم استراتيجيات خاصـة بالطاقة الإنتاجيـة

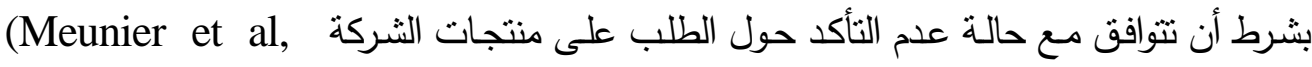
(2016، بما قد يؤثر على اختيار التكوين النسبى لهيكل التكاليف وما يتضمنه من تكاليف ثابتة (Olhager et al, 2001; Dekkers and ومتغيرة، ومن أهم هذه الاستراتيجيات مـا يلى لونى

:Kanapathy, 2012) أ- استراتيجية توافق الطاقة مع الطلب Matching Capacity to the Demand) تتخذ هذه الاستراتيجية موققاً معتدلاً فيما بين الطلب والطاقة وذلك بهدف تحقيق الموائمسة بين الإضـافات فى الطاقـة الإنتاجيـة مـن جهة والطلب مـن جهـة أخرى، ومـن ثم يتتم توسيع الطاقـة الإثتاجية بشكل يماثل مقدار الطلب المتوقع، حيث يتم زيادة الطاقة الإنتاجية بمقادير قليلة تحسباً لاحتمـال زيـادة الطلاب على منتجـات الثـركة، وتتوافق هذه الاستراتيجية مـع إحدى استراتيجيات التصنيع المرن والخاصـة بموازنـة الإنتاج وذلك نتيجة انتاج كميات صـيرة من كل منتج بمعدل ثابت يومياً، وذلك حتى لا تكون هناك حاجة لإنتاج كميات كبيرة من المنتج عند حدوث الطلب عليه، وبالتالى يتم تجميع كميات من المخزون لغرض استعمال الطاقة بشكل فعال، لذا قد يميل

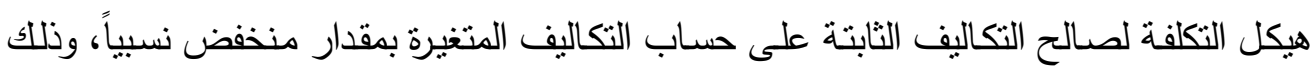
وفقاً لمقدار الزيادة فى الطاقة الإنتاجية (Bagshaw, 2015).

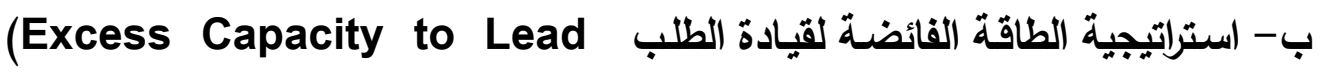

Demand) تقوم هذه الاستراتيجية على فكرة الاحتفاظ بطاقة إنتاجية زائدة تحسباً لزيادة الطلب، ومن ثم القضاء على احتمالات عدم قدرة الثركة على تلبية الطلب على منتجاتها، وبالتالى تساعد هذه لهاه الاستراتيجية الثركة فى الاحتفاظ باحتياطى موجب من الطاقة بغرض تمكينها من الاستجابة للطلب فى السوق ومنع المنافسين من الدخول إلى السوق، لذا فإن من إيجابيات استراتيجية

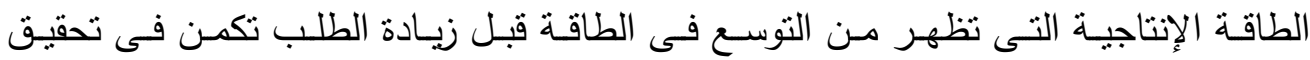


اقتصـاديات الحجم، وتوسيع الحصـة السوقية، ومنـع المنافسين من التوسـع، وتخفيض التأخر عن تلبية احتياجات العملاء إلى أقصى حد ممكن، وتتمثل طرق زيادة الإنتاجية فيى: زيادة

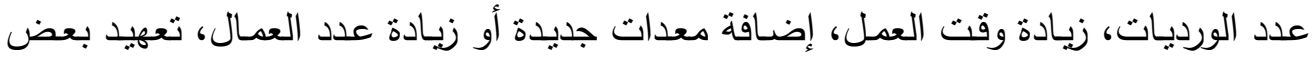

الأعمال لموردين من خارج الثركة (Holtewert and Bauernhansl, 2016). ولكن تتعرض هذه الاستراتيجية للعديد من الانتقادات من أهمها ما يثار حول مخاطر التقادم فى المعدات نتيجة كثرة استعمال المعدات بما يؤدى إلى التباطو فى أداء عملها، بالإضـافة إلى وجود طاقة فائضة بما قد ثؤدى إلى تخفيض الأسعار (Julka et al, 2007)، ولكن تعتمد هذه الاستراتيجية على فكرة أن حالة عدم التأكد حول الطلب على منتجات الثركة قد الثد يصاحبها احتمال وجود ارتفاع غير عادى فى الطلب الفعلى المحقق طالما أن الثركة لم تمر لـر بمرحلة الهبوط، بما قد يؤدى إلى زيادة حدة وخطورة تكاليف الازدحام (الاختناقات) بالثكل الذى قد يترتب عليه انخفاض الكفاءة الإنتاجية، بما قد يدفع الثركة إلى زيادة الطاقة الإنتاجية واتباع استراتيجية قيادة الطلب للحد من تكاليف الإزدحام. وجدير بالذكر أن الاختتاقات تعد بمثابة عنق الزجاجة فى العملية الإنتاجية، حيث أنها تعوق

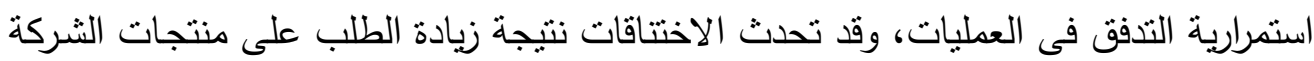
وذلك نحو غيرعادى، وقد تؤدى هذه الاختناقات إلى (Kikolski, 2016): - حدوث صفوف انتظار وتراكم للمواد تحت التتغيل، بما قد يترتب عليه وجود وقت ضائع، وزيادة فى المخزون تحت التشغيل، بالثكل الذى قد يؤدى إلى إرباك العمل وتحمل الثركة

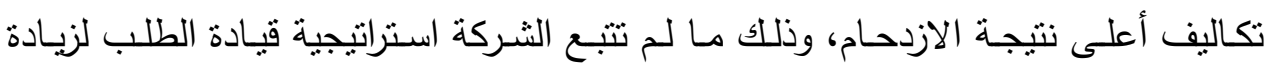
الطاقة الإنتاجية بغرض مواجهة الازدحام ونقاط الاختتاق.

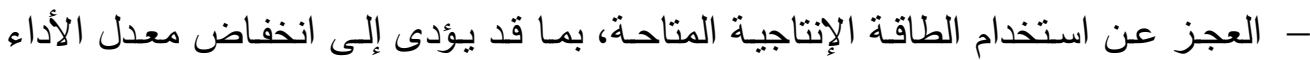
والنتغغيل وتننية مستوى الإنتاجية. لذا فإن إتباع استراتيجية قيادة الطلب لمواجهة حالة عدم التأكد حول الطلب على منتجات الثـركة قد يدفع الثـركة إلى اختيـار هيكل تكلفة أقل مرونـة وذلك بزيـادة التكاليف الثابتـة وتخفيض التكاليف المتغيرة، نتيجة زيادة الطاقة الإنتاجية التى قد تستلزم زيادة التكاليف الثابتة على حساب التكاليف المتغيرة. 


\section{جـ - اسـتراتيجية التــأخير أو عجـز الطاقـة Lag Strategy or Capacity}

Shortage)

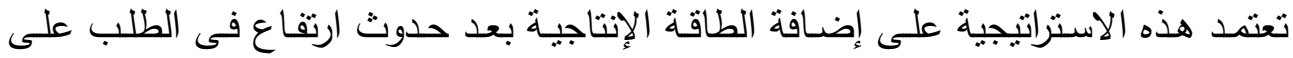

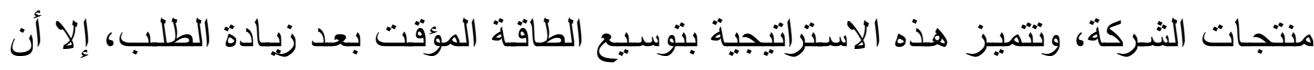
الثركة يمكن أن تفقد العديد من العملاء نتيجة الثأخر فى تلبية احتياجات العملاء من منتجات

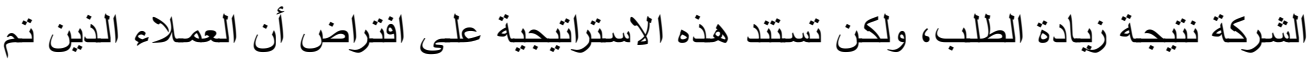

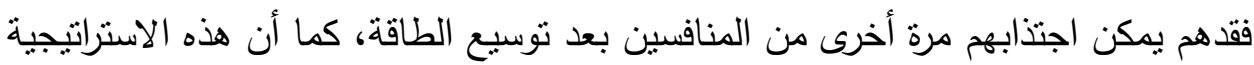
قد نؤدى إلى إظهار احتباطى طاقة سالب بسبب وجود طاقة غير كافيـة لتلبيـة الطلب

.(Jacobs et al, 2011)

وتتبنى هذه الاستراتيجية فكرة أن حالة عدم التأكد حول الطلب يمكن أن يصاحبها احتمال وجود انخفاض غير عادى فى الطلب الفعلى خاصة عندما تزداد مخاطر هبوط أو انحدار الثركة، بما يخفض من تكاليف الازدحام (الاختناقات)، بمـا قد يضطر الإدارة إلى اختيار

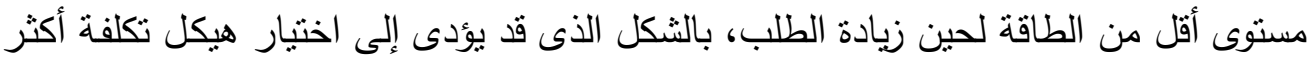
مرونة وأقل جموداً وذلك بزيادة التكاليف الدتغيرة وتخفيض التكاليف الثابتة. وبعد استعراض مبررات العلاقة المتوقعة بين حالة عدم نأكد الطلب وهيكل التكلفة يتضح أن الن النيان

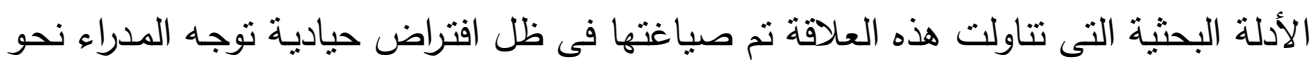
المخاطرة، بالإضـافة إلى عدم دراسة هذه العلاقة خلال المراحل المختلفة لدورة حياة الثركة، وهو ما سوف يتناوله الباحث فى الجزء التالى.

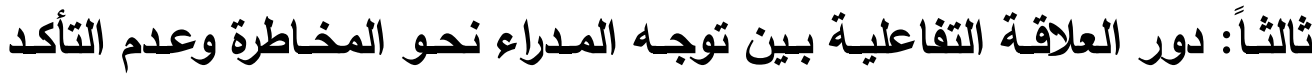 حول الطلب فى اختيار هيكل التكلقة خلال دورة حياة الثركة} تبين من العرض السابق أن العلاقة بين عدم التأكد حول الطلب واختيار هيكل التكلفة تم

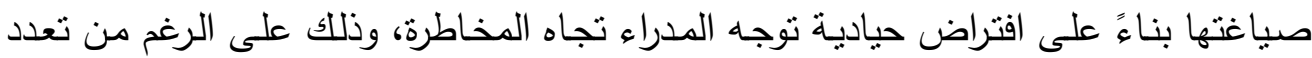

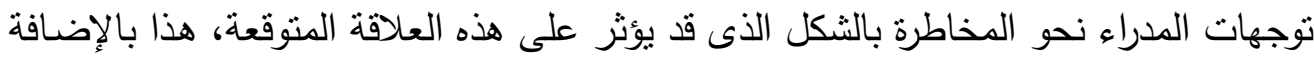

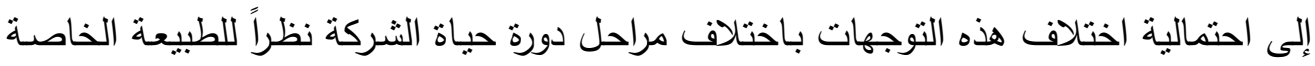
بكل مرحلة من مراحل دورة حياة الثركة. وسيعتمد الباحث على التدليل على طبيعة العلاقة التفاعلية النى قد تتشأ بين توجه المدراء 
نحو المخاطرة وعدم التأكد حول الطلب فى اختيار هيكل التكلفة خلال المراحل المختلفة لدورة حياة الثركة على استخدام نظرية المنفعة (Utility Theory) وذللك باعتبارها توفر نموذجاً يطلق عليه نموذج المنفعة المنوقعة، حيث يعتبر هذا النموذج بمثابة المرشد الملائم للقرارات التى قد يتخذها المدراء فى ظل حالة عدم التأكد (Baranoff et al, 2009). وتقوم نظريـة المنفعـة على تقدير دوال المنفعـة المتوقعـة للمدراء، ففى كثير مـن الحـالات يلاحظ أن سـلوك متخذى القرار تحت ظـروف عدم التأكد لا تطـابق معيـار القيمـة النقديـة

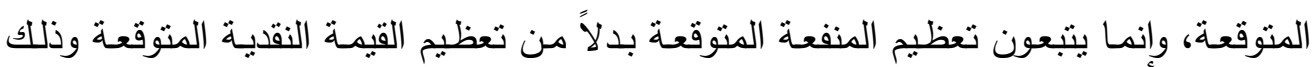
عند اتخاذ قراراتهم، وجدير بالذكر الإشارة إلى اختلاف مقدار المنفعة من شخص لآخر وذلك

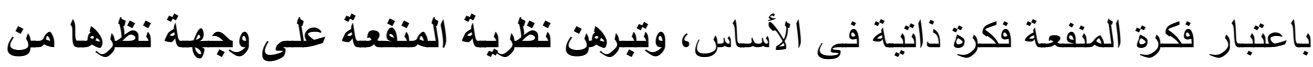
(Concina, 2014; Bo خلال تقسيم موقف المدراء تجاه المخاطرة إلى ثُلاث مجموعات التحرة and Sterken, 2007; Shapira, 1995; Hillson and Murray, 2007; Harvett,

\section{أ- متجنبو (كارهى) المخاطرة (Risk Averter)}

تفترض نظرية المنفعة أن أغلب المدراء وغيرهم من متخذى القرارات يدخلون فى فئة متجنبى

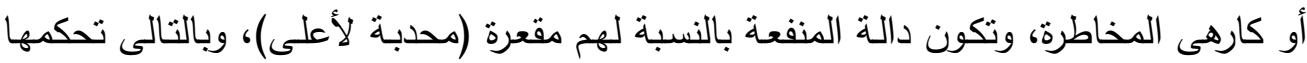

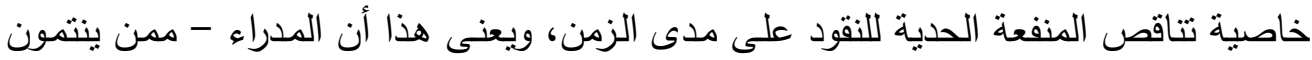
لهذه الفئة - كلما طالبوا بقدر متزايد من العائد فى مقابل كل وحدة من المخاطرة فإنهم يحصلوا على قدر منتاقص من المنفعة، وذلك مع كل وحدة إضافية للاخل أو الثروة الخاصـة بهح وفقاً

لقانون تتاقص المنفعة الحدية. وبالتالى يقبل الددراء على تحمل المزيد من المخاطرة إذا كانت الزيادة فى وحدة منها يقابلها زيادة فى العائد بمعدل يفوق الزيادة التى حصل عليها من إضافة الوحدة السابقة للمخاطرة.

ب - محايدون تجاه المخاطرة (Risk Neutral)

يتسم المدراء ممن بغلب عليهم حيادية توجههم نحو المخاطرة بأنهم على حد سواء بالنسبة

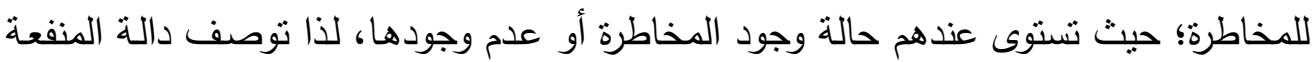

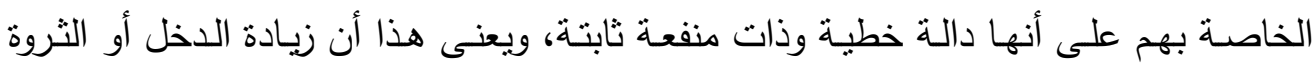
بمقدار معين سوف تؤدى إلى زيادة المنفعة أو نقصها بنفس المقدار . 


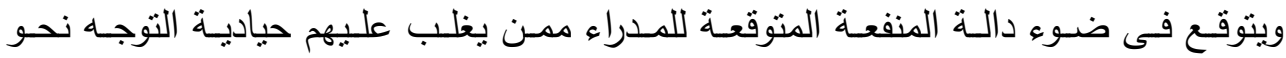
المخاطرة عدم تأثثر هذا التوجه على العلاقة بين حالة عدم التأكد واختيار هيكل التكلفة، بما قد ينبىء عن عدم وجود علاقة تفاعلية بين حيادية توجه المدراء نحو المخاطرة وحالة عدم التأكد حول الطلب، نظراً لأن معامل المخاطرة فى هذه الحالة يساوى الصفر ، وبالتالى يتم الاكتفاء بالأثر الأساسى لحالة عدم التأكد حول الطلب على اختيار هيكل التكلفة، لذا يخرج من نطاق تحليل نظرية المنفعة متجنبو المخاطرة من المدراء. ج - محبى (راغبى) المخاطرة (Risk Lover) توجد فئة من المدراء ممن هم على استعداد تام لتحمل المخاطرة، وهم من يفضلون التوقعات ذات المخـاطرة ولديهم تفضيل لمواجهة المخـاطرة، لذا فإن دالـة المنفعـة الخاصـة بهم تكون محدبة لأسفل، بما يعنى أن المنفعة الحدية متزايدة، وهو افتراض غير واقعى من قبل نظريـة المنفعة، لذا يخرج محبى أو راغبى المخاطرة من المدراء من نطاق تحليل نظرية المنفعة.

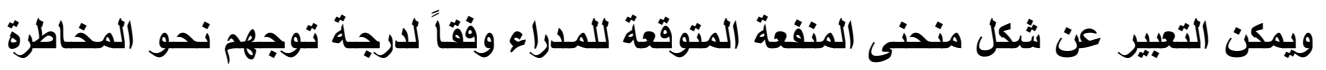
كما فى الشكل رقم (1) - (1)

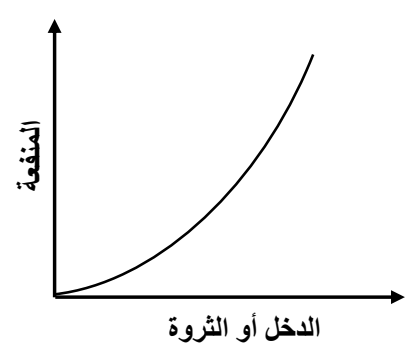

دالة منفعة المدراء محبى

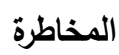

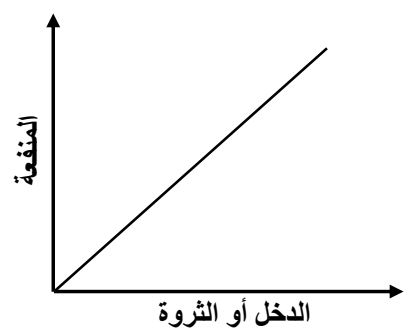

دالة منفعة المدراء المحايدون تجاه

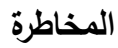

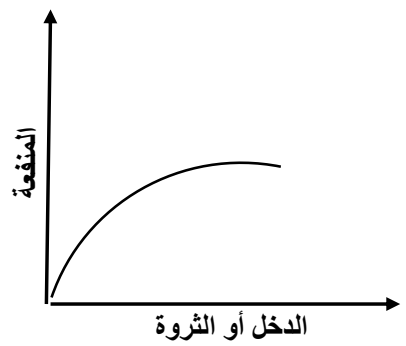

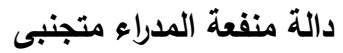

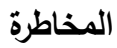

شكل رقم (1) دوال المنفعة المتوقعة وفقاً لتوجه المدراء نحو المخاطرة 
وممـا سبق يتضـح أن نظريـة المنفعة نؤيد الفكرة الخاصـة بـأن معظم المدراء يغلب عليهر التوجه الخاص بتجنب أو كره المخاطرة، ولكن جاءت نظرية الموقف (Prospect Theory) لتشير إلى أن افتراض تجنب المخاطرة لبس صحيحاً فى جميع المواقف، حيث يثقبل المدراء المخـاطرة عندما يثـعروا بـأن العائد المحقق أقل مـن مستوى الهدف المتوقع، بينمـا يتجنبوا المخاطرة عندما يشعروا بأن العائد المحقق أعلى من مستوى الهدف المتوقع، وبناءً على ذلك فإن دالة متخذ القرار تأخذ شكل حرف (S) حيث تبدو مقعرة (سلوك تجنب المخاطرة) فى في منطقة الأرباح، ومحدبة (سلوك تقبل المخاطرة) فى منطقة الخسائر ، وبالتالى فإن العلاقة بين العائد والمخاطرة ليست موجبة فى جميع الأحوال، ويعتبر هذا الاتجاه أكثر واقعية من الفرض ولى التقليدى لنظرية المنفعة للاتجاه نحو المخاطرة (Levy and Wiener, 2013). لذا فإن ارتفاع درجة تجنب (كره) المخاطرة قد تجعل المدراء يرون حالة عدم التأكد حول الطلب على أنها بمثابة تهديد أو إنذار لتوقع تحقيق الثركة خسائر محتملة نتيجة عدم استقرار

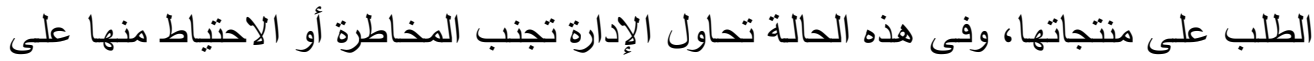
الأقل، بما قد يدفعهم نحو تخفيض مستويات الطاقة الإنتاجية ومستوى الطاقة المتلى ومن ثم تخفيض مستوى الإنتاج الأمثل، بالثكل الذى قد يضطر الإدارة إلى تبنى هياكل تكلفة أكثر

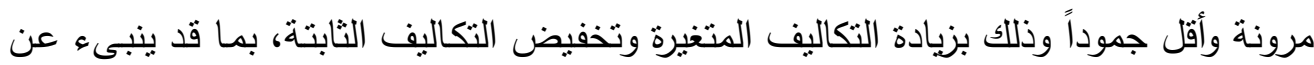
استجابة هيكل التكلفة للعلاقـة التفاعلية بين توجـه المدراء نحو تجنب المخاطرة وحالة عدم التأكد حول الطلب.

وعلى النقضض فإن انخفاض درجة تجنب (كره) المخاطرة أو سلوك تقبل المخاطرة قد تجعل

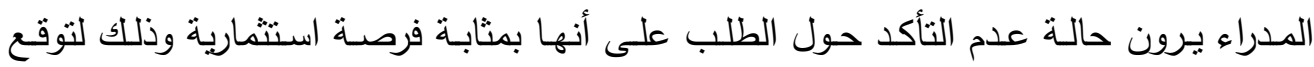
تحقيق الثـركة أرباحـاً نتيجـة لأن حالة عدم التأكد حول الطلب قد يصـاحبها احتمـال تحقيق طلب غير عادى على منتجات الثركة، بما قد يدفع الإدارة نحو زيادة مستوى الطاقة الإنتاجية

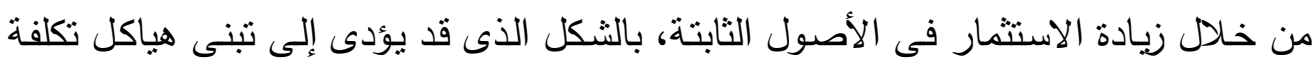

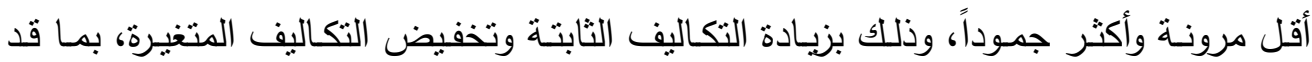
ينبىء عن أن انخفاض درجة نفور (كراهية) المخاطرة مرتبط بوجود أثر موجب للعلاقة بين حالة عدم التأكد حول الطلب واختيار هيكل تكلفة أكثر جموداً وأقل مرونة. 
ولكن استجابة هيكل التكلفة للعلاقة التفاعلية بين توجها المدراء نحو المخاطرة وحالة عدم التأكد حول الطلب قد تختلف بـاختلاف مراحل دورة حيـاة الثـركة، نظراً لتوقع تبـاين توجـه المدراء نحو المخاطرة وحالة عدم التأكد حول الطلب فى المراحل المختلفة لدورة حياة الثركة، ومن ثم توقع اختلاف استجابة التكوين النسبى لهيكل التكلفة وما يتضمنه من تكاليف ثابتة ومتغيرة، ويمكن استعراض الخصائص المختلفة لمراحل دورة حياة الثركة وما يقابلها من توقع لحالة كل من عدم التأكد حول الطلب وتوجه المدراء نحو المخاطرة، لاستتناج التكوين النسبى لهئ لهيكل التكلفة وذلك كما يوضح الجدول التالى Costa et al, 2017; Liu, 2008; Vorst) :and Yohn, 2017; Habib and Hasan, 2015)

\section{جدول رقم (1) خصائص مراحل دورة حياة الشركة}

\begin{tabular}{|c|c|}
\hline \multicolumn{2}{|l|}{ مراحل دورة حياة الشركة } \\
\hline \multicolumn{2}{|l|}{ أولاً: مرحلة التقديم (Introduction) } \\
\hline المفهــــــوم & الخصائص \\
\hline 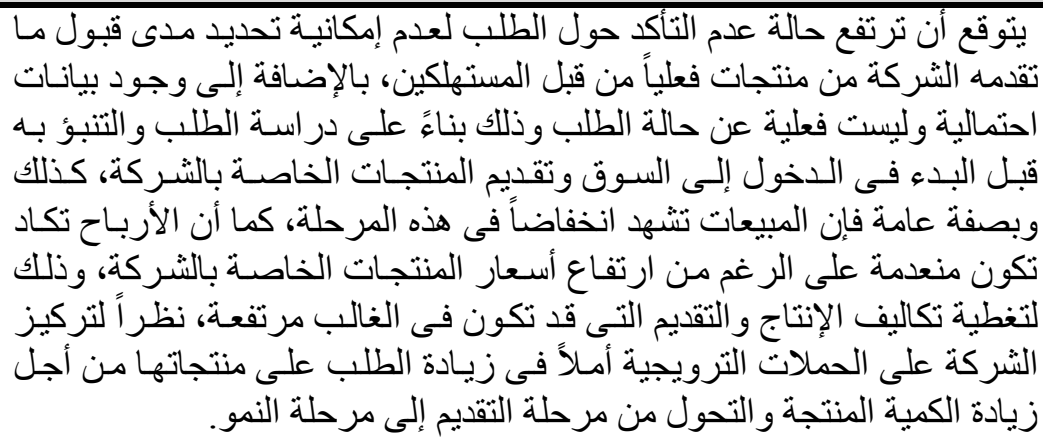 & تأكد الطالة عدم \\
\hline 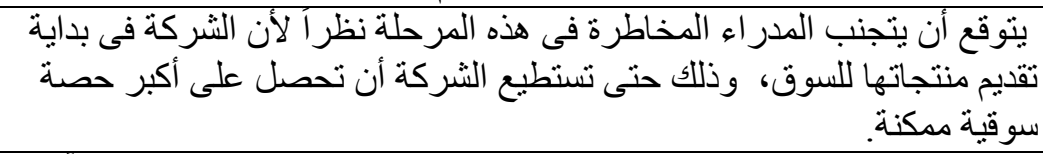 & توجو المخاطرة المدراء \\
\hline 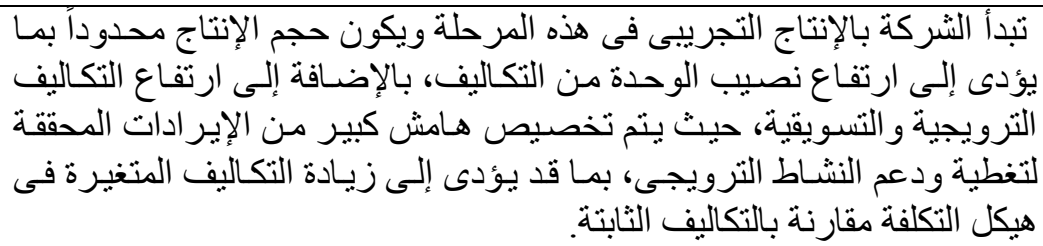 & التكوين النسبيى التكلفة \\
\hline \multicolumn{2}{|l|}{ ثنانياً: مرحلة النمو (Growth) } \\
\hline 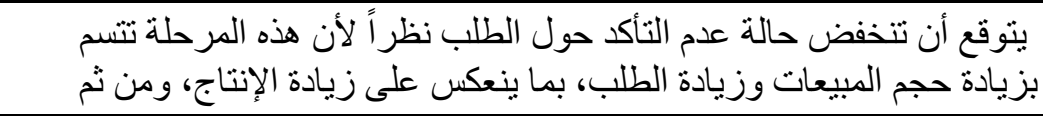 & تأكد الطلة عدم \\
\hline
\end{tabular}


تخفيض تكاليف الإنتاج، وتخفيض أسعار المنتجات الخاصة بالثركة، وبالتالى

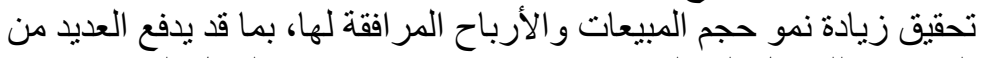

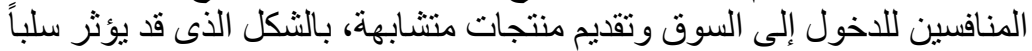

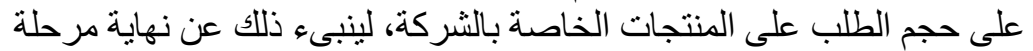
النمو وبداية مرحلة الاهنز ازل (الاضطر اب).

يتوقع أن يتقبل المدر اء المخاطرة فى هذه المرحلة أباً كانت توجهاتهم نحوها،

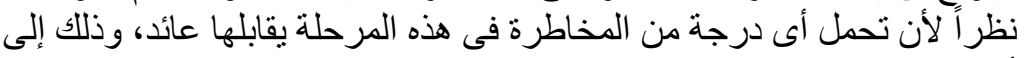
أن ينت دخول العديد من المنافسين إلى السوق، وتثبع السئ السوق بالمنتجات الخاصة

توجه المدراء نحو المخاطرة بالشركة.

يتوقع أن يميل هيكل التكلفة لصالح التكاليف الثابتة مقارنة بالتكاليف المتغيرة و ذلك لمو اجهة الطلب المتز ايد على المنتجات الخاصة بالثركة ولته وذلك من خلال زيادة الاستثمار ات في الأصول الثابتانة.

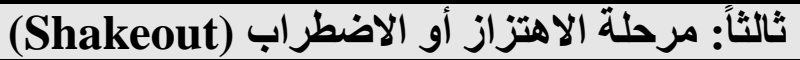

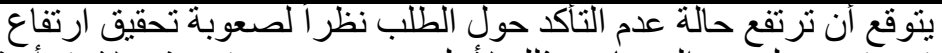

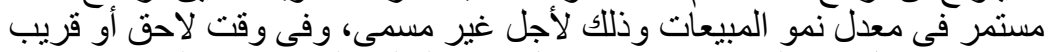

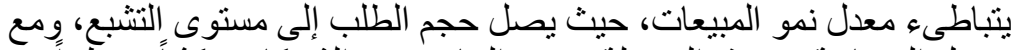

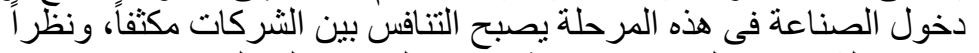

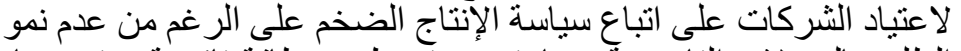

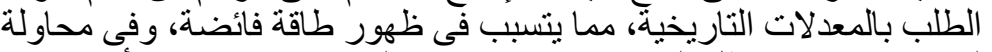

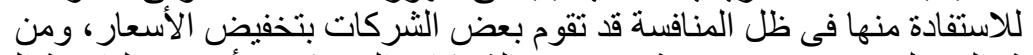

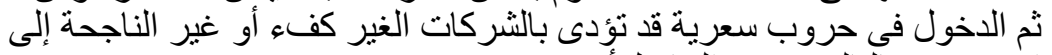

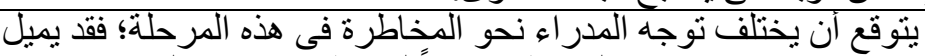

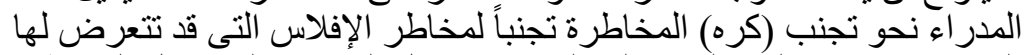

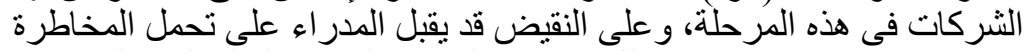

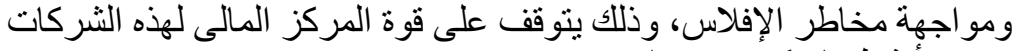
وتنوع أنشطتها وكبر حجمها.

يتوقع أن يختلف التكوين النسبى لهيكل التكلفة؛ فمن الممكن أن يميل هيكل

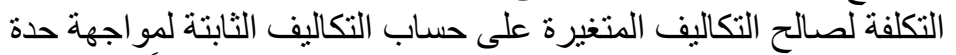
المنافسة و الخروج من هذه المرحلة، وقد يحدث العكس انطلاقاً من مقولة البقاء

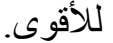

حالة عدم تأكد الطلب
توجه المدراء نحو المخاطرة المدرة

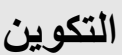
النسبى لهيكل التكلقة

\section{رابعاً: مرحلة النضج (Maturity)}

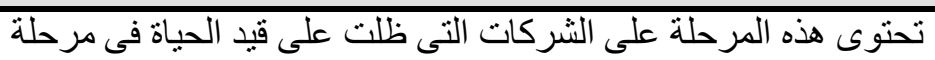

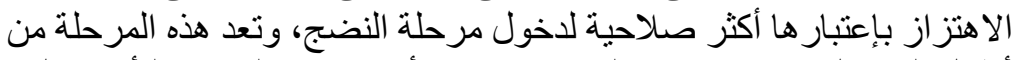

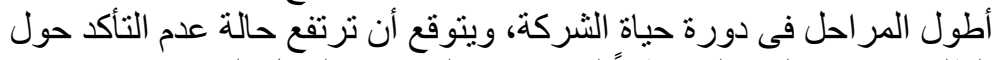

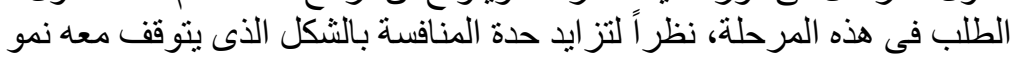

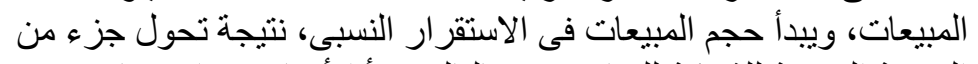

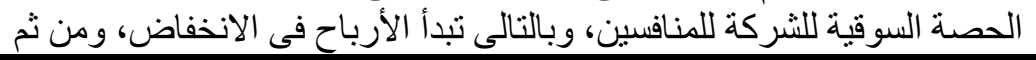

حالة عدم تأكد الطلب 
يجب التنكير فى إبقاء الثركة فى السوق لأطول فترة ممكنة بشرط أن تكون

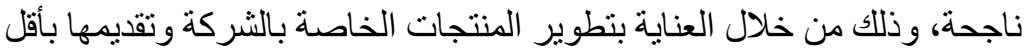

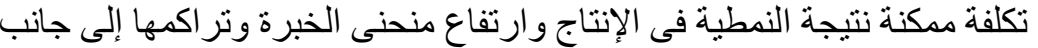

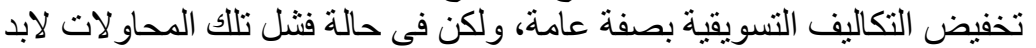

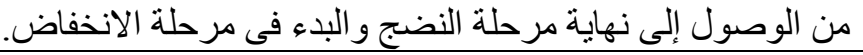

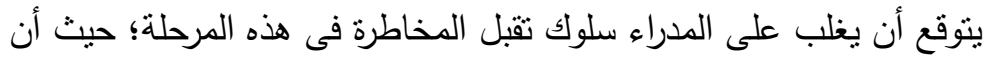

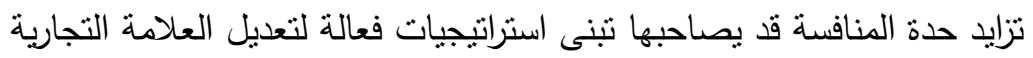
أو تعديل المنتجات الخاصة بالثركة من حيث الجودة والموثوقية، بالإضافة إلى إلى

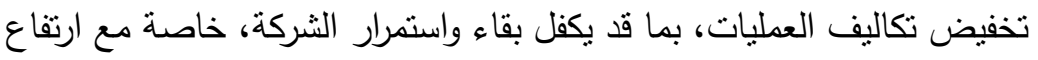
حواجز الدخول للصناعات الناضجة، ومن ثم تخفيض التهديدات من المنافسين

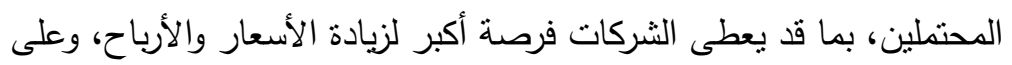

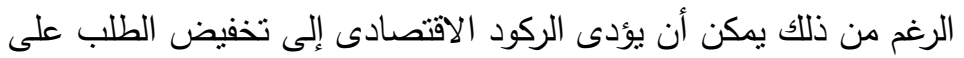

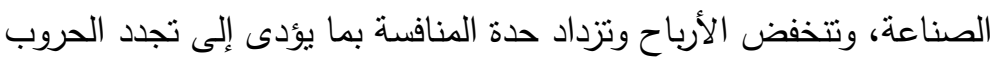
السعرية.

يتوقع أن تواجه الثركة تزايد حدة المنافسة فى هذه المرحلة من خلال تبنى هيكل تكلفة أقل مرونة وذلك بزيادة التكاليف الثابتة وتخفيض التكاليف المتغيرة نتيجة تطبيق استراتيجيات فعالة لمواجهة تلك المنافسة، إلى جانب توقع تحقيق مزيد من

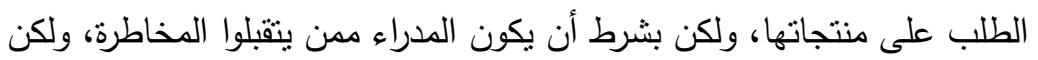

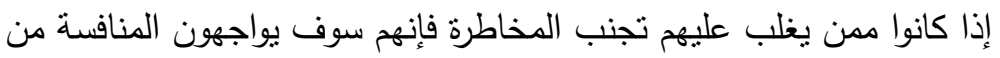
خلال تبنى هيكل تكلفة أكثر مرونة.

توجه المدراء نحو المخاطرة المداء

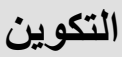
النسبى لهيكل النكوين التكلفة

\section{خامساً: الانخفاض (Decline)}

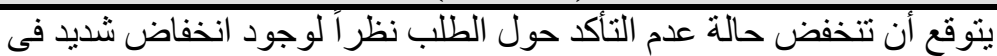

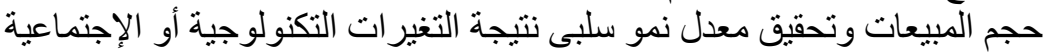

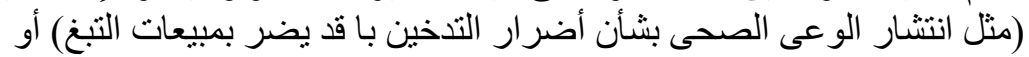

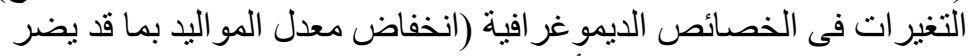

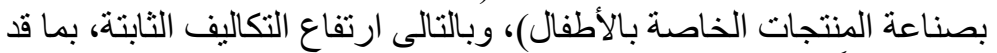

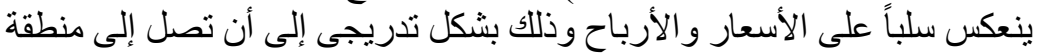

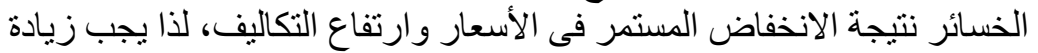

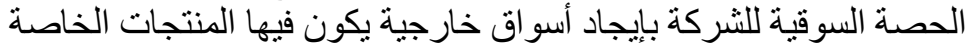

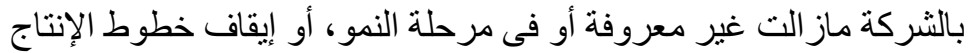

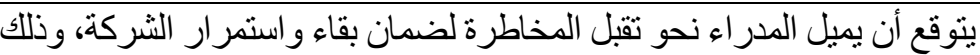

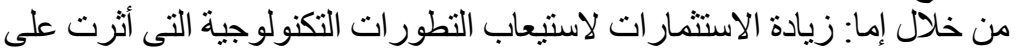

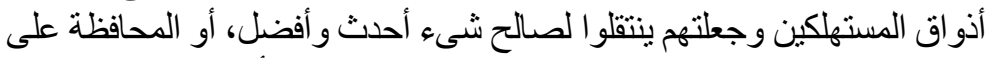

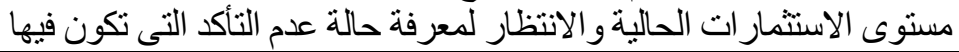


الصناعة، أو اختيار مستوى محدد من الاستثمار بهدف البقاء فى السوق التنافسى.

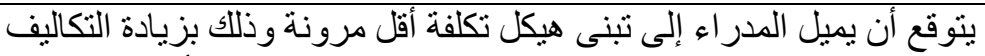

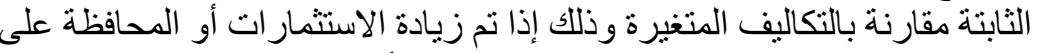

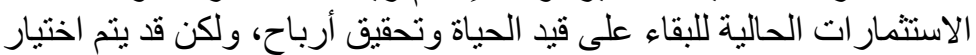

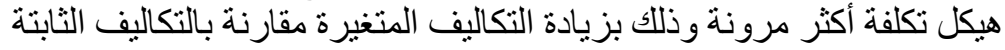
وذللك إذا تم تحديد مستوى محدد من الاستثمار لضمان بقاء و استمر ار الثركة
التكوين

النسبى لهيكل

التكلفة

وبتضـح فى ضـوء الجدول السـابق أن توجـه المدراء نحو المخاطرة قد يتغير بتغير المواقف التى يتعرضون لها فى المراحل المختلفة لدورة حياة الثركة، بالإضـافة إلى اختلاف حالة عدم التأكد حول الطلب خلال تلك المراحل، بالثكل الذى قد يؤدى إلى تغير التكوين النسبى لهيكل التكلفة وذلك استجابة للعلاقة التفاعلية المتوقعة بين توجهه المدراء نحو المخاطرة وحالة عدم التأكد حول الطلب خلال المراحل المختلفة لدورة حياة الثركة. وبعد استعراض الخلفية النظرية للبحث، أصبحت هناك حاجة إلى اختبار طبيعة العلاقة بين حالة عدم التأكد حول الطلب واختيار هيكل التكلفة، بالإضـافة إلى اختبار أثر توجه المدراء نحو المخاطرة على طبيعة هذه العلاقة خلال المراحل المختلفة لدورة حياة الثركة، وذلك وفقاً لمنهجية الدراسة الاختبارية التى سيتم تصميمها فى القسم الثانى من البحث.

\section{القسم الثانحى}

\section{الدراسة الاختبارية}

يهمتم هـا القسـم ببيـان تصسميم الدراسـة الاختباريـة التى سـيعتمد عليهـا الباحث لاختبـار الفروض الرئيسية للبحث، لذا يجب تحديد ما يلى: أولاً: متغيرات الدراسة وكيفية قياسها إجرائياً. ثانياً: توصيف نموذج الدراسة. ثالثاً: فترة الدراسة. رابعاً: مجتمع وعينة الدراسة. خامساً: مصادر الحصول على البيانات. سادساً: الأساليب الإحصائية المستخدمة. 


\section{وسيتم التعرض للقاط السابقة بالتفصيل كما يلى: أولاً: متغيرات الاراسة وكيفية قياسها إجرائياً:}

فى ضوء فروض البحث يمكن تحديد المتغيرات الرئيسية وكيفية قياسها إجرائياً كما يلى:

(1) المتغير التابع: هيكل التكلفة (Cost Structure)

سيعتمد الباحث على قياس التكوين النسبى لهيكل التكلفة وذلك لتحديد مـا إذا كان يميل لصـالح التكاليف الثابتة أم إلى التكاليف المتغيرة من خـلال استخدام النموذج الخاص بدراسـة Banker et al, 2014 "b") $\Delta \ln \operatorname{Cost}_{i, t}=\beta_{0}+\beta_{i, t} \Delta \ln$ SALES $_{i, t}+\gamma_{0}$ Controls $_{i, t}+\varepsilon_{i, t}$

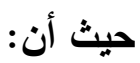

اللوغاريتم الطبيعى للتغيرات فى إجمالى التكاليف (المصروفات البيعية والإدارية، $: \Delta \ln \operatorname{Cost}_{i, t}$ وتكلفة البضاعة المباعة، والمصروفات التشغيلية) المعدلة بأثز معدل التضخم

$$
\text { للثشركة (i) من الفترة (t-1) حتى الفترة (t). }
$$

اللوغاريتم الطبيعى للتغيرات فى إيراد المبيعات (كمقياس تقريبى للحجم) المعدلة بأثر معدل التضخم للشركة (i) من الفترة (t-1) حتى الفترة (t).

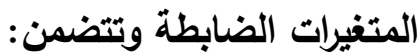
$: \triangle \ln S A L E S_{i, t}$

معدل نمو الناتج المحلى الإجمالى فى الفترة (t). : Controls $_{i, t}$

(i) : نوع الصناعة التى تتنمى إليها الثركة

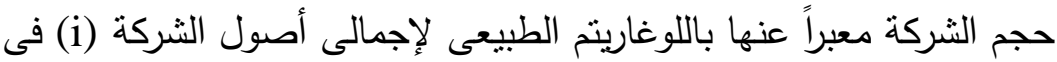

:Firm Size

$$
\text { الخطاية الفترة (t). }
$$

معامل الانحدار الذى يقيس نسبة تغير التكاليف نتيجة لتغير إيراد المبيعات بمقدار 1\%، ويعبر عن مرونة هيكل التكلفة.

(2) المتغير المستقل: عدم التأكد حول الطلب (Demand Uncertainty):

سبعتمد الباحث على قيـاس حالـة عدم التأكد حـول الطلب باستخدام معامـل الاختلاف الخاص باللوغاريتم الطبيعى للتغير فى المبيعات المعدلة (Coefficient of Variation) 
بأثز معدل التضخم للشـركة (i) خـلال سلسـلة زمنيـة مقدارها 10 سنوات وذلك وفقاً لدراسـة .(Banker et al, 2014 "b")

\section{(3) المتغير المنظم: توجه المدراء نحو المخاطرة (RiskAttitude of Managers):}

سيعتمد الباحث على قياس نوجه المدراء نحو المخاطرة على مستوى كل شركة من الثركات

محل الدراسة باستخدام نموذج (Bo and Sterken, 2007) وذللك وفقاً للخطوات التالية: - تقدير معدل العائد المعدل بالمخاطرة على مستوى الثركة وذلك من خلال تشغيل النموذج

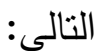

$$
P T_{t}^{R}=\mathrm{PT}^{*}+\alpha_{1} \mathrm{SD}_{\mathrm{t}}+\alpha_{2} \mathrm{SKEW}_{\mathrm{t}}
$$

\section{حيث أن:}

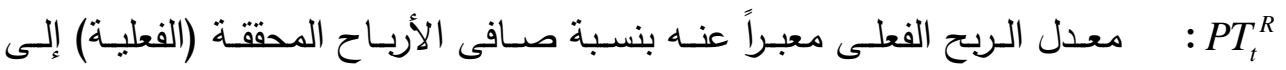

$$
\text { إجمالى أصول الثركة (i) فى نهاية الفترة (t). }
$$

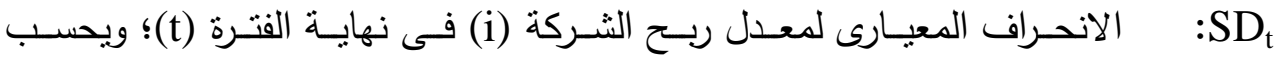

باستخدام المشاهدات السنوية لصافى الأرباح المحققة خلال سلسلة زمنية قدرها

$$
10 \text { سنوات. }
$$

SKEWt السنوية لصافى الأرباح المحققة خلا سلسلة زمنية قدرها 10 سنوات.

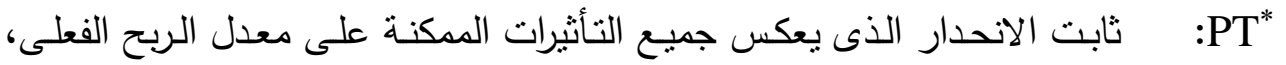

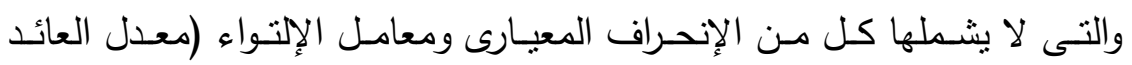

$$
\text { المعدل بأثز المخاطرة). }
$$

( $\alpha_{1}, \alpha_{2}$

- تقدير علاوة المخاطرة (Risk Premium "RP") على مستوى الثركة فى نهاية الفترة (t) وذلك بـالفرق بين صـافى الأرباح المحقة (الفعلية) منسوباً لإجمالى الأصسول (

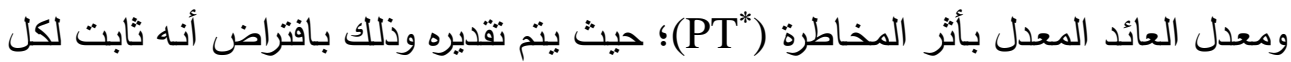
شركة خلال الفترة محل الدراسة بأكملها، ومن ثم بمكن التعبير عن المقياس التقريبى لعلاوة

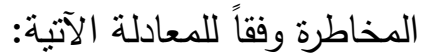

$$
\mathrm{RP}_{\mathrm{t}}=\mathrm{PT}_{\mathrm{t}}^{\mathrm{R}}-\mathrm{PT}^{*}
$$


(Risk-Aversion of حسـاب المقيـاس التقريبـى لدرجـة تجنب المـدراء المخـاطرة وذلك باستخدام قيمة عـلاوة المخاطرة المحسوبة لكل شركة وذلك باستخدام

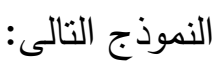

$$
\mathrm{RP}_{\mathrm{t}}=\mathrm{RC} * \mathrm{SD}_{\mathrm{t}}+\omega * \mathrm{SKEW}_{\mathrm{t}}
$$

ومما سبق يعكس معامل المخاطرة الموجب (RC > R أن مدراء الثركات يميلون إلى تجنب المخاطرة، بينما يعكس معامل المخاطرة السالب (RC $)$ (RC) أن مدراء الثركات يميلون إلى الإقبال على تحمل المخاطرة، ولكن التوصل إلى معامل مخاطرة غير معنوى يشير إلى حيادية توجه المدراء تجاه المخاطرة.

\section{(4) (المتغيرات الضابطة} سيعتمد الباحث على استخدام المتغيرات الضابطة التالية: أ- حجم الثركة (Firm Size): معبراً عنها باللوغاريتم الطبيعى لإجمالى أصول الثركة (i) فى نهاية الفتزة (t).

ب- معدل نمو الناتج المحلى الإجمالى (GDP). ج- دورة حياة الثركة (Firm Life cycle). أنثارت دراسة (Dickinson, 2011) إلى أن دورة حياة الثركة يمكن تصنيفها إلى خمس

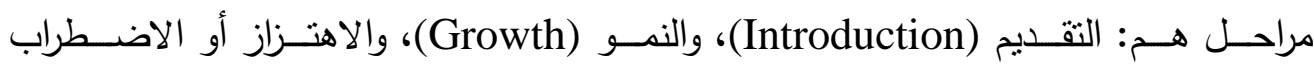

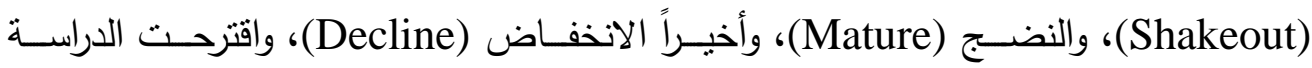

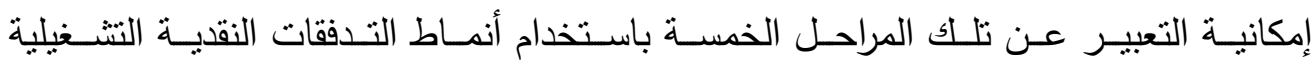
والاستثمارية والتمويلية، وذلك باعنبارها تلخص النتائج المالية لمراحل دورة حياة الشركة وذلك بلك

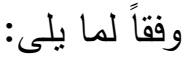

\section{التدفقات النقدية من الأنشطة التشغيلية}

تفتقر الثركات التى تمر بمرحلة التقديم إلى وجود قاعدة راسخة من العملاء، بالإضـافة إلى أنها تعانى من نقص المعرقة حول الإيرادات والتكاليف المحتملة، بالثكل الذى قد يتسبب فى في وجود صافى تدفقات نقدية سالبة من الأنشطة التتخيلية، بينما تحقق الشركات صافى تدفقات

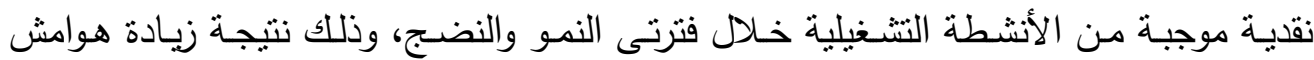
الربح من خلال زيادة الاستثمارات ذات الكفاءة. 
ولكن سرعان مـا تنخفض معدلات النمو فى المبيعات، بما يؤدى إلى انخفاض الأسعار ، ومن ثم ينخفض صـافى التدفقات النقديـة من الأنشطة النتشيلية وتصبح سلبية بمجرد دخول الثركة مرحلة الانخفاض.

\section{التدفقات التقدية من الأنشطة الاسنثمارية}

يشجع التفاؤل الإدارى للشركات على القيام بالاستثمارات المبكرة التى تقف حاجزاً أمام دخول منافسين جدد إلى السوق، بما قد يتسبب فى تحقيق الثركات صـافى تدفقات نقدية سالبة من الأنشطة الاستثمارية وذلك خـلال مرحلتى التقديم والنمو، بينمـا تقوم الثـركات خـلال مرحلـة النضـج بتخفيض الاستثمارات وذلك مقارنـة بمرحلة النمو، ولكن تواصل الثـركات خـلال فترة النضج الاستثمار وذللك للحفاظ على رأس المال. لذا إذا زادت تكـاليف الحفاظ على مسـتوى الاستثمار بمـرور الوقت فإن صـافى التدفقات

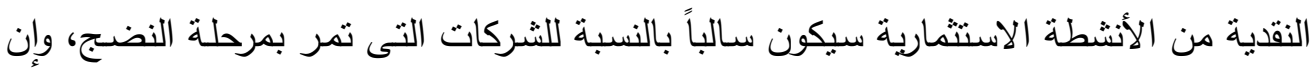

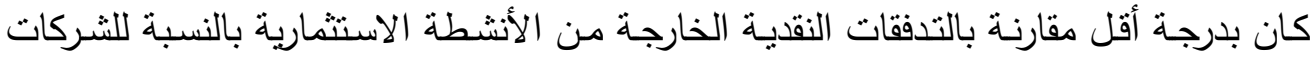
التى تمر بمرحلة التقديم والنمو ، أما الثركات التى تمر بمرحلة الانخفاض تضطر إلى تصفية

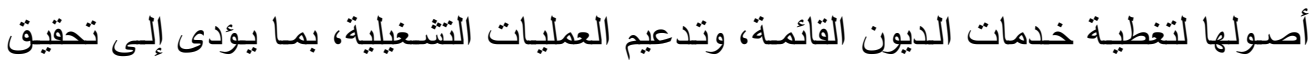
صافى تدفقات نقدية موجبة من الأنشطة الاستثمارية.

\section{التدفقات النقدية من الأنشطة التمويلية}

تقترض نظريـة ترتيب أفضلية مصادر التمويل The Pecking Order theory) لجوء معظم الثركات إلى القروض المصرفية، ثم إصدار أسهم ملكية، وذللك لتحقيق التوازن بين المزايا

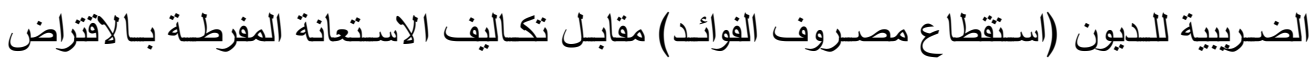
الخارجى، ومن ثم تلجأ الثركات التى تمر بمرحلة الثقديم والنمو إلى الاقتراض الخارجى لتحقيق

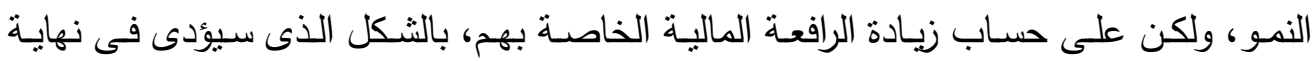
المطاف إلى تخفيض صافى التدفقات النقدية لتغطية خدمات الديون. علاوة على ذللك، أثنارت دراسة (Barclay and Smith, 2005) إلى أنه من المتوقع أن تنخفض السيولة مع استمرار الاقتراض، بما يؤدى إلى نقص الاستثمار فى المشروعات ذات

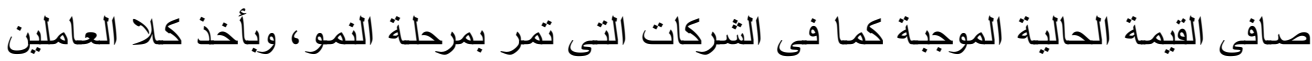
فى الاعتبار، نجد أن صافى التذفقات النقدية من الأنشطة التمويلية يتوقع لها أن تكون موجبة لهنة 
على الأقل فى الثركات التى تمر بمرحلة التقديم، وأكثر احتمالاً بالنسبة للشركات التى تمر بمرحلة النمو باعتبارها تقبل على الاقتراض من أجل التوسع.

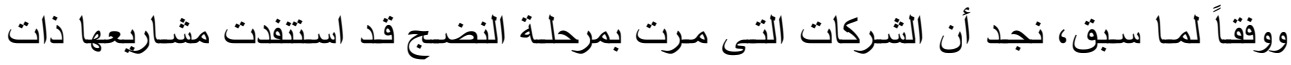

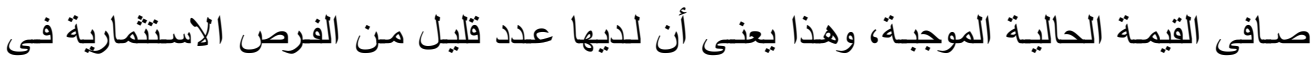

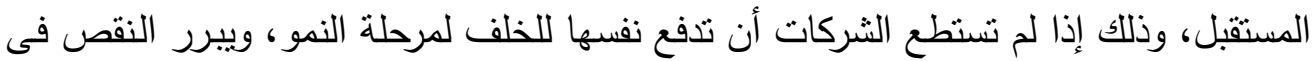
الفرص الاستثمارية انخفاض الحاجـة إلى الاقتراض الإضـافى، حيث تمتلك هذه الثـركات أفضل مركز مالى للقيام بتمويل استتماراتها (Barclay and Smith 2005)، إلا أن دراسة النها (Jensen, 1986)

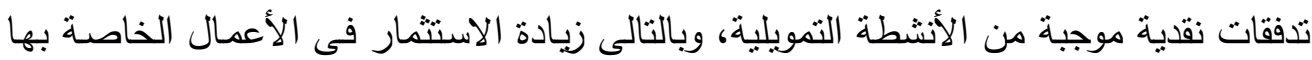
(أو القيام بأنشطة الاستحواذ) وإن كان ذللك يحقق عوائد أقل. ثم تبدأ الثركات الناضجة إما فى تغطية خدمات الديون الخاصـة بها، أو توزيع النقدية على دانى المساهمين، وذلك لأنها استتفدت الفرص الاستتمارية التى تُدر صافى قيمة حالية موجبة، أو

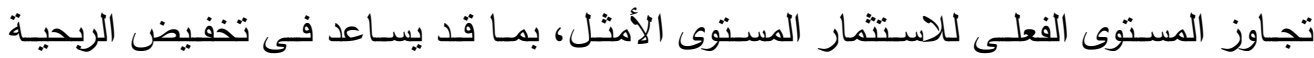

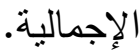
وتتشير الأدبيات المرتبطة بنظرية الإثـارة إلى أن الثركات توزع التدفقات النقدية الحرة على المسـتثرين لإثبـات أنهـم لا يسـتثمرون فـى المجـالات التـى تلحـق الضـرر بقيمـة الثـركة (Jensen, 1986; Barclay and Smith, 2005; Oler and Picconi, 2010) ضـوء الافتراض الخـاص بنظريـة الإثـارة ونقص الفرص الاستثمارية تنتبـأ الدراسـة بـأن تقوم

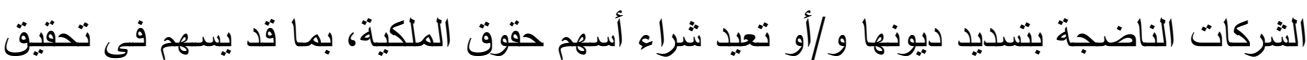
صافى تدفقات نقدية سالبة من الأنشطة التمويلية، وجدير بالذكر وجود فراغ فى الأدبيات فيما لتهاء يتعلق بالتدفقات النقدية من الأنشطة التمويلية بالنسبة للشركات التى تمر بمرحلة الانخفاض، ومن ثم لم يتم التتبؤ بأى اتجاه لها قبل ذلك. 
وفى ضوء مـا سبق يمكن التعرف على مراحل دورة حياة الشركة فى (8) مستويات وفقاً لاراسة (Dickinson, 2011) كما فى الجدول رقم (2) التالى:

جدول رقم (2) أنماط التدفقات التقدية خلال مراحل دورة حياة الثركة

\begin{tabular}{|c|c|c|c|c|c|c|c|c|}
\hline \multicolumn{8}{|c|}{ مر احل دورة حياة الشركة } & \multirow{3}{*}{ النقدية } \\
\hline 8 & 7 & 6 & 5 & 4 & 3 & 2 & 1 & \\
\hline الانخفاض & الانخفاض & النضج & الاهتزاز & الاهتزاز & الاهتزاز & النمو & التقديم & \\
\hline- & - & + & + & + & - & + & - & تشغيلية \\
\hline+ & + & - & + & + & - & - & - & استثمارية \\
\hline - & + & - & - & + & - & + & + & تمويلية \\
\hline
\end{tabular}

وبالتالى ينتم تقسيم الثـركات محل الدراسـة وفقاً للمرحلة التى تمر بها من مراحل دورة حياة

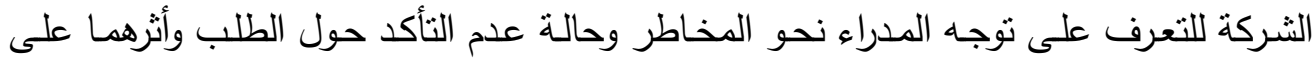
التكوين النسبى لهيكل التكلفة خلال كل مرحلة من هذه المراحل، وذلك بالتعبير عن مراحل دورة

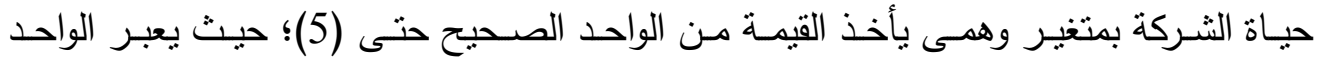

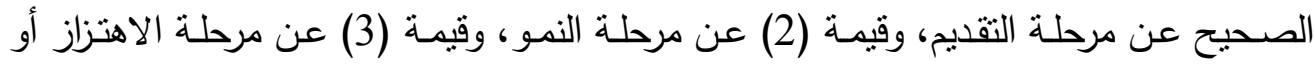
الاضطراب، وقيمة (4) عن مرحلة النضج، وقيمة (5) عن مرحلة الانخفاض.

\section{ثانياً: توصيف نموذج الاراسة}

تحقيقاً لأهداف البحث الخاصـة بدراسـة العلاقة بين حالـة عدم التأكد حول الطلب وهيكل التكلفة خـلال المراحل المختلفـة لدورة حيـاة الثـركات الصـناعية العاملـة فـى بيئة الأعمـال المصرية, بالإضـافة إلى معرفـة أثنر توجهـ المدراء نحو المخـاطرة على هذه العلاقـة، يمكن تصوير نموذج الدراسة المستخدم فى التحقق من مدى صحة أو خطأ فرضى البحث كلِ على لِّى حدة من خلال نطوير نموذج (Banker et al, 2014 "b") وذللك كما يوضح الجدول التالى: 


\section{جدول رقم (3) نموذج الدراسة}

\begin{tabular}{|c|c|c|}
\hline \multicolumn{2}{|l|}{ نماذج الاتحدار المستخدمة } & الفروض \\
\hline 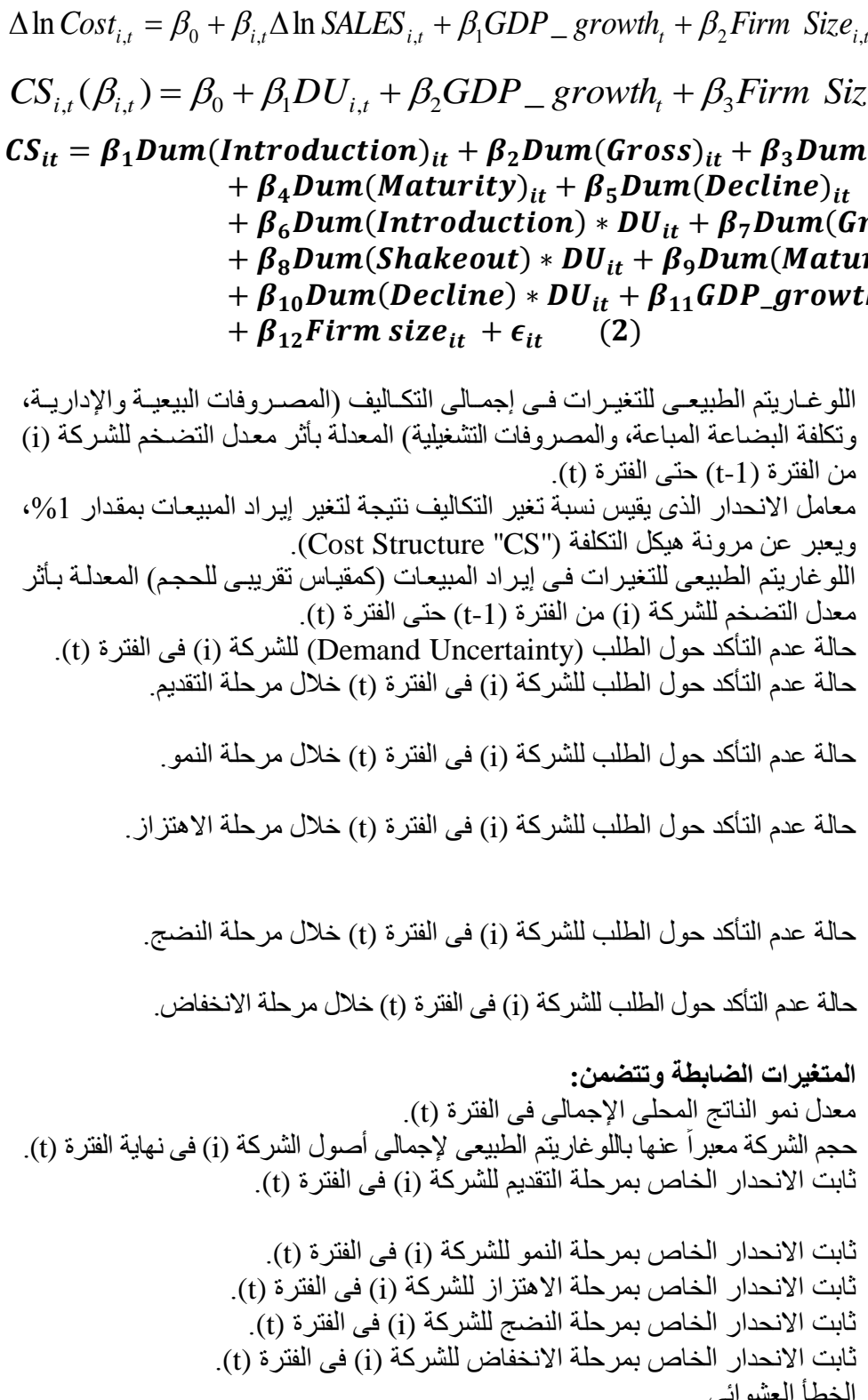 & 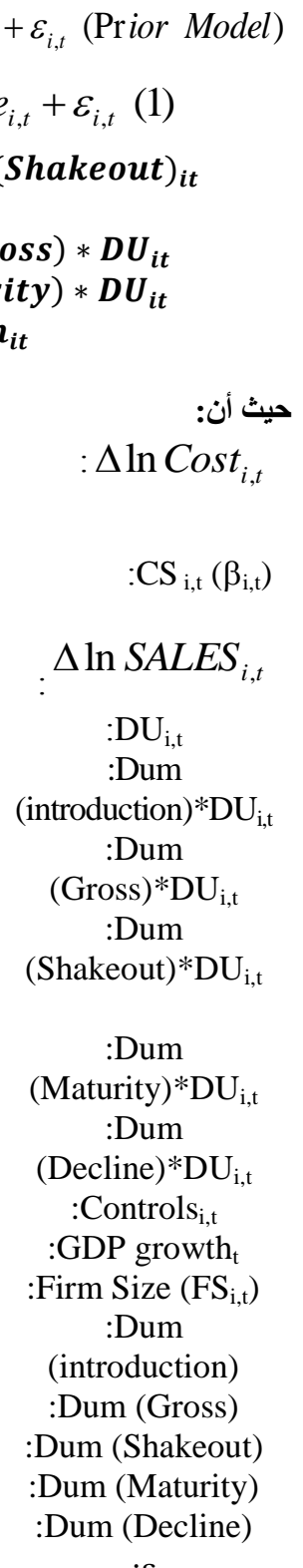 & 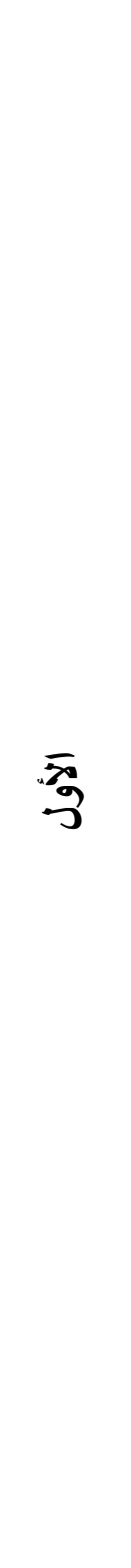 \\
\hline
\end{tabular}




\begin{tabular}{|c|c|c|}
\hline \multicolumn{2}{|l|}{ نماذج الاتحدار المستخدمة } & الفروض \\
\hline 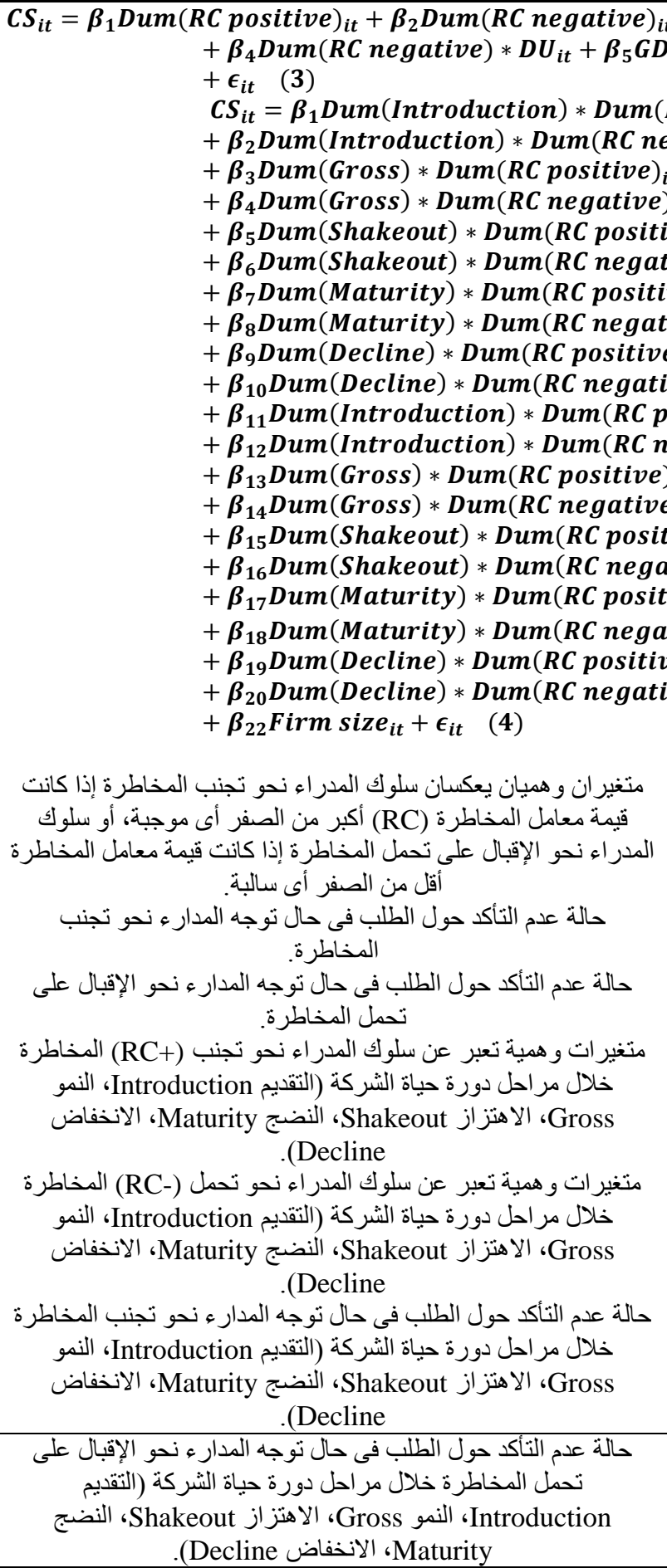 & 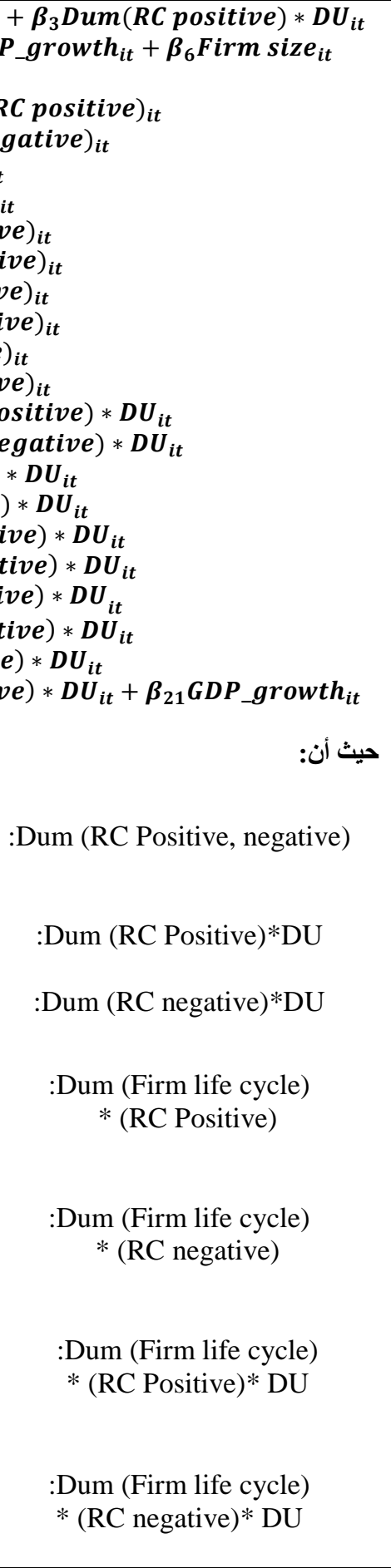 & \\
\hline
\end{tabular}




\section{وفى ضوء استعراض نماذج الانحدار المستخدمة فى اختبار فرضى البحث يلاحظ ما يلى:}

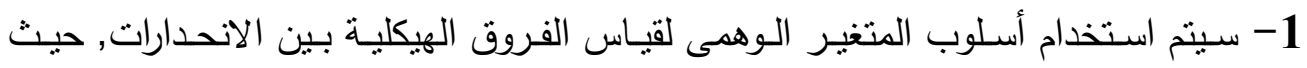

تسمح لنا هذه الطريقة بالمحافظة على درجات الحريـة وعدم فقدانها نتيجة تقسيم عينـة الدراسة إلى مجموعة من العينات الفرعية (Gujarati, 2009)، حيث يجب أن يتث تقسيم

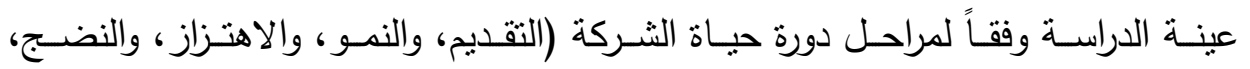

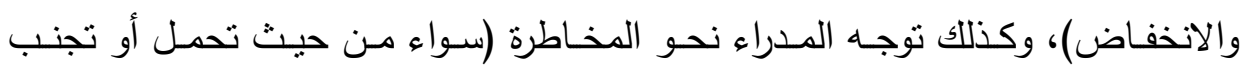
المخاطرة)، وذلك عند دراسة العلاقة الرئيسية بين حالة عدم التأكد حول الطلب ومرونـة حورة هيكل التكلفة، بالإضـافة إلى دراسـة مدى تأثز هذه العلاقة الرئيسية بتوجه المدراء نحو المخاطرة.

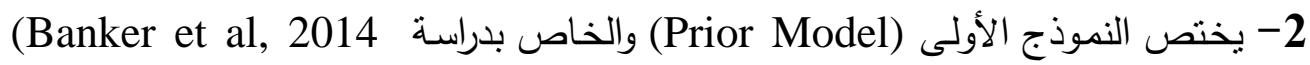
(Cost Structure- بتقدير (م) التى تعبر عن مدى مرونـة هيكل التكلفة "b") "CS")

$$
\text { لكل شركة. }
$$

3- يختص النموذج الأول (Model 1) بدراسة العلاقة بين حالة التأكد حول الطلب وهيكل التكلفة فقط دون أخذ المراحل المختلفة لدورة حياة الثركات الصناعية فى الاعتبار، حيث لدرانه يعبر (30) عن الجزء الثابت, بينما (CS) تعبر عن المتغير التابع وهو مرونـة هيكل التكلفة, ويعبر (م) عن معامل حالة عدم التأكد حول الطلب (DU) (المتغير المستقل), بينما $)$

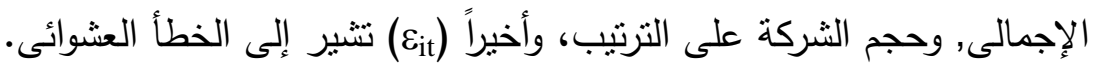

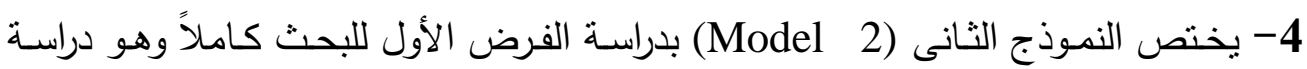
العلاقة بين حالة التأكد حول الطلب وهيكل التكلفة خـلال المراحل المختلفة لدورة حياة الشركات الصناعية، وسيتم ذلك عن طريق: - إضافة خمسـة متغيرات وهميـة تعبر عن الخمسة مراحل لدورة حياة الثركات, والتى تتمثل فئل

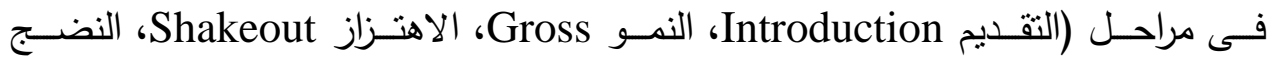
Maturity ، الانخفاض Decline) على الترنيب. 
- ضرب المتغيرات الوهمية المعبرة عن المراحل المختلفة لدورة حياة الثركات فى متغير حالة

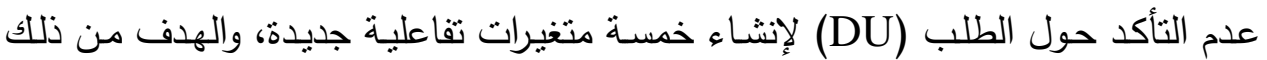
هو اختبار هل هناك فروق هيكلية فى الاتحدار بين المراحل المختلفة لدورة حياة الثركات أم لا, أى معرفة مـا إذا كان انحدار هيكل التكلفة (كتغير تابع) على حالة عدم التأكد

حول الطلب (كمتغير مستقل) يختلف باختلاف مراحل دورة حياة الثركات أم لا.

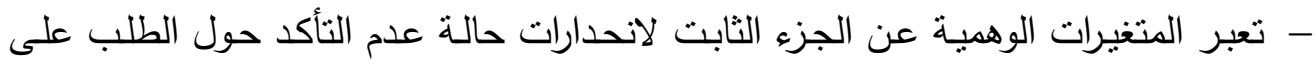

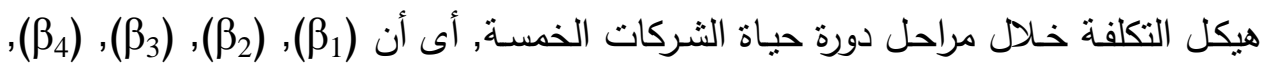
(مأر) تعبر عن الجزء الثابت لمعادلة انحدار هيكل التكلفة (كمتغير تابع) على حالة عدم

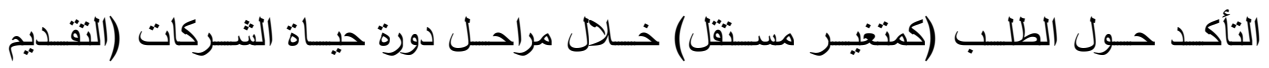

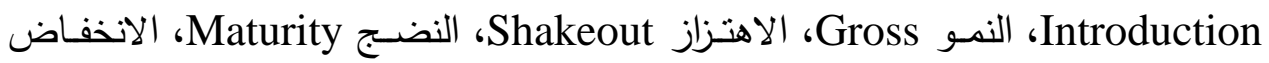
(Decline - تعبر المتغيرات التفاعلية الخمسة عن معاملات الانحدار لهيكل التكلفة (كمتغير تابع) على حالة عدم التأكد حول الطلب (كمتغير مستقل) خـل مراحل دورة حياة الثركات؛ أى أن

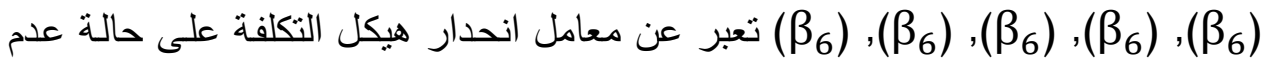

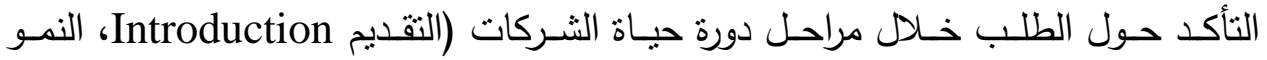

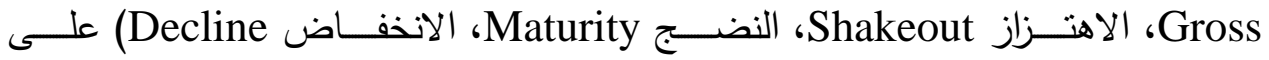

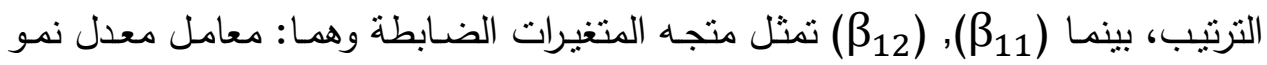
الناتج المحلى الإجمالى, وحجم الثـركة على الترتيب. وأخيراً

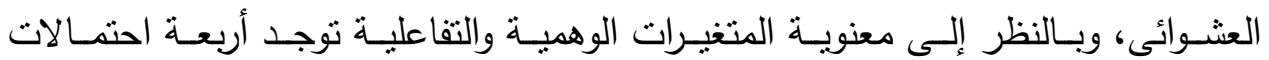
:(Gujarati, 2009) إذا كانت المتغيرات الوهية والمتغيرات التفاعلية غير معنوية؛ فهذا معناه أن الانحدارت منطابقة (أى الفترات منطابقة) ولا يوجد بينهما أى فروق هيكلية. إذا كانت المتغيرات الوهمية معنوية، بينما كانت المتغيرات التفاعلية غير معنويـة؛ وهذا يعنى أن هناك تغير هيكلى فى الجزء الثابت فقط، وتسمى هذه الانحدارات بالانحدارات

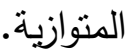


إذا كانت المتغيرات الوهمية غير معنوية، بينما كانت المتغيرات التفاعلية معنويـة؛ فهذا يشير إلى وجود تغير هيكلى بين الانحدارات فى معاملات انحدار المتغيرات المستقلة فقط، وتسمى هذه الانحدارات بالانحدارات المتزامنة.

وأخبراً إذا كانت المتغيرات الوهية والمتغيرات التفاعلية معنوية؛ وهذا بعنى أن هنالك تغير هيكلى كامل بين الانحدارات (أى بين الفترات) سواء في الجزء المقطوع من المحور الصادى (الجزء الثابت) أو معاملات انحدار المتغيرات المستقلة، وتسمى هذه الانحدارات بالغير متماتلة.

5- يختص النموذج الثالث (Model3) بدراسة أثر توجه المدراء نحو المخاطرة على العلاقة بين حالة التأكد حول الطلب ومرونة هيكل التكلفة فقط وذللك دون أخذ المراحل المختلفة

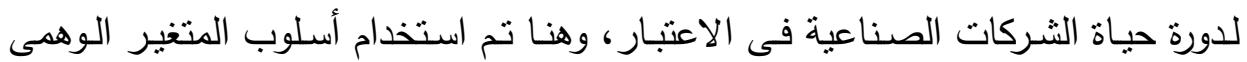
لقياس الفروق الهيكلية بين الانحدارات مثل النموذج الثانى (Model 2)، ويتم ذلك عن طريق:

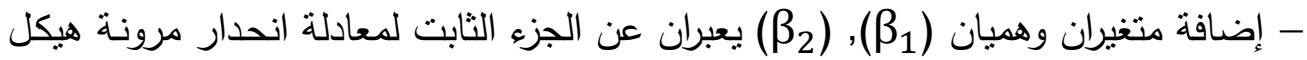
التكلفة (كمتغير تابع) على حالة عدم التأكد حول الطلب (كمتغير مستقل) فى حالة اختلاف توجـه (سلوك) المـدراء نحسو المخـاطرة سـواء كـان المـدراء يميلون إلى تجنب

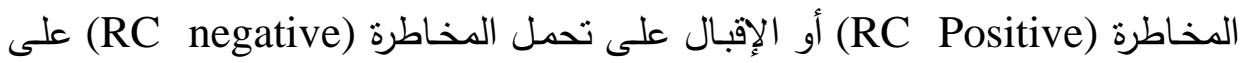
الترتيب.

- ضرب المتغيران الوهميان فى متغير حالة عدم التأكد حول الطلب (DU) لإنشـاء متغيرين

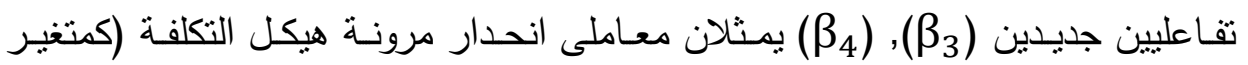

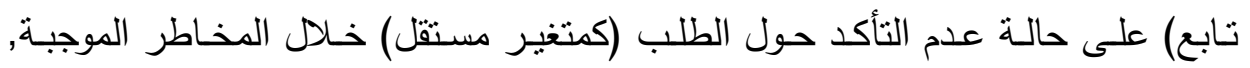

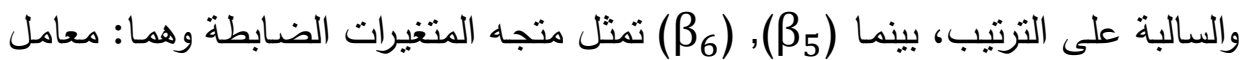
معدل نمو الناتج المحلى الإجمالى, وحجم الثركة على الترتيب، وأخيراً الخطأ العشوائى. - - مأخيراً يختص النموذج الرابع (Model 4) بدراسـة الفرض الثانى للبحث كاملاً وهو دراسـة أثر توجـه المدراء نحو المخاطرة على العلاقة بين حالة التأكد حول الطلب وهيكل التكلفة خلال المراحل المختلفة لدورة حياة الثركات الصناعية، وتم استخدام نفس الأسلوب والفكرة 
المتبعة فى دراسة الفرض الأول للبحث بالنموذج الثانى (Model 2), ولكن يزيد عليه أنه تم

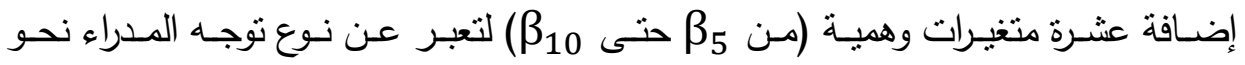
المخاطرة سواء كان إيجابى فى حالة تجنب المخاطرة، أو سلبى فى حالة الإقبال على تحمل

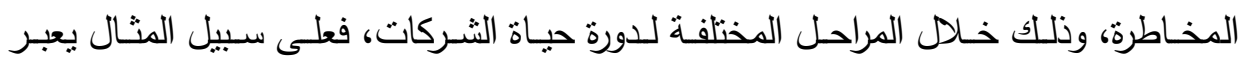

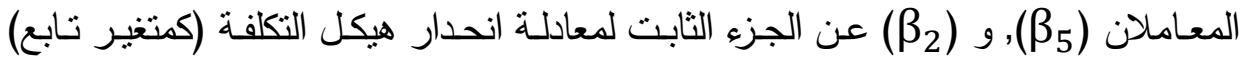
على حالة عدم التأكد حول الطلب (كمتغير مستقل) فى حالة تجنب المدراء المخاطرة, وحالة الإقبـال على تحمل المخـاطرة على الترتيب وذلك خـلال مرحلـة التقديم (Introduction),

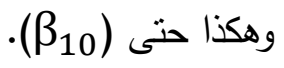 \\ ثنالثًاً: فترة الدراسة}

سيعتمد الباحث عند اختبار فرضى البحث على سلسلة زمنية تمتد من عام 2000 حتى عام 2017، ولكن سيتم فقد (10 مشاهدات) لكل شركة من عام 2000 حتى عام 2009، ومن ثم تصبح فترة التقدير من عام 2010 حتى عام 2017 وذللك لنقدير حالة عدم التأكد حول الطلب وتوجه المدراء نحو المخاطرة.

\section{رابعاً: مجتمع وعينة الدراسة}

يتمثل مجتمـع الدراسـة فى الثـركات الصناعية المصرية المقيدة والمتداول أسـهـها فى بورصـة

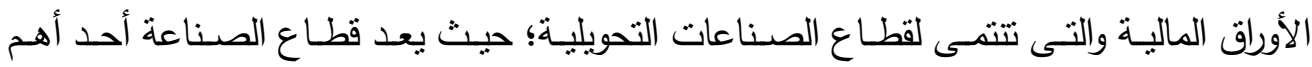
القطاعات المكونة للاقتصاد المصري ككل، حيث بلغت نسبة مساهمة قطاع الصناعات التحويلية غير البترولية 16 \% من الناتج المحلي الإجمالى، وفي حال إضـافة صناعة تكرير البترول إليه سوف تصل نسبة قطاع (الصناعة البترولى وغير البترولى) إلى حوالى 18\% من حجم الاقتصاد المصري (وزارة التجارة والصناعة، 2020/2016). وجدير بالذكر تبدأ السلسلة الزمنيـة للبحث الحالى بدايـة من عام 2010 نظراً لأن البيانـات الصـادرة عن وزارة التخطيط للنصـف الأول مـن العـام المـالي (2016/2015) تشير إلى تأثنر النمو الحقيقي لقطاع الصناعة على مدار الخمسة أعوام الأخيرة، وعلى الأخص فى بداية العام

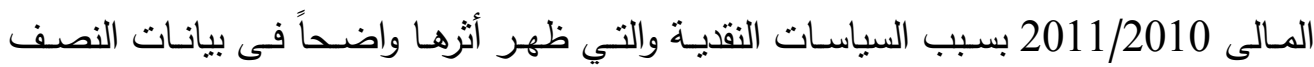

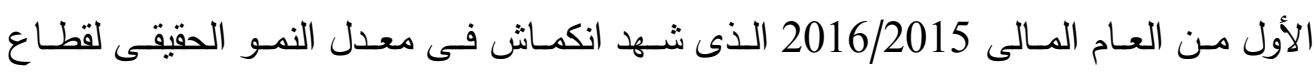
الصناعة ليصل إلى (-1.1\%) (وزارة التجارة والصناعة، 2016/ 2020). 
ويعتمد الباحث على سحب عينة عشوائية من قطاع الصناعات التحويلية وذللك بواقع (76) شـركة - كما هو مبين فى ملحق البحث - خـلال الفترة من عام 2010 حتى عام 2017 بإجمالى (535) مشاهدة، نظراً لاعتماد الباحث خلال تلك السلسلة الزمنية على بيانات طولية غير متوازنة (Unbalanced Panel Data). خامساً: مصادر الحصول على البيانات اعتمد الباحث فى تجميع البيانات اللازمة لاختبار فرضى البحث على المصادر التالية - شركة مصر لنشر المعلومات للحصول على التقرير المالى للشركات محل الدراسة خلال

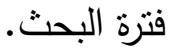
- الموقع الأكترونسى لصندوق النقد الدولى (http:/data.WorldBank.Org) للحصول على المؤشرات الاقتصادية المرتبطة بمعدل نمو الناتج المحلى الاجمالى، ومعدل التضخم. سادساً: الأساليب الإحصائية المستخدمة سيعتمد الباحث على تحليل بيانات طولية غير متوازنة (Unbalanced Panel Data)، وذلك باستخدام برنامج التحليل الإحصائى (EviewsVersion 10)، كما تم: 1- استخدام نموذج الأثار الثابتة (FEM) (Fixed effects model) أو ما يسمى بنموذج المربعات الصغرى باستخدام المتغيرات الوهمية Least-squares dummy variable)

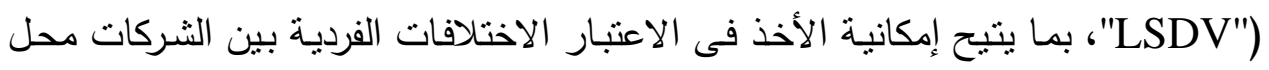

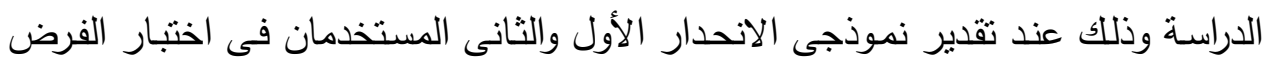
الأول للبحث.

2- استخدام طريقة المربعات الصغرى المرجحة (Weighted Least Squares "WLS") عند تقدير نموذجى الانحدار الثالث والرابع المستخدمان فى اختبار الفرض الثانى للبحث, وهى طريقة مشابهة لنموذج الأثار الثابتة, حيث تأخذ فى اعنبارها عند التحليل الاختلافات

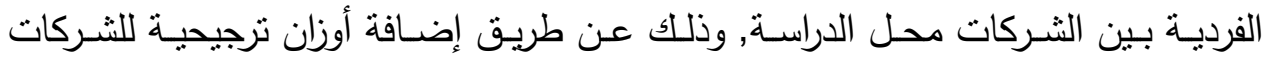

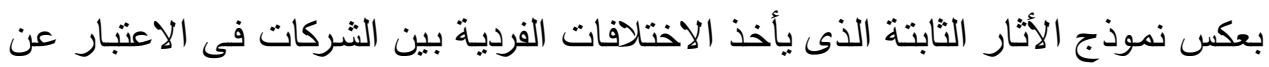
طريق وضع متغيرات وهمية لكل شركة.

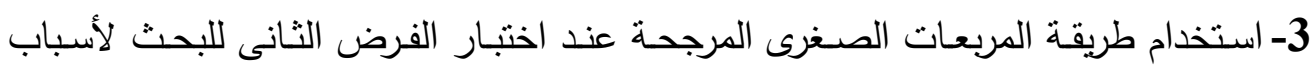

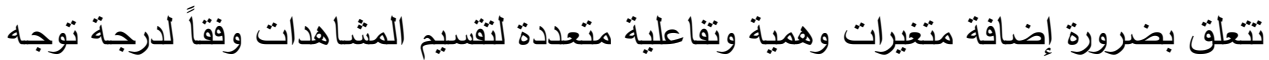


المدراء نحو المخاطرة خلال مراحل دورة حياة الثركات، بما يهدد بانخفاض درجات الحرية - خاصـة لانخفاض عدد المشـاهدات المرتبطـة بتوجـه المدراء نحو المخـاطرة سواء مدن لـن

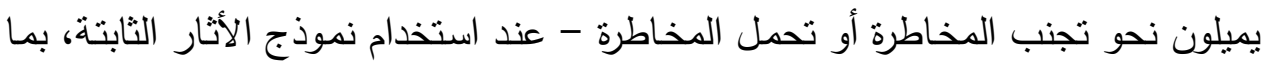
قد يؤثز على كفاءة النتائج التى يتم التوصل إليها. 4- تقدير نمـاذج الانحـدار الأربعـة المسـتخدمة فـى اختبـار فرضـى البحــث باسـتخدام أمـر (Robust Standard Errors "Panel-Corrected Standard Error (PCSE)") للتخلص من مشكلة الارتباط التسلسلى بين البواقى (Serial Correlation) ومثكلة عدم ثبات التباينات (Heteroscedasticity) معاً. القسم الثالث

\section{تحليل ومناقشية النتائج}

يهتم هذا القسـم باستـعراض نتائج الاختبـارات الإحصـائية المتعلقـة بفرضـى البحث تمهيداً لتحليلها ومناقثتها وذللك على النحو التالى: أولاً: الإحصاءات الوصفية (Descriptive Statistics) يعرض الجدول رقم (4) أهم الإحصاءات الوصفية لمتغيرات الدراسة المعبرة عن خصائصـها المميزة على مستوى عينة الثركات محل البحث وذللك على النحو التالى: 


\section{جدول رقم (4) الإحصاءات الوصفية}

\begin{tabular}{|c|c|c|c|c|c|c|}
\hline \multicolumn{4}{|c|}{ مقاييس الإحصاء الوصفى } & \multirow{2}{*}{$\begin{array}{l}\overline{3} \\
3 \\
\frac{8}{9} \\
\end{array}$} & \multirow[b]{2}{*}{ 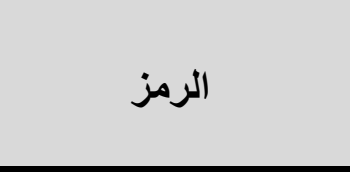 } & \multirow[b]{2}{*}{ المتغـيرات } \\
\hline أعلى قيمة & أدنى قيمة & المعيارى & المتوسط & & & \\
\hline 2.3066 & 0.1525 & 0.269 & 0.8959 & 535 & $\mathrm{CS}$ & التكلفة التغير التابع: \\
\hline 0.143 & 0.024 & 0.020 & 0.0578 & 559 & DU & حالة عدم التأكد المتل: \\
\hline 1 & صفر & 0.396 & 0.1939 & 109 & Dummy RC+ & 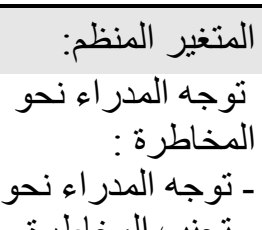 \\
\hline 1 & صفر & 0.416 & 0.222 & 125 & Dummy RC- & ــ تحمل المخاطرة المدر اء نحو \\
\hline 1 & صفر & 0.493 & 0.584 & 328 & Dummy RC neutal & المخاطرة نحوة \\
\hline & & & & & & الضنابطة:ة \\
\hline 5.1 & 1.8 & 1.139 & 3.313 & 608 & GDP growth & المعدل نمو الناتج \\
\hline 24.24 & 17.417 & 1.315 & 20.391 & 604 & FS & مراحت الثركة دياة \\
\hline 1 & صفر & 0.327 & 0.1217 & 74 & Dummy Introduction & - مرحلة التقديم \\
\hline 1 & صفر & 0.311 & 0.1085 & 66 & Dummy Gross & ـ ـ مرحلة النمو \\
\hline 1 & صفر & 0.420 & 0.2286 & 139 & Dummy Shakeout & ـ ـ مرحلة الاهتز از \\
\hline 1 & صفر & 0.499 & 0.4572 & 278 & Dummy Maturity & - مرحلة النضج \\
\hline 1 & صفر & 0.277 & 0.0839 & 51 & Dummy Decline & ـ ـ مرحلة الانخفاض \\
\hline
\end{tabular}


وفى ضوء الجدول السابق ويإلقاء النظر على مقاييس الدراسة يلاحظ: - انخفاض مرونة هيكل التكلفة (CS) على مستوى شركات العينة؛ حيث سجلت أدنى قيمة لمرونة هيكل التكلفة ما قيمته (0.2)، بينما سجلت أعلى قيمة (2.3) وذللك بمتوسط عام (0.9) وانحراف معيارى (0.27)، ليعكس ذللك تباين مرونـة هيكل التكلفة بين الثشركات محل البحث، إلى جانب ميل هيكل التكلفة فى هذه الثركات نحو التكاليف الثابتة على حساب التكاليف المتغيرة. - تتراوح حالة عدم التأكد حول الطلب (DU) فى مدى أقل من مرونـة هيكل التكلفة؛ حيث

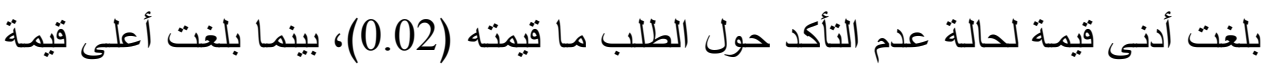
(0.14) وذللك بمنوسط عام (0.06) وانحراف معيارى (0.02)، ليعكس ذللك انخفاض حالة عدم التأكد حول الطلب على منتجات الشركات الصناعية محل البحث. - اختلاف المتوسط العـام وعدد المشـاهدات المرتبطــة بتوجـه المـدراء نحـو المخـاطرة (كمتغير منظم)، وذلك يرجع إلى تقسيم عينة الدراسة الإجمالية خلاد فترة الدراسة إلى عدد من العينات الفرعيـة داخل التحليل الإجمالى على حسب سلوك المدراء نحو المخاطرة، حيث بلغت عدد

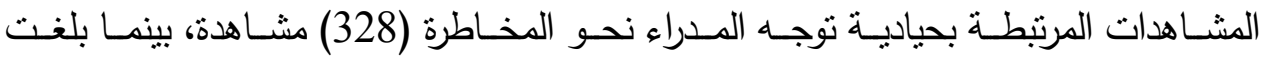
المشاهدات المرتبطة بإقبال المدراء على تحمل المخاطرة (125) مشاهدة، أمسا المدراء متجنبى لهنى المخاطرة فقد كانت المشاهدات المرتبطة بها (109) مشاهدة. - بلـن متوسط معدل نمو الناتج المحلى الإجمالى (كمتغير ضـابط) فى جمهوريـة مصـر

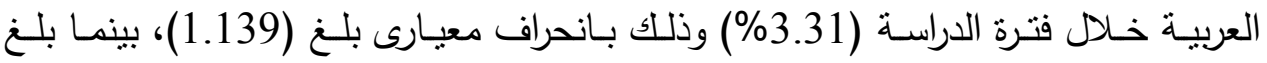
منوسط حجم الثركات محل الدراسة (20.39) وذلك فى مدى يتراوح فيما بين (17.42) و

- اختلاف المتوسط العـام وعدد المشـاهدات المرتبطـة بمراحل دورة حيـاة الثـركات محل الدراسة (كمتغير ضابط)، وذلك يرجع إلى تقسيم عينة الدراسة الإجمالية خلال فترة الدراسة إلى عدد من العينات الفرعية داخل التحليل الإجمالى على حسب المراحل المختلفة لدورة

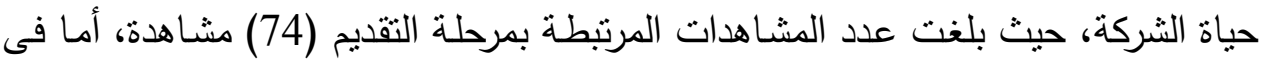

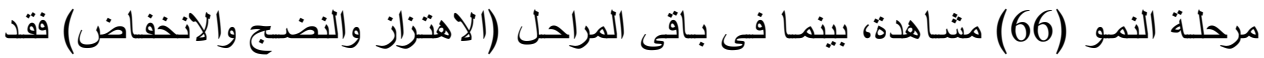
بلغـت المشـاهدات المرتبطـة بكل مرحلـة على حـدة (139، 278، 51) مشــاهدة على لى 
الترتيب، ليعكس ذلك انخفاض عدد المشاهدات المرتبطة بمرحلتى النمو والانخفاض مقارنـة بباقى المراحل، بالاضافة إلى تركز المشاهدات فى مرحلة النضج. ثانياً: مصفوفة الارتباطات (Correlation Matrix)

تهـتم مصـفوفة الارتباطـات بتحليـل الارتبـاط مـن الدرجـة الصـفرية بـين متغيـرات الدراسـة باسـتخدام الارتباطـات ثنائيـة المتغيـر (Bivariate Correlations)، حيــ تشـمح هـــه

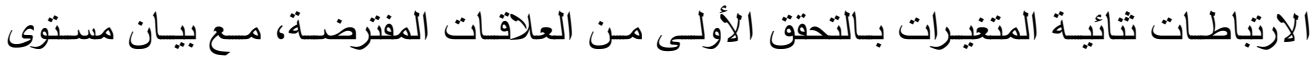
معنوياتها وذللك كما يوضح الجدول رقم (5) على النحو التالى: جدول رقم (5) مصفوفة الارتباطات

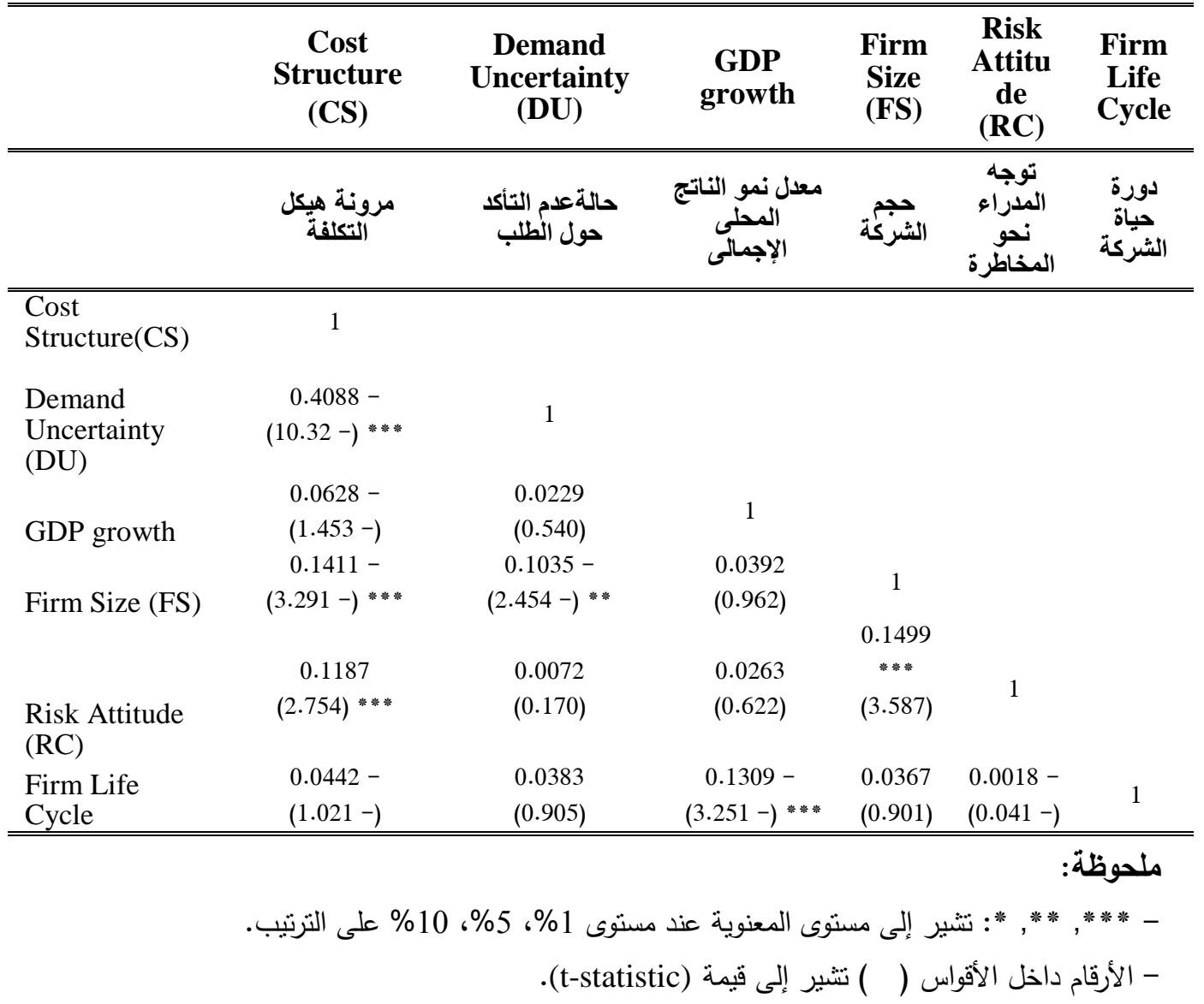




\section{وفى ضوء قيم معاملات الارتباط الثنائية بين متغيرات الدراسة يتضح ما يلى:}

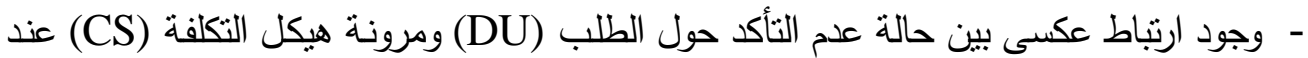

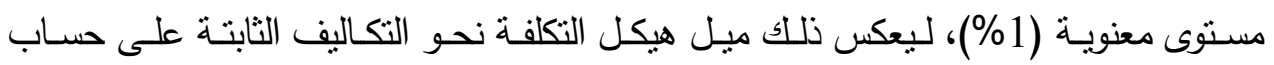

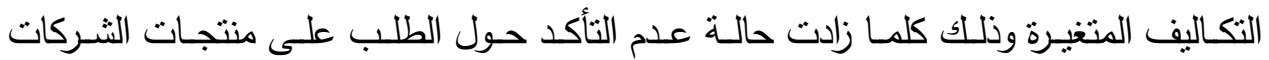
الصناعية محل الدراسـة، وذلك قد يرجع لتوقع اسنقرار الطلب على المنتجات بعد فترة زمنيـة قصيرة الأجل بعدما تسود حالة من عدم التأكد حولها، بالثكل الذى يجعل من هذه المنتجات سلع استراتيجية يصعب الاستغناء عنها من قبل المستهلكين كما فى بعض الصناعات ك:

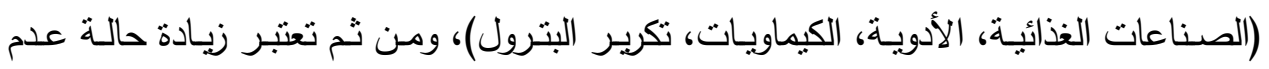
التأكد حول الطلب بمثابة فرص استثمارية مستقبلية. - وجود ارتباط موجب ومعنوى بين توجـه المدراء نحو المخاطرة (RC) ومرونـة هيكل التكلفة (CS)

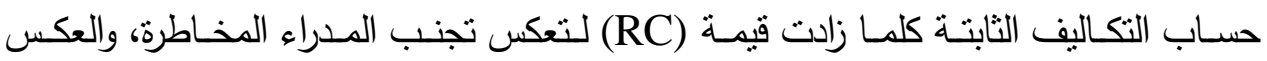
صحيح كلما انخفضت قيمة (RC) وذلك عند إقبال المدراء على تحمل المخاطرة. - وجود ارتباط عكسى بين حجم الثـركة (FS) ومرونـة هيكل التكلفة (CS) عند مستوى معنويـة (1\%)، لبعكس ذلك انخفاض مرونـة هيكل التكلفة والاتجاه نحو التكاليف الثابتة كلما زاد حجم الشركة، والعكس صحيح عند انخفاض حجم الشركة. - وجود ارتباط ضـعيف وغير دال احصـائياً بين معدل نمو الناتج المحلى الإجمالى ودورة حياة الثركة ومرونة هيكل التكلفة. - أوضحت معاملات الارتباط بين المتغيرات المستقلة وبعضها البعض كما توضحها بـاقى هـئ أعمدة الجدول ضعيفة القوى وأغلبها غير معنوية، وقد يشير هذا الأمر إلى عدم تعرض التصن نماذج الدراسة لمشكلة الازدواج الخطى.

ثالثاً: تحليل نتائج نماذج الانحدار المستخدمة فى اختبار فروض البحث: اعتمد الباحث على تتغيل أربعة نماذج للانحدار لاختبار فرضى البحث، ويمكن تلخيص الته أهم النتائج التى تم التوصل إليها على مستوى كل فرض لبهل على حدة كما يلى: 


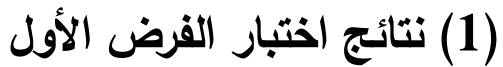

اهتم الفرض الأول للبحث باختبار العلاقة بين حالة عدم التأكد حول الطلب ومرونة هيكل التكلفة خـلال المراحل المختلفة لدورة حياة الثركة وذلك من خـلال تشغيل نموذجى الاتحدار الأول والثانى، ويمكن تلخيص أهم نتائجهما فى الجدول التالى: جدول رقم (6) نتائج اختبار الفرض الأول

\begin{tabular}{|c|c|c|c|}
\hline \multicolumn{3}{|c|}{ مرونة هيكل التكلفة (Cost Structure "CS') } & \multirow{2}{*}{ المتغيرات المستقلة التبابع } \\
\hline $\begin{array}{l}\text { نموذذج (2) } \\
\text { Model (2) }\end{array}$ & $\begin{array}{l}\text { (1) نموذج } \\
\text { Model (1) }\end{array}$ & 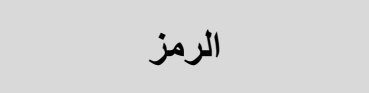 & \\
\hline \multirow[b]{3}{*}{$\begin{array}{l}0.0117267- \\
(2.263-) * *\end{array}$} & $\begin{array}{c}0.855056- \\
(1.841-)^{*}\end{array}$ & (Constant) & \multirow{4}{*}{ 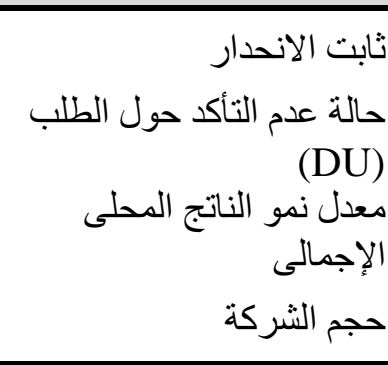 } \\
\hline & $\begin{array}{l}2.845696- \\
(5.661-)^{* * *}\end{array}$ & Demand Uncertainty & \\
\hline & $\begin{array}{c}0.091964- \\
(5.324-)^{* * *}\end{array}$ & GDP growth & \\
\hline \multirow{6}{*}{$\begin{array}{c}0.0682315- \\
(3.157-)^{* * *} \\
1.12589 \\
(2.925)^{* * *} \\
1.03741 \\
(2.677)^{* * *} \\
1.12612 \\
(2.968)^{* * *} \\
1.14801 \\
(3.043)^{* * *} \\
0.918320 \\
(2.442)^{* * *}\end{array}$} & $\begin{array}{c}0.073862- \\
(3.684-)^{* * *}\end{array}$ & FS & \\
\hline & & Dum(Introduction) & \multirow{10}{*}{ 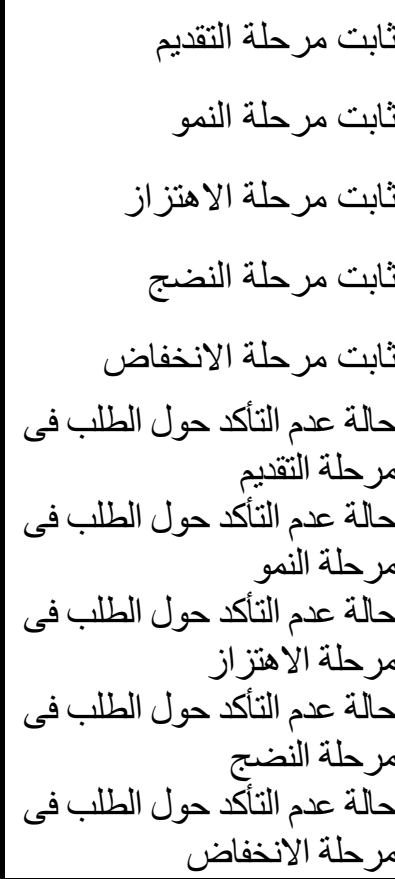 } \\
\hline & & Dum(Gross) & \\
\hline & & Dum(Shakeout) & \\
\hline & & Dum(Maturity) & \\
\hline & & Dum(Decline) & \\
\hline $\begin{array}{c}2.39274- \\
(2.270-)^{* * *}\end{array}$ & & $\begin{array}{c}\text { Dum(Introduction) } \\
\text { *DU }\end{array}$ & \\
\hline $\begin{array}{l}1.30289- \\
(1.207-)\end{array}$ & & $\operatorname{Dum}(\mathrm{Gross}) * \mathrm{DU}$ & \\
\hline $\begin{array}{c}2.73260- \\
(3.247-)^{* * *}\end{array}$ & & Dum(Shakeout)*DU & \\
\hline $\begin{array}{c}3.27259- \\
(4.382-)^{* * *}\end{array}$ & & Dum(Maturity)*DU & \\
\hline $\begin{array}{l}1.06603- \\
(1.064-)\end{array}$ & & Dum(Decline)*DU & \\
\hline $\begin{array}{c}\text { two-way } \\
\text { fixed effects }\end{array}$ & $\begin{array}{c}\text { two-way } \\
\text { fixed effects }\end{array}$ & \multicolumn{2}{|c|}{ Effects Specification } \\
\hline 0.822633 & 0.829704 & $\mathrm{R}^{2}$ & معامل التحديد \\
\hline
\end{tabular}




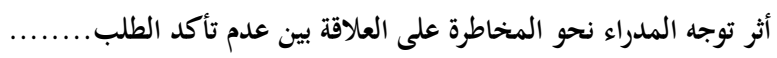

د/السبد أحمد محمود فودة

\begin{tabular}{|c|c|c|c|}
\hline \multicolumn{3}{|c|}{ مرونة هيكل التكلةة (Cost Structure "CS"') } & المتغيز التابع \\
\hline $\begin{array}{l}\text { (2) نموذذج } \\
\text { Model (2) }\end{array}$ & $\begin{array}{l}\text { (1) نموذذج } \\
\text { Model (1) }\end{array}$ & 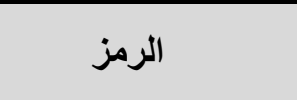 & 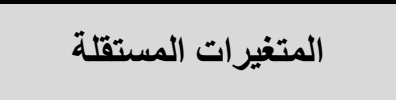 \\
\hline 0.788432 & 0.797774 & Adjusted $\mathrm{R}^{2}$ & \multirow{2}{*}{ اختبار (F-test) معامل التحديد المعدل } \\
\hline $\begin{array}{c}25.822 \\
* * *(0.000)\end{array}$ & $\begin{array}{c}25.985 \\
* * *(0.000)\end{array}$ & F- Sat. (Prob.) & \\
\hline $\begin{array}{c}19.885 \\
* * *(0.000)\end{array}$ & $\begin{array}{c}19.649 \\
* * *(0.000)\end{array}$ & & \multirow{4}{*}{ 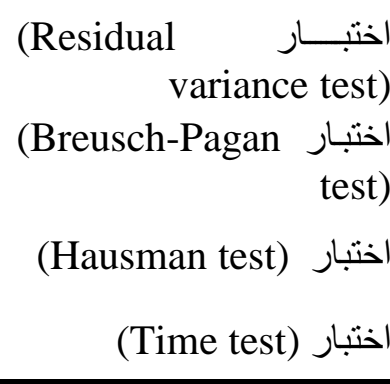 } \\
\hline $\begin{array}{c}680.25 \\
* * *(0.000)\end{array}$ & $\begin{array}{c}743.08 \\
* * *(0.000)\end{array}$ & & \\
\hline $\begin{array}{c}21.077 \\
* *(0.033)\end{array}$ & $\begin{array}{c}9.2312 \\
* *(0.026)\end{array}$ & & \\
\hline $\begin{array}{c}40.209 \\
* * *(0.000)\end{array}$ & $\begin{array}{c}46.048 \\
* * *(0.000)\end{array}$ & & \\
\hline \multicolumn{4}{|c|}{ *******,*** تثير إلى وجود دلالة إحصائية عند مستوى معنوية 1\%, 5\%, 10\% على الترنتب. } \\
\hline \multicolumn{4}{|c|}{ Cross-section included: 76 , Total panel (unbalanced) observations: 535} \\
\hline \multicolumn{4}{|c|}{$\begin{array}{l}\text { - Residual variance test: Null hypothesis: The Pooled OLS model is adequate, in } \\
\text { favor of FEM alternative. }\end{array}$} \\
\hline \multicolumn{4}{|c|}{$\begin{array}{c}\text { - Breusch-Pagan test: Null hypothesis: The Pooled OLS model is adequate, in favor } \\
\text { of REM alternative. }\end{array}$} \\
\hline \multicolumn{4}{|c|}{ - Hausman test: Null hypothesis: The REM is consistent, in favor of the FEM. } \\
\hline \multicolumn{4}{|c|}{$\begin{array}{l}\text { - Time test (wald test for joint significance of time dummies): Null hypothesis: The } \\
\text { time is not affect. }\end{array}$} \\
\hline
\end{tabular}

ويتضـح من نتائج الجدول السـابق العديد من النتائج المثيرة للاهتمـام والتى يمكن تلخيصـها فى شكل معـادلات أفقيـة لسـهولة التحليـل والمقارنـة وخاصـة فى النمـوذج الثانى الذى بتطلب المقارنة بين المراحل الخمسـة لدورة حياة الثركات الصناعية محل الدراسـة، لمعرفة هل هناك فروق هيكلية بين هذه المراحل أم لا, وذلك كما يلى: 


\begin{tabular}{|c|c|}
\hline \multicolumn{2}{|r|}{ Model (1) النموذج الأول } \\
\hline العينة الإجمالية & 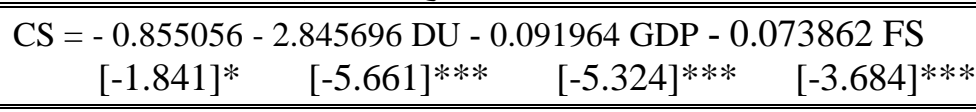 \\
\hline \multicolumn{2}{|r|}{ Model (2) النموذج الثانى } \\
\hline \multicolumn{2}{|r|}{ تقسيم عينة الدر اسة وفقاً لمر احل دورة حياة الشركة } \\
\hline $\begin{array}{c}\text { مرحلة التقديم) } \\
\text { (Introduction) } \\
\end{array}$ & \multirow{5}{*}{$\begin{array}{c}-0.0117267 \mathrm{GDP}-0.0682315 \mathrm{FS} \\
{[-2.263]^{* *} \quad[-3.157] * * *}\end{array}$} \\
\hline مرحلة النمو & \\
\hline مرحلة الاهتزاز & \\
\hline مرحلة النضج & \\
\hline $\begin{array}{c}\text { مرحلة الانخفاض) } \\
\text { (Decline) }\end{array}$ & \\
\hline
\end{tabular}

وفى ضوء مـا سبق يمكن الإشـارة إلى النتائج المتعلقة بنموذج الانحدار الأول فى النقاط التاليةه:

أ- معنويـة نمـوذج الانحـدار الأول ككـل؛ حيـث أثنــار اختبـار (F-statistic) إلـى معنويـة المتغيرات المكونـة لنمـوذج الاتحدار ككل عند مسـتوى معنويـة (1\%)، وكذللك بلغت القوة التقسيرية لمتغيرات النموذج نقريباً حوالى (80\%) من التغيرات فى مرونة هيكل التكلفة خلد

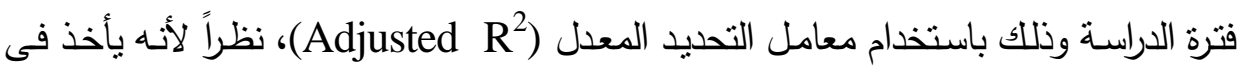
اعتباره عدد المتغيرات المسنقلة المكونة للنموذج. ب- معنوية اختبار (Residual Variance test) تشير إلى قبول الفرض البديل ليوضـح أن نموذج الأثنار الثابتة (Fixed Effect Model) هو المناسب وذلك مقارنة بنموذج المربعات الصغرى المجمعة (Pooled OLS)، كما أثنارت معنوية اختبار - Breusch) (Random إلى قبول الفرض البديل ليوضح أن نموذج الأثنار العشوائية Pagan test)

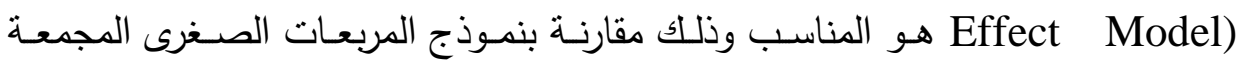

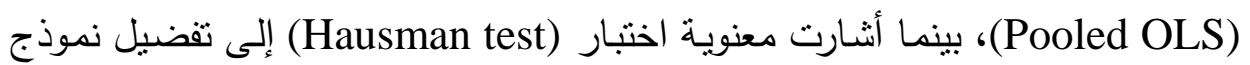
الأثار الثابتة مقارنة بنموذج الأثار العشوائية، ليعكس ذلك وجود اختلافات فى الثركات

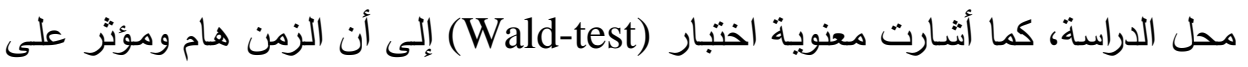


النتائج التـى يمكن التوصـل إليهـا، لـذا تـم اسـتخدام نمـوذج الأثار الثابتـة مـع مراعـاة الاختلافات فى الزمن والثركات محل الدراسة (Two- Way Fixed Effects). ج- اختص نموذج الانحدار الأول بدراسة العلاقة بين حالة عدم التأكد حول الطلب (DU) ومرونة هيكل التكلفة (CS) وذلك دون الأخذ فى الاعتبار المراحل المختلفة لدورة حياة الثركات الصناعية محل الدراسة، واتضـح من تشغيل هذا النموذج على عينة الثركات الصناعية محل الدراسـة وجود أثر سلبى ومعنوى (عند مستوى معنوية 1\%) لحالة عدم

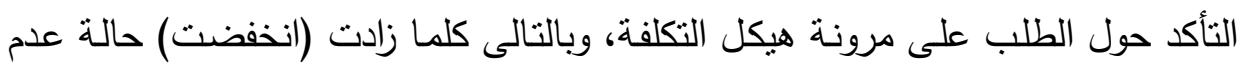
التأكد حول الطلب تتخفض (تزداد) مرونة هيكل التكلفة وذلك فى ظل ارتفاع (انخفاض)

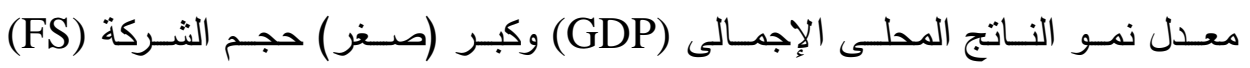
باعتبارهما متغيران ضـابطان - ثبتت معنوية تأثنيرهما السلبى على مرونـة هيكل التكلفة

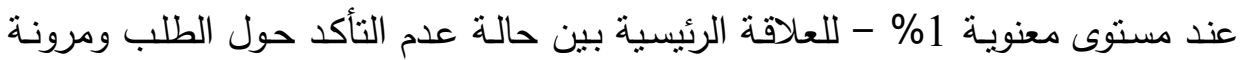
هيكل التكلفة.

د- تعكس نتائج تشغيل نموذج الانحدار الأول أن زيادة حالة عدم التأكد حول الطلب ستؤدى إلى انخفاض مرونـة هيكل التكلفة، ومن ثم ميل هيكل التكلفة الثركات الصناعية محل

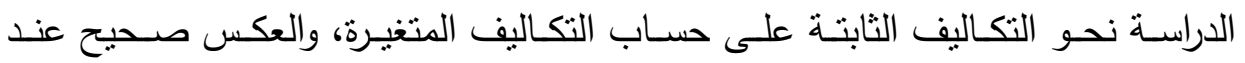
انخفاض حالة عدم التأكد حول الطلب، وقد يرجع ذللك إلى:

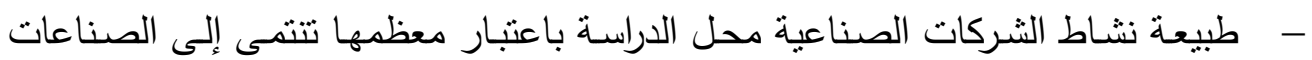

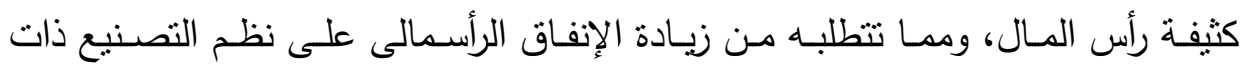

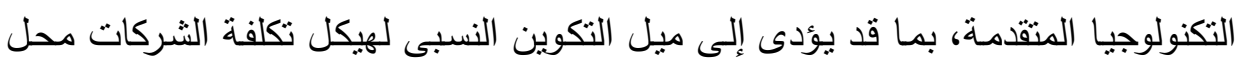
البحث نحو زيادة التكاليف الثابتة مقارنة بالتكاليف المتغيرة.

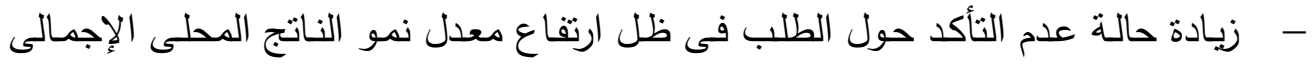

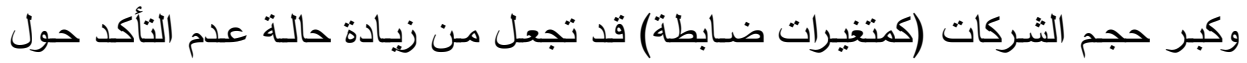

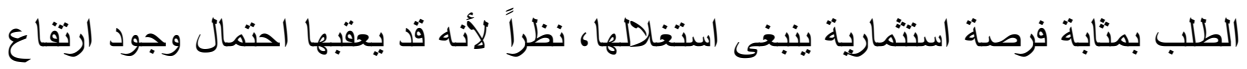

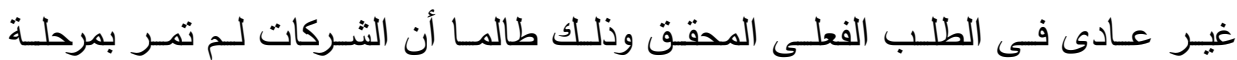

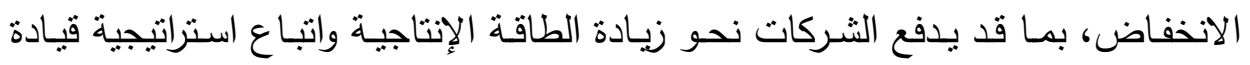
الطلب للحد من زيادة حدة وخطورة تكاليف الازدحام، ومن ثم ميل هيكل التكلفة نحو

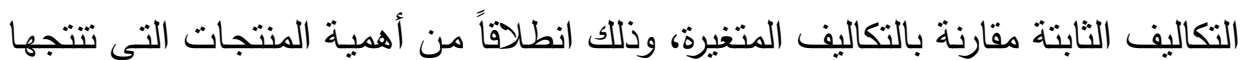


الشـركات محل البحث (التى تتنــى لقطـاع الصـناعات التحويليـة) باعتبارهـا منتجـات أساسية (رئيسية) تهم كافة المستهلكين باختلاف فئاتهم. أما بالنسبة للنموذج الثانى والخاص بالتحقق من الفرض الأول للبحث كاملاً، يمكن الإشـارة إلى النتائج المتعلقة به فى النقاط التالية:

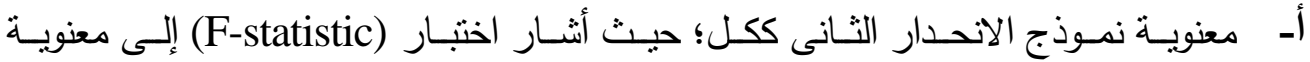
المتغيرات المكونـة لنمـوذج الاتحدار ككل عند مسـتوى معنويـة (1\%)، وكذلك بلغت القوة التفسيرية لمتغيرات النموذج نقريباً حوالى (80\%) من التغيرات فى مرونة هيكل التكلفة خلال

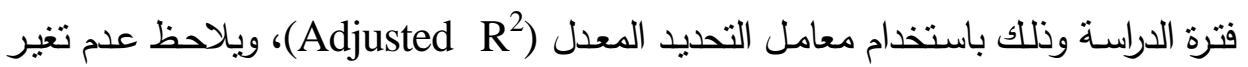
القوة التقسيرية للنمـوذج الثانى مقارنـة بـالنموذج الأول، وذلك لأن النموذج الثانى هو نفســا النموذج الأول ولكن مع مراعاة المراحل المختلفة لدورة حياة الثركات.

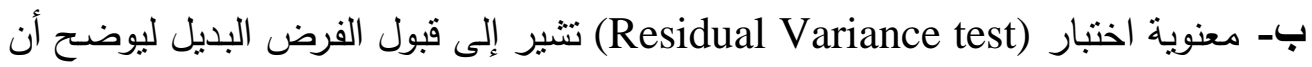
نموذج الأثار الثابتة (Fixed Effect Model) هو المناسب وذلك مقارنة بنموذج المربعات الصغرى المجمعة (Pooled OLS)، كما أثنارت معنوية اختبار - Breusch) (Random إلى قبول الفرض البديل ليوضح أن نموذج الأثار العشوائية Pagan test) هـ Eـffect Model) (PooledOLS) الأثنار الثابتة مقارنة بنموذج الأثار العشوائية، ليعكس ذللك وجود اختلافات فى الثركات

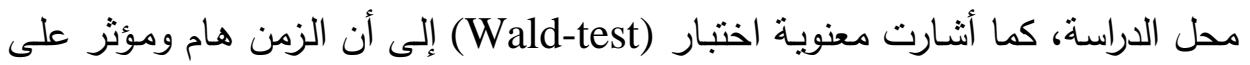

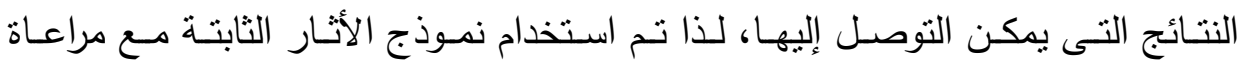
الاختلافات فى الزمن والثركات محل الدراسة (Two- Way Fixed Effects). ج- اختص نموذج الاتحدار الثانى بدراسة العلاقة بين حالة عدم التأكد حول الطلب (DU) ومرونة هيكل التكلفة (CS) خلال المراحل المختلفة لدورة حياة الثركات الصناعية محل الدراسة، واتضح من تشغيل هذا النموذج على عينة الثركات الصناعية محل الدراسة: - معنويـة التأثثر الإيجابى للجزء الثابت (Constant) عند مستوى معنويـة (1\%) خـلال المراحل الخمسة لدورة حياة الثركات الصناعية. 
- معنوية التأثير السلبى لحالة عدم التأكد حول الطلب على مرونة هيكل التكلفة عند مستوى معنوية

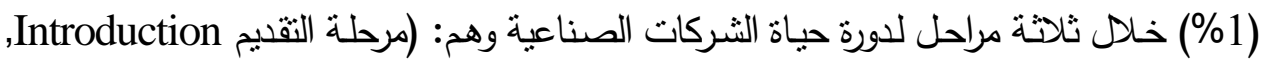
الاهتزاز Shakeout, النضج Maturity)، بينما لم يكن لحالة عدم التأكد حول الطلب أى تأثنير (على الرغم مـن إثنـارتها السـالبة) على مرونـة هيكل التكلفة خـلاص مرحلتى : (النمـو Gross,

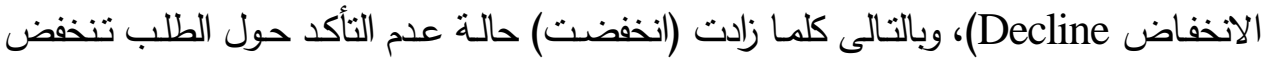
(تزداد) مرونة هيكل التكلفة وذلك فى ظل ارتقاع (انخفاض) معدل نمو الناتج المحلى الإجمالى (GDP) وكبر (صغر) حجم الثركة (FS) باعتبارهما متغيران ضابطان (ثتبت معنوية تأثيرهما السلبى على مرونـة هيكل التكلفة عند مستوى معنويـة 5\% بالنسبة لمعدل نمو الناتج المحلى بـى

$$
\text { الإجمالى، و 1\% بالنسبة لحجم الثركة). }
$$

- وجود تغير هيكلى كامل (انحدارات غير منماتلةة) عند دراسة العلاقة بين حالة عدم التأكد

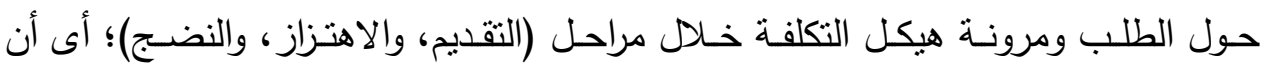
علاقة حالة عدم التأكد حول الطلب بمرونة هيكل التكلفة تختلف سواء فى الجزء الثابت أو معامل إنحدار (DU) خلال تلك المراحل. - وجود تغير هيكلى غير كامل وذلك فى الجزء الثابت فقط (انحدارات متوازية) عند دراسة

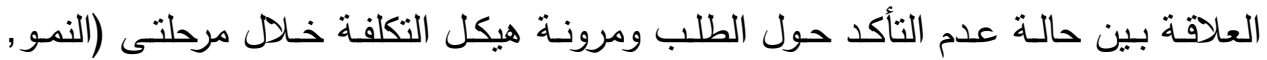
والانخفاض)، بينما لا يختلف معامل انحدار (DU) خـلال مرحلتى (النمو، والانخفاض)

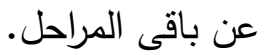
- ارتفاع درجة التأثير السلبى لحالة عدم التأكد حول الطلب (DU) على مرونة هيكل التكلفة

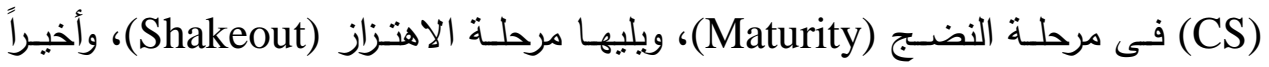
مرحلة التقديم (Introduction)؛ حيث بلغت قيمة معامل انحدار حالة عدم التأكد حول الطلب (- 3.27، - 2.73، - 2.39) خلال المراحل الآتية: (النضج، والاهتزاز، والتقديم) على الترتيب. وفى ضـوء مناقتــة نتائج نموذجى الانحدار الأول والثانى المتعلقين باختبـار الفرض الأول للبحث، يتضح بصفة عامة وجود تأثنير سلبى لحالة عدم التأكد حول الطلب على مرونة هيكل التكلفة، وبالتالى كلما زادت (انخفضت) حالة عدم التأكد حول الطلب تنخفض (تزداد) مرونـة هيكل التكلفة وذلك فى ظل ارتفاع (انخفاض) معدل نمو الناتج المحلى الإجمالى (GDP) 
وكبر (صغر) حجم الثركة (FS) (كمتغيرات ضـابطة)، ومن ثم ميل هيكل تكلفة الثركات محل البحث نحو التكاليف الثابتة على حساب التكاليف المتغيرة، وذلك خاصة في مراحل دورة

حباة الثركة المتعلقة بـ (النضج، والاهتزاز ، وأخيراً التقديم) على التزتيب دون باقى المراحل.

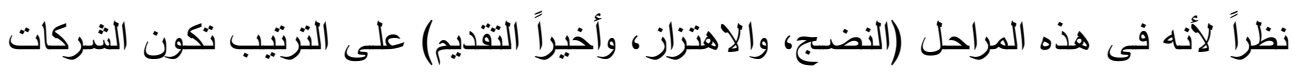

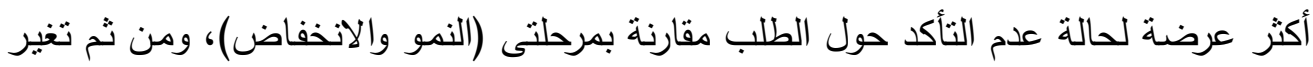
التكوين النسبى لهيكل التكلفة فى هذه المراحل دونً عن غيرها حيث:

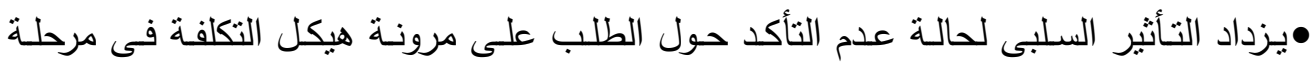
النضـج وذلك مقارنـة بباقى مراحل دورة حياة الثركة (خاصـة فى مرحلتى التقديم والاهتزاز)؛

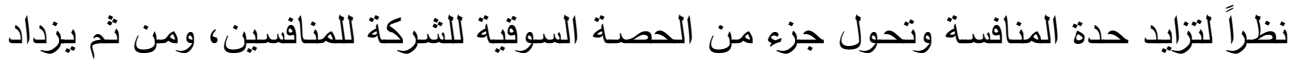
دافع المدراء نحو تنبى استراتيجيات فعالة لمواجهة المنافسة لنطوير منتجاتها لإبقاء الثركة

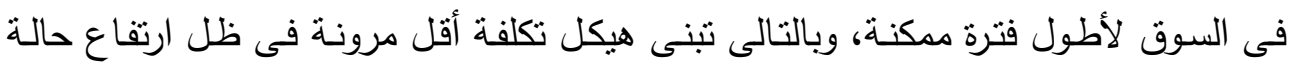
عدم التأكد حول الطلب وذللك بزيادة التكاليف الثابتة على حساب التكاليف المتغيرة. •يزداد التأثثر السلبى لحالـة عدم التأكد حول الطلب على مرونـة هيكل التكلفة فى مرحلـة

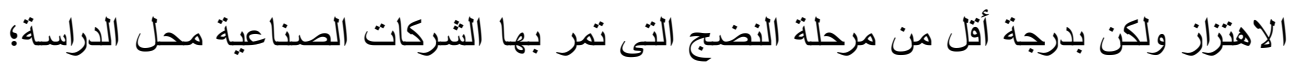

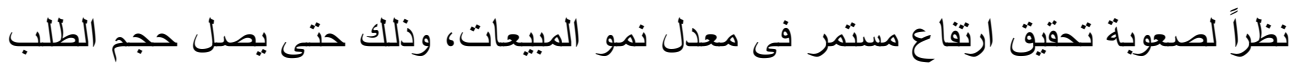

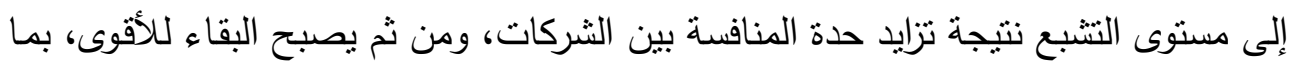

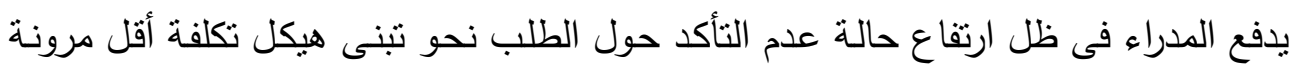

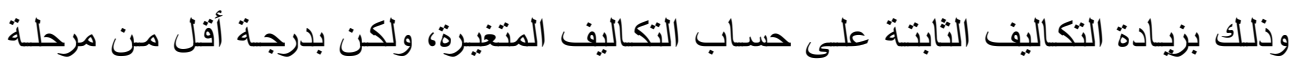

النضج.

•يزداد التأثنر السلبى لحالـة عدم التأكد حول الطلب على مرونـة هيكل التكلفة فى مرحلـة

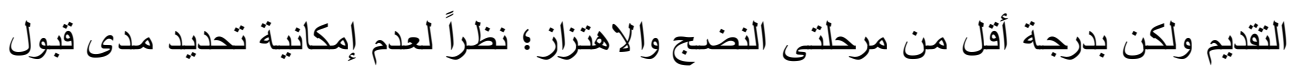

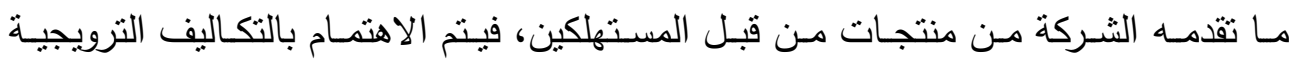
والتسويقية (كتكاليف متغيرة) على حساب التكاليف الثابتة، ولكن طبيعة قطاع الصناعات التحويلية الذى نتتمى إليه الثركات الصناعية محل الدراسـة قد يفرض على المدراء التوجها نحو زيادة الإنفاق الرأسمالى على الأصول الثابتة، ومن ثم تبنى هيكل أقل مرونة في ظل طل 
ارتفاع حالة عدم التأكد حول الطلب وذللك بزيـادة التكاليف الثابتة على حسـاب التكاليف المتغيرة ولكن بدرجة أقل من مرحلتى النضج والاهتزاز .

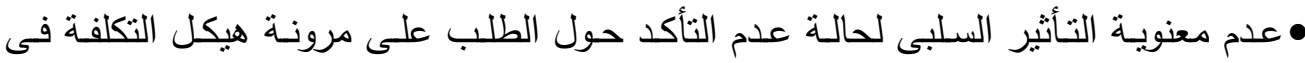

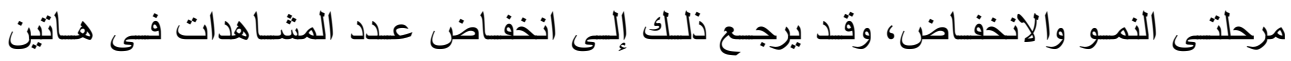
المرحلتين؛ حيث بلغ عدد المشاهدات (64، 51) مشاهدة فى مرحلتى النمو والانخفاض على ولى لهى التوالى، بينما تركزت باقى المشاهدات فى باقى المراحل، هذا وبالإضافة إلى انخفاض حالة

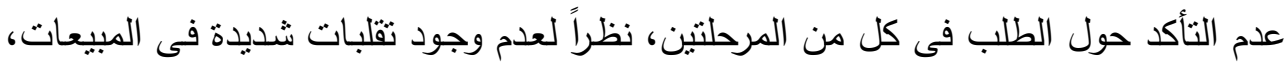

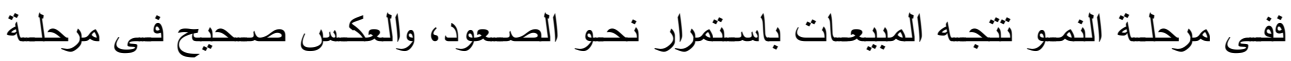
الانخفاض، وبالتالى تنخفض درجة تباين حالة عدم التأكد حول الطلب فى مرحلتى النمو

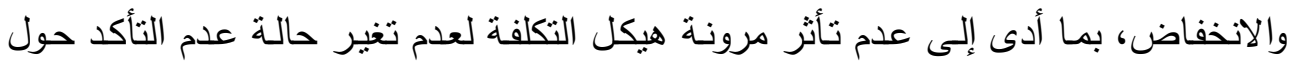
الطلب فى هاتين المرحلتين.

وفى ضـوء مـا سبق يتضـح رفض الفرض الأول للبحث والذى ينص على أنه: "لا يوجود اختلاف فى العلاقة بين حالة عدم التأكد حول الطلب وهيكل التكلفة خلال المراحل المختلفة

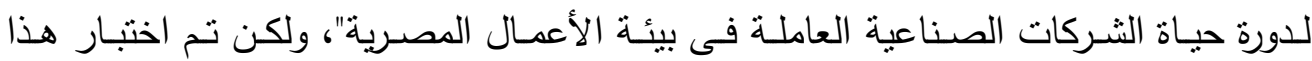
الفرض فى ظل حيادية توجه المدراء نحو المخاطرة، ولاختبار أثر توجه المدراء نحو المخاطرة على العلاقة بين حالة عدم التأكد حول الطلب وهيكل التكلفة خـال المراحل المختلفة لدورة حباة الثركات الصناعية، ينبغى التطرق لنتائج اختبار الفرض الثانى للبحث وذلك كما فى

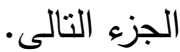

\section{(2) ت نتائج اختبار الفرض الثانى}

اهتم الفرض الثانى للبحث باختبار أثر توجه المدراء نحو المخاطرة على العلاقة بين حالة

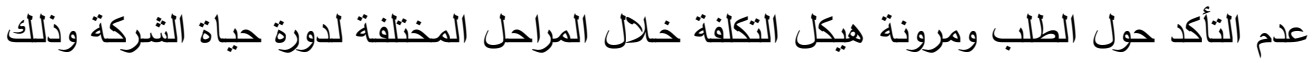
من خلال نتشيل نموذجى الانحدار الثالث والرابع، ويمكن تلخيص أهم نتائجهما فى الجدول 
جدول رقم (7) نتائج اختبار الفرض الثانى

\begin{tabular}{|c|c|c|c|}
\hline \multicolumn{3}{|c|}{ مرونة هيكل التكلفة (Cost Structure "CS') } & تتغير التابع \\
\hline $\begin{array}{c}\text { نموذج (4) (4) } \\
\text { Model }\end{array}$ & $\begin{array}{l}\text { نموذج (3) (3) } \\
\text { Model }\end{array}$ & 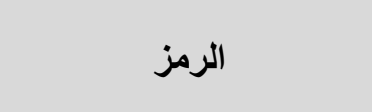 & المستقلة \\
\hline $\begin{array}{c}0.065934- \\
(3.064-)^{* *} \\
0.042321- \\
(82.09-)^{* * *}\end{array}$ & $\begin{array}{c}0.091002- \\
(5.109-)^{* * *} \\
0.042140- \\
(80.93-)^{* * *} \\
0.186070 \\
(7.408)^{* * *} \\
0.425371 \\
(6.529)^{* * *} \\
3.925904- \\
(7.340-)^{* * *} \\
6.106826- \\
(5.765-)^{* * *}\end{array}$ & $\begin{array}{l}\text { GDP growth } \\
\text { Firm Size } \\
\text { Constant (RC+) } \\
\text { Constant (RC-) } \\
\text { DU(RC+) } \\
\text { DU(RC-) }\end{array}$ & 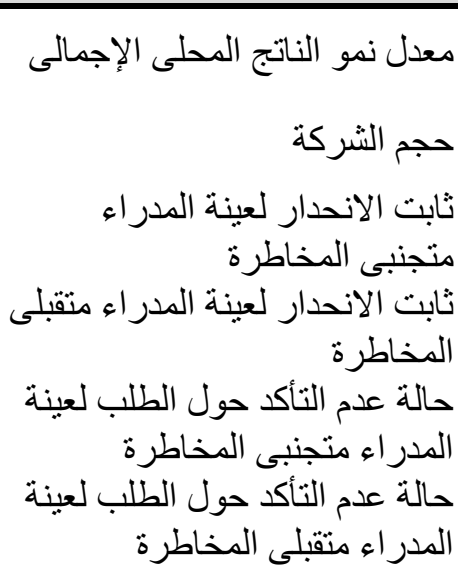 \\
\hline $\begin{array}{l}1.02071 \\
(2.409)^{*} *\end{array}$ & & $\begin{array}{c}\text { Constant(Introduction) } \\
(\mathrm{RC}+)\end{array}$ & لـ لمخلة التقديم لعينة \\
\hline $\begin{array}{l}1.03714 \\
(2.384)^{* *}\end{array}$ & & $\begin{array}{c}\text { Constant(Introduction) } \\
\text { (RC-) }\end{array}$ & لمرحلة التقديم لعينة \\
\hline $\begin{array}{l}0.999954 \\
(2.384)^{* *}\end{array}$ & & Constant(Gross)(RC+) & المدر اء متجنبـى الانحدار لمرحلة النمو لعينة \\
\hline $\begin{array}{l}0.727774 \\
(3.029)^{* * *}\end{array}$ & & Constant(Gross)(RC-) & المدر اء متقبلى الانحدار لمرحلة النمو لعينة \\
\hline $\begin{array}{c}0.351141 \\
(4.450)^{* * *}\end{array}$ & & $\begin{array}{c}\text { Constant(Shakeout) } \\
(\mathrm{RC}+)\end{array}$ & لعابتة الانحدار لمرحلة الاهنز از متجنبى المخاطرة \\
\hline $\begin{array}{l}0.464446 \\
(3.722)^{* * *}\end{array}$ & & $\begin{array}{c}\text { Constant(Shakeout) } \\
\text { (RC-) }\end{array}$ & 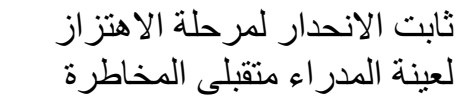 \\
\hline $\begin{array}{l}0.098671 \\
(2.921)^{* * *}\end{array}$ & & $\begin{array}{c}\text { Constant(Maturity) } \\
(\mathrm{RC}+)\end{array}$ & المدر اء متجنبى الانحدار لمرحلة النضـج لعينة \\
\hline $\begin{array}{c}0.385401 \\
(4.358)^{* * *}\end{array}$ & & $\begin{array}{c}\text { Constant(Maturity) } \\
\text { (RC-) }\end{array}$ & المدر اء متقبلى الانحدار لمرحلة النضاطرة لعينة \\
\hline $\begin{array}{c}0.682931 \\
(3.324)^{* * *}\end{array}$ & & $\begin{array}{c}\text { Constant(Decline }) \\
(\mathrm{RC}+)\end{array}$ & لعابتة الانحدار لمرحلة الانخفاض متجنبى المخاطرة \\
\hline $\begin{array}{c}0.568057 \\
(3.455)^{* * *}\end{array}$ & & $\begin{array}{c}\text { Constant(Decline }) \\
\text { (RC-) }\end{array}$ & لثابت الانحدار لمرحلة الانخفاض المدقبل المخاطرة \\
\hline $\begin{array}{l}3.474310- \\
(1.744-)^{*}\end{array}$ & & $\begin{array}{l}\text { DU(Introduction) } \\
(\mathrm{RC}+)\end{array}$ & 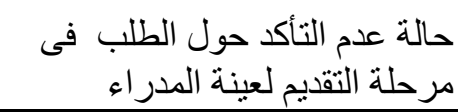 \\
\hline
\end{tabular}




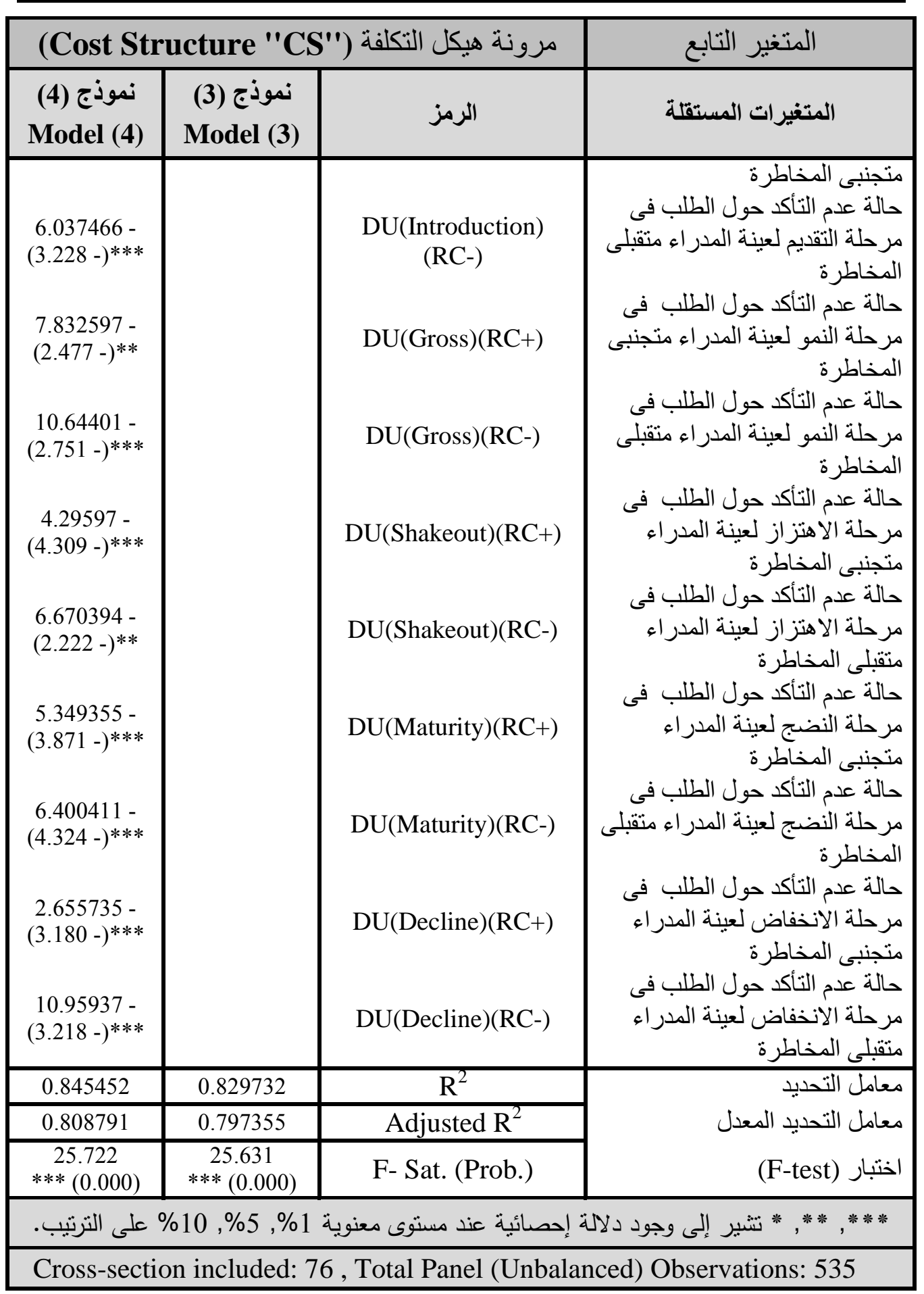


ويتضح من نتائج الجدول السابق العديد من النتائج التى يمكن تلخيصها فى شكل معادلات أفقية لسهولة التحليل والمقارنة وخاصة فى النموذج الرابع الذى يتطلب دراسـة العلاقة بين حالة

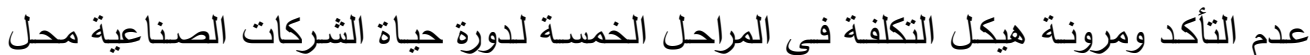
الدراسـة، لمعرفـة هل هناك فروق هيكليـة بين هذه المراحل أم لا ؟، وذلك بعد تقسيم عينـة الدراسة وفقاً لتوجه المدراء نحو المخاطرة سواء تجاه تجنب أو الإقبال على تحمل المخاطرة, وذللك كما يلى:

\section{Model (3) النموذج الثالث}

\begin{tabular}{|c|c|c|c|}
\hline \multirow{2}{*}{ العينة الإجمالية } & $\begin{array}{l}\mathrm{RC} \\
(+)\end{array}$ & $\begin{array}{l}\mathrm{CS}=0.186070-3.925904 \mathrm{DU} \\
{[7.408] * * * \quad[-7.340] * * *}\end{array}$ & \multirow{2}{*}{$\begin{array}{c}-0.091002 \text { GDP }-0.04214 \mathrm{FS} \\
{[-5.109]^{* * *}[-80.93]^{* * *}}\end{array}$} \\
\hline & $\begin{array}{l}\mathrm{RC} \\
(-)\end{array}$ & $\begin{array}{l}\mathrm{CS}=0.425371-6.106826 \mathrm{DU} \\
{[6.529] * * *[-5.765] * * *}\end{array}$ & \\
\hline
\end{tabular}

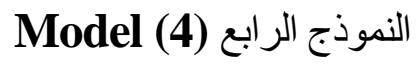

تقسيم عينة الاراسة وفقاً لمراحل دورة حياة الشركة وتوجه المدراء نحو المخاطرة

\begin{tabular}{|c|c|c|c|}
\hline \multirow{2}{*}{$\begin{array}{c}\text { مرحلة التقديم } \\
\text { (Introduction) }\end{array}$} & $\begin{array}{l}\mathrm{RC} \\
(+)\end{array}$ & $\begin{array}{l}\mathrm{CS}=1.02071-3.474310 \mathrm{DU} \\
{[2.409]^{* *} \quad[-1.744]^{*}}\end{array}$ & \multirow{8}{*}{$\begin{array}{r}-0.0659337 \text { GDP }-0.042321 \mathrm{FS} \\
{[-3.064]^{* *} \quad[-82.09]^{* * * *}}\end{array}$} \\
\hline & $\begin{array}{l}\mathrm{RC} \\
(-)\end{array}$ & $\begin{array}{l}\mathrm{CS}=1.03714-6.037466 \mathrm{DU} \\
{[2.384]^{* *} \quad[-3.228]^{* * *}}\end{array}$ & \\
\hline \multirow{2}{*}{ مرحلة النمو } & $\begin{array}{l}\mathrm{RC} \\
(+)\end{array}$ & $\begin{array}{l}\mathrm{CS}=0.999954-7.832597 \mathrm{DU} \\
{[2.384]^{* *} \quad[-2.477]^{* *}}\end{array}$ & \\
\hline & $\begin{array}{r}\mathrm{RC} \\
(-)\end{array}$ & $\begin{array}{l}\mathrm{CS}=0.727774-10.64401 \mathrm{DU} \\
{[3.029]^{* *} \quad[-2.751]^{* * *}}\end{array}$ & \\
\hline \multirow{2}{*}{ مرحلة الاهنز از } & $\begin{array}{l}\mathrm{RC} \\
(+)\end{array}$ & $\begin{array}{l}\mathrm{CS}=0.351141-4.29597 \mathrm{DU} \\
{[4.450]^{* * *}[-4.309]^{* * *}}\end{array}$ & \\
\hline & $\begin{array}{l}\mathrm{RC} \\
(-)\end{array}$ & $\begin{array}{l}\mathrm{CS}=0.464446-6.670394 \mathrm{DU} \\
{[3.722]^{* * *}[-2.222]^{* *}}\end{array}$ & \\
\hline \multirow{2}{*}{ مرحلة النضجج } & $\begin{array}{l}\mathrm{RC} \\
(+)\end{array}$ & $\begin{array}{l}\mathrm{CS}=0.098671-5.349355 \mathrm{DU} \\
{[2.921]^{* * *}[-3.871]^{* * *}}\end{array}$ & \\
\hline & $\begin{array}{l}\mathrm{RC} \\
(-)\end{array}$ & $\begin{array}{l}\mathrm{CS}=0.385401-6.400411 \mathrm{DU} \\
{[4.358]^{* * *}[-4.324]^{* * *}}\end{array}$ & \\
\hline
\end{tabular}




\begin{tabular}{c|c|l}
\hline \hline & $\mathrm{RC}$ & $\mathrm{CS}=0.682931-2.655735 \mathrm{DU}$ \\
& $(+)$ & {$[3.324]^{* * *}[-3.180]^{* * *}$} \\
\cline { 2 - 3 } (Decline) & $\mathrm{RC}$ & $\mathrm{CS}=0.568057-10.95937 \mathrm{DU}$ \\
& $(-)$ & {$[3.455]^{* * *}[-3.218]^{* * *}$} \\
\hline \hline
\end{tabular}

وفى ضوء مـا سبق يمكن الإشـارة إلى النتائج المتعلقة بنموذج الانحدار الثالث فى النقاط

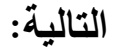
أ- معنوية نموذج الانحدار الثالث ككل؛ حيث أثنار اختبار (F-statistic) إلى معنوية المتغيرات الككونـة لنمـوذج الانحدار ككل عند مسنتوى معنويـة (1\%)، وكذلك بلغت القوة التفسيرية لمتغيرات النموذج تقريباً حوالى (80\%) من التغيرات فى مرونـة هيكل التكلفة خـل فترة

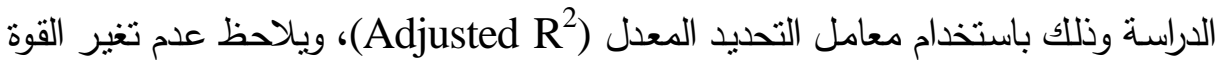
التفسيرية للنموذج الثالث عن نموذجى الانحدار الأول والثانى، وذلك فى ظل مراعاة أثر توجه المدراء نحو المخاطرة سواء تجاه تجنب أو إقبال المدراء على تحمل المخاطرة. ب- اختص نموذج الانحدار الثالث بدراسة أثر توجه المدراء نحو المخاطرة على العلاقة بين حالة عدم التأكد حول الطلب (DU) ومرونة هيكل التكلفة (CS) دون مراعاة المراحل المختلفة لدورة حياة الثركات الصناعية محل الدراسة، واتضـح من تشغيل هذا النموذج على عينة الثركات الصناعية محل الدراسة: - - معنوية التأثير الإيجابى للجزء الثابت (Constant) عند مستوى معنوية (1\%) وذلك بعد تقسيم عينة الدراسـة الإجمالية وفقاً لتوجه المدراء نحو المخاطرة، وذلك سواء كان مدراء الثركات الصناعية محل الدراسة ينتهون سلوك تجنب المخاطرة أو تحمل المخاطرة. - معنوية التأثثر السلبى لحالة عدم التأكد حول الطلب على مرونـة هيكل التكلفة عند مستوى معنويـة (1\%)، إلا أن درجة التأثنير السلبى لحالة عدم التأكد حول الطلب على مركى مرونـة هيكل التكلفة تزداد بمقدار الضـف كلمـا كان مدراء الثـركات الصناعية محل الدراسـة يميلـون تجـاه تحمـل المخـاطرة (RC-) وذلـك مقارنـة بسـلوك تجنـب المخـاطرة (RC+)؛ حيث بلغت قيمة معامل الانحدار لحالة عدم التأكد حول الطلب فى حال توجها المدراء نحو تحمـل المخـاطرة (- 6.106)، بينمـا فـى حالـة توجـه المدراء نحو تجنب المخاطرة بلغت (- 3.926). 
- معنوية التأثير السلبى للمتغيرات الضابطة (معدل نمو الناتج المحلى الإجمالى، وحجم

الثركة) على مرونة هيكل التكلفة وذللك عند مستوى معنوية (1\%)، وذللك سواء لعينة

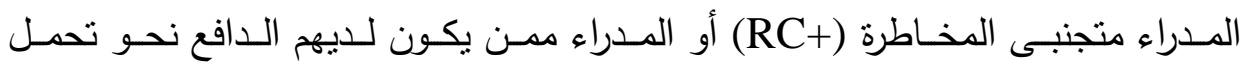

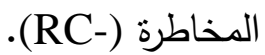

وفى ضوء النتائج السابقة يتضح وجود تغير هيكلى كامل (انحدارات غير منمانلة) فى علاقة حالة عدم التأكد حول الطلب بمرونـة هيكل التكلفة فى حالـة مـا إذا كان توجهه مدراء الثـركات الصناعية محل الدراسة فى اتجاه تجنب المخاطرة وذلك مقارنة بتوجه المدراء نحو تحمل المخاطرة، ومـن ثم يمكن استتتاج أن اختلاف علاقة حالـة عدم التأكد حول الطلب بمرونـة هيكل التكلفة تتوقف على توجه المدراء نحو المخاطرة سواء من حيث تجنب المخاطرة أو الإقبال عليها؛ حيث تزداد درجـة التأثثر السلبى لحالـة عدم التأكد حول الطلب على مرونـة هيكل التكلفة وفقاً للنتائج

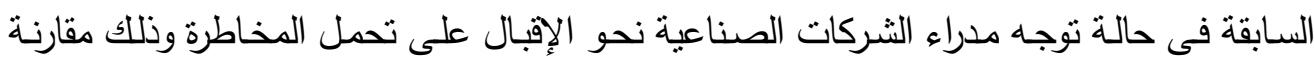
بتوجه المدراء نحو تجنب المخاطرة. وبالتالى كلمـا زادت (انخفضت ) حالـة عدم التأكد حول الطلب تنخفض (تزداد) مرونـة هيكل التكلفـة وذلك فـى ظلـل ارتفـاع (انخفاض) معدل نمـو النـاتج المحلى الإجمـالى (GDP) وكبر (صغر ) حجم الثركة (FS) (كمتغيرات ضابطة)، ومن ثم ميل هيكل نكلفة الثركات محل البحث

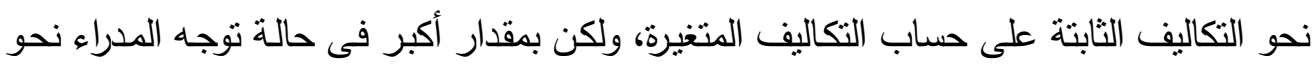

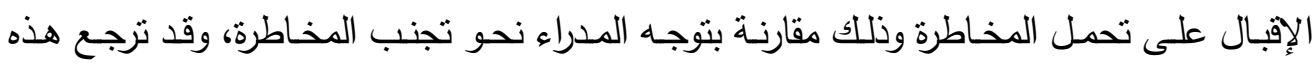

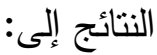
•طبيعة نشاط الثركات الصناعية محل الدراسة باعتبار معظمها تتنمى إلى الصناعات كثيفة

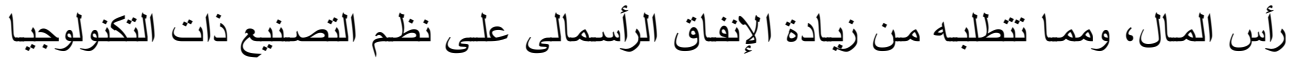

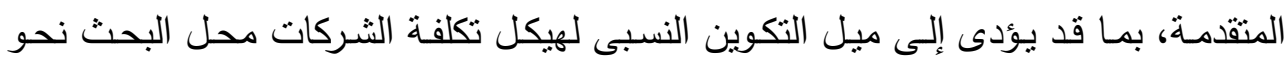
زيادة التكاليف الثابتة مقارنـة بالتكاليف المتغيرة وذلك بغض النظر عن توجها المدراء نحو

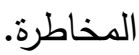

•انخفاض درجة تجنب (كره) المخاطرة أو سلوك تقبل المخاطرة قد تجعل المدراء يرون حالة عدم التأكد حول الطلب على أنها بمثابة فرصة استثمارية وذلك لنوقع تحقيق الثركة أرباحاً نتيجة لأن حالة عدم التأكد حول الطلب قد يصاحبها احتمال تحقيق طلب غير عادى على لهى 
منتجات الثـركة، بما قد يدفع الإدارة نحو زيـادة مستوى الطاقـة الإنتاجيـة من خـلال زيـادة الاستثمار فى الأصـول الثابتة، بالثكل الذى قد يؤدى إلى تبنى هياكل تكلفة أقل مرونـة

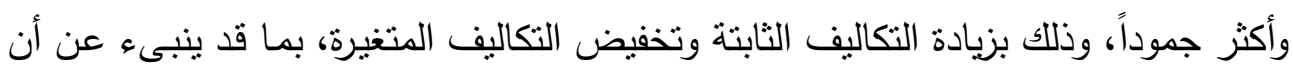
انخفاض درجـة نفور (كراهية) المخاطرة مرتبط بوجود أثر موجب للعلاقة بين حالـة عدم التأكد حول الطلب واختيار هيكل تكلفة أكثر جموداً وأقل مرونة. أما بالنسبة للنموذج الرابع والخاص بالتحقق من الفرض الثانى للبحث كاملاً، يمكن الإشـارة إلى النتائج المتعلقة به فى النقاط التالية:

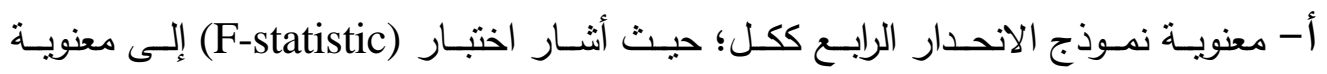
المتغيرات المكونـة لنموذج الانحدار ككل عند مستوى معنويـة (1\%)، وكذللك بلغت القوة التقسيرية لمتغيرات النموذج تقريباً حوالى (81\%) من التغيرات فى مرونة هيكل التكلفة خلال فترة الدراسة وذلك باستخدام معامل التحديد المعدل (Adjusted R2). ب- اختص نموذج الانحدار الرابع بدراسة أثر توجه المدراء نحو المخاطرة على العلاقة بين حالـة عـدم التأكد حـول الطلب (DU) ومرونــة هيكل التكلفـة (CS) خـلال المراحـل المختلفة لدورة حياة الثركات الصناعية محل الدراسـة، واتضـح من نشغيل هذا النموذج على عينة الثركات الصناعية محل الدراسة: - معنويـة التأثثر الإيجـابى للجزيء الثنابـ (Constant) عند مسـتوى معنويـة (5\%) خـلال مرحلتى التقديم (Introduction) والنمو (Gross)، وعند مسنوى معنوية (1\%) في بـ باقى مراحل دورة حيـاة الثـركات الصـناعية محل الدراسـة، وذلك على حسب اختلاف توجـهـ

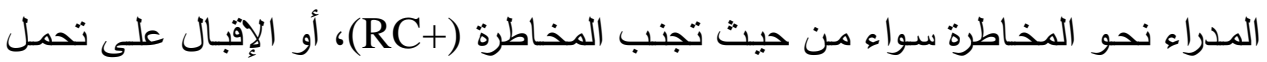
المخاطرة (RC).

- معنوية التأثير السلبى لحالة عدم التأكد حول الطلب على مرونـة هيكل التكلفة عند مستوى

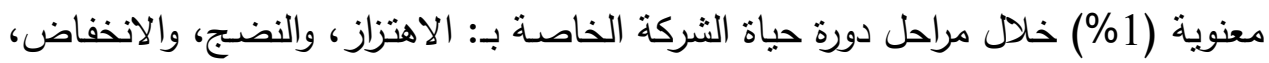
وعند مستوى معنوية (5\%) فى مرحلة النمو ، ولكن عند مستوى معنوية (10\%) في مرحلة التقديم، وذللك فى حالة توجه المدراء نحو تجنب المخاطرة (RC+). - معنوية التأثير السلبى لحالة عدم التأكد حول الطلب على مرونـة هيكل التكلفة عند مستوى نوله معنويـة (5\%) خـل مرحلة الاهنزاز ، وعند مستوى معنويـة (1\%) فى بـاقى مراحل دورة 
حياة الثـركات الصناعية محل الدراسـة، وذلك فى حالة توجهـ المدراء نحو الإقبال على

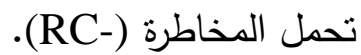
- بصفة عامـة تزداد درجة التأثثر السلبى لحالة عدم التأكد حول الطلب على مرونـة هيكل التكلفة خلال المراحل المختلفة لدورة حياة الثركات الصناعية محل الدراسة فى حال توجهـ المدراء نحو تحمل المخاطرة (RC) وذلك مقارنة بحال توجه المدراء نحو تجنب المخاطرة

- - تختلف درجة التأثنر السلبى لحالة عدم التأكد حول الطلب على مرونة هيكل التكلفة فى حال توجه مدراء الثركات الصناعية محل الدراسة نحو تجنب المخاطرة (RC+) باختلاف مراحل دورة حياة الثـركة؛ حيث تبلغ ذروتها فى مرحلة النمو (Gross) بمعامل انحدار

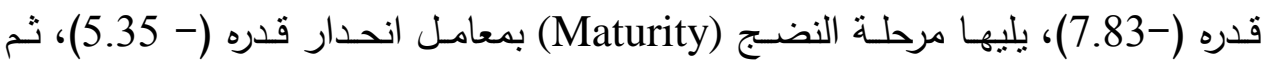
مرحلـة الاهتزاز (Shakeout) بمعامـل انحدار قدره (- 4.29)، وأخبـراً مرحلتى التقديم (Decline) وذلــك بمعامـل انحـدار قـدره (- 3.47، - (Introduction) 2.65) على التزتيب. - - تختلف درجة التأثير السلبى لحالة عدم التأكد حول الطلب على مرونة هيكل التكلفة فى حال توجه مدراء الثركات الصناعية محل الدراسة نحو تحمل المخاطرة (RC) باختلاف مراحل دورة حياة الثـركة؛ حيث تبلغن ذروتها فى مرحلة الانخفاض (Decline) بمعامل

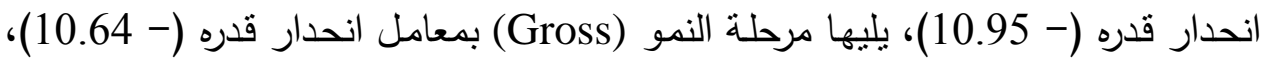

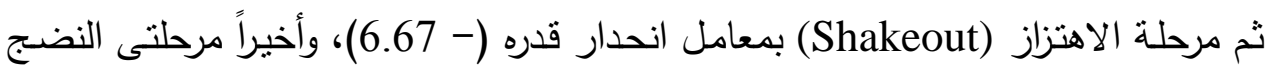
(Maturity) على الترتيب. - معنويـة التـأثير السـلبى لمعـدل نـــ النـاتج المحلى الإجمـالى (GDP) وحجـم الثــركة (كمتغيرات ضابطة) على مرونة هيكل التكلفة خلال المراحل المختلفة لدورة حياة الثركات الثرات

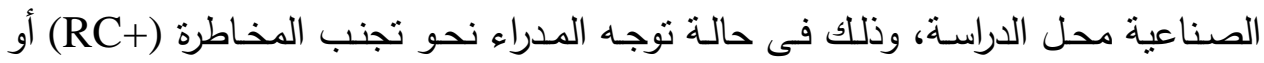
الإقبال على تحمل المخاطرة (RC). وفى ضدو النتائج السابقة ينضح وجود تغير هيكلى كامل (انحدارات غير متمانــة) فى علاقة حالة عدم التأكد حول الطلب بمرونـة هيكل التكلفة خـل مراحل دورة حياة الثـركات الصناعية 
محل الدراسة فى حالة ما إذا كان توجه مدراء الثُركات الصناعية محل الدراسة فى اتجاه تجنب

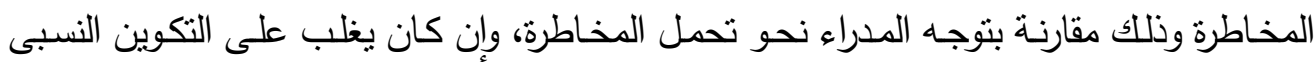
لهيكل التكلفة اتجاهـه بصفة عامـة نحو التكاليف الثابتة على حساب التكاليف المتغيرة، وهذا قد يرجع إلى طبيعة النشاط والقطاع (قطاع الصناعات التحوبلية) الذى تتنمى إليه الثركات الصناعية

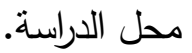

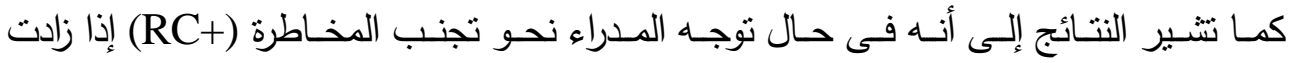
(انخفضت) حالة عدم التأكد حول الطلب تنخفض (تزداد) مرونة هيكل تكلفة الثركات الصناعية محل الدراسة وذلك فى ظل ارتفاع (انخفاض) معدل نمو الناتج المحلى الإجمالى وحجم الثركة

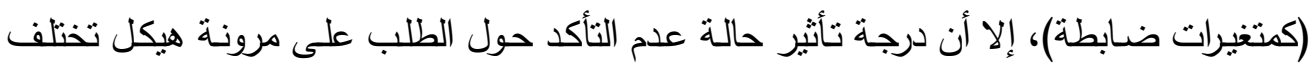
باختلاف مراحل دورة حياة الثركة وذلك بالترتيب التالى ووفقاً للأسباب الآتية: فـى مرحلة النمو تزداد درجة التأثير السلبى لحالة عدم التأكد حول الطلب على مرونة هيكل التكلفة؛ بما يشير إلى ارتفاع التكاليف الثابتة فى هيكل التكلفة كلما زادت حالة عدم التأكد حول الطلب، وذلك فى ظل ارتفاع معدل نمو الناتج المحلى الإجمالى وحجم الثـركات والعكس صحيح، حيث تشهد هذه المرحلة زيادة فى حجم الطلب، بما قد يؤدى إلى زيادة

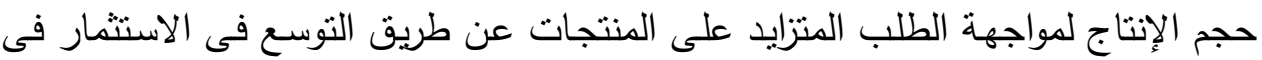

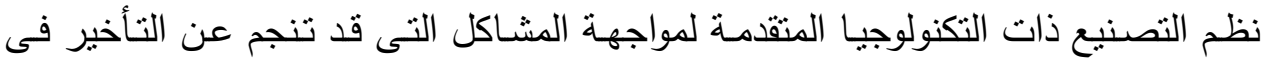
تسليم المنتجات للعملاء فى التوقيت المحدد. تزداد درجـة التأثثر السلبى لحالـة عدم التأكد حول الطلب على مرونـة هيكل التكلفة فى لـى

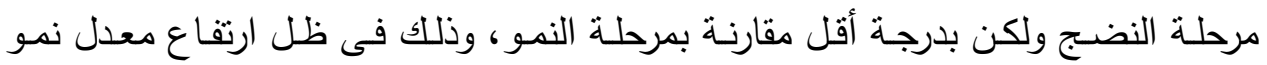
الناتج المحلى الإجمـالى وحجم الثـركات والعكس صـحيح؛ بمـا يشبر إلى ارتفـاع نسبة التكاليف الثابتة فى هيكل التكلفة كلمـا زادت حالة عدم التأكد حول الطلب ولكن بشرط تحسن الأحوال الاقتصادية المرتبطة بزيادة معدل نمو الناتج المحلى الإجمالى وزيادة حجم الثركة، حيث تتزايد حدة المنافسة فى هذه المرحلة، بما يجعل الثركات تتتبه لضرورة إبقاء الثركة فى السوق لأطول فترة ممكنة من خـلاد تطوير منتجاتها الحالية وتقديمها بأقل تكلفة ممكنة نتيجة النمطية فى الإنتاج وارتفاع منحنى الخبرة، بما يدفع الثركات نحو اتباع 
استراتيجيات فعالـة لمواجهة المنافسـة مـن خـلال زيـادة التكاليف الثابتة مقارنـة بالتكاليف المتغيرة.

فى مرحلة الاهتزاز تتخفض نسبة التكاليف الثابتة مقارنة بالتكاليف المتغيرة فى هيكل التكلفة إذا زادت حالة عدم التأكد حول الطلب وذلك مقارنة بمرحلتى النمو والنضـ، نظراً لما تشههده مرحلة هيلة الاهتزاز مـن صسوبة فى تحقيق ارتفاع مستمر فى معدل نمو المبيعـات نتيجـة ازديـاد حدة المنافسة والدخول فى حروب سعرية قد تؤدى إلى الإفلاس، وبالتالى يقوم المدراء مدن يغلب عليهم التوجه نحو تجنب المخاطرة التعامل بحذر فى هذه المرحلة. فى مرحلة التقديم تتخفض نسبة التكاليف الثابتة مقارنة بالتكاليف المتغيرة فى هيكل التكلفة إذا زادت حالة عدم التأكد حول الطلب وذلك مقارنة بمرحلتى النمو والنضج والاهتزاز ، نظراً لما قد تشهذه هذه المرحلة من عدم إمكانية تحديد مدى قبول ما تقدمه الثركة من منتجات

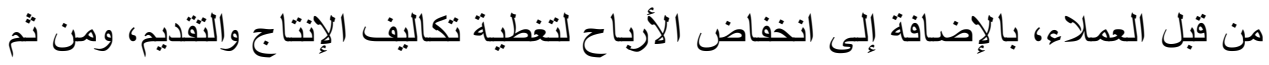
يغلب على المدراء خاصـة ممن تزداد لديهم حوافز تجنب المخاطرة إلى تخفيض نسبة الإسة التكاليف الثابتة والاعتماد على التكاليف المتغيرة فى هيكل التكلفة. فى مرحلة الانخفاض تنخفض نسبة التكاليف الثابتة مقارنة بالتكاليف المتغيرة فى هيكل التكلفة إذا زادت حالة عدم التأكد حول الطلب وذللك مقارنة بباقى مراحل دورة حياة الثركة، حيث يغلب على المدراء مـن متجنبى المخاطرة القيام بتحديد مستوى معين للاستثمار

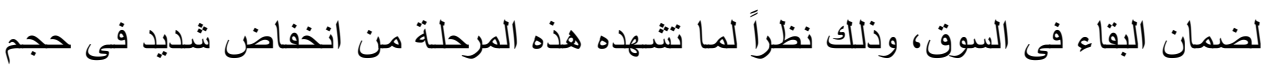

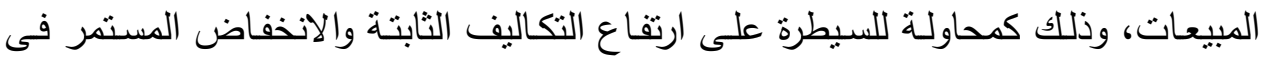

$$
\text { الأسعار فى هذه المرحلة. }
$$

ولكن فى حال توجه المدراء نحو تقبل المخاطرة (RC) تختلف درجة التأثير السلبى لحالة عدم التأكد حول الطلب على مرونة هيكل التكلفة باختلاف مراحل دورة حياة الثركة، وذلك

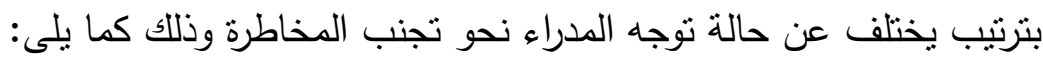
O فى مرحلة الانخفاض تزداد درجة التأثنير السلبى لحالة عدم التأكد حول الطلب على مرونـة هيكل التكلفة، حيث بلعب توجه المدراء نحو تقبل المخاطرة دوراً هاماً فى هذه المرحلة لزيادة التكاليف الثابتة فى هيكل التكلفة فى حالة زيادة حالة عدم التأكد حول الطلب وذللك فى ظل ارتفاع معدل نمو الناتج المحلى الإجمالى وزيادة حجم الثركة (كمتغيرات ضابطة) والعكس 


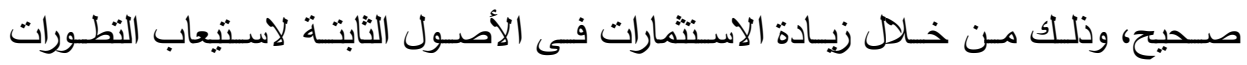

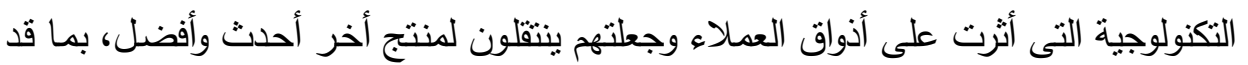

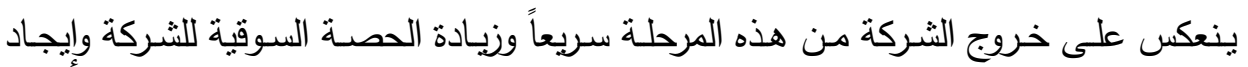
أسواق خارجية جديدة.

فى مرحلة النمو يزداد توجه المدراء نحو تبنى هيكل تكلفة أقل مرونة - ولكن بدرجة أقل مقارنة بمرحلة الانخفاض-فى حال زيادة حالة عدم التأكد حول الطلب وفى ظل ارتفاع معدل نمو النـاتج المحلى الإجمالى وزيـادة حجم الثـركة (كتنغيرات ضـابطة) والعكس

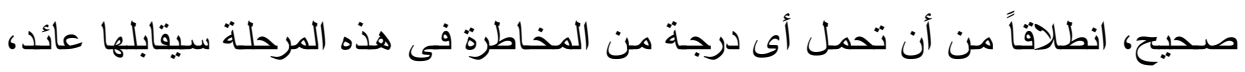

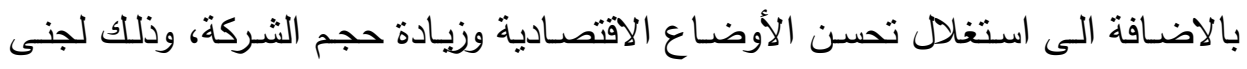

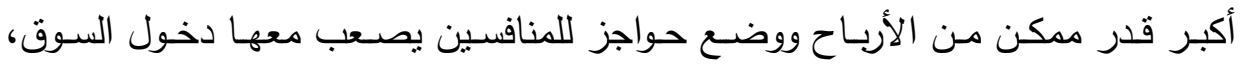

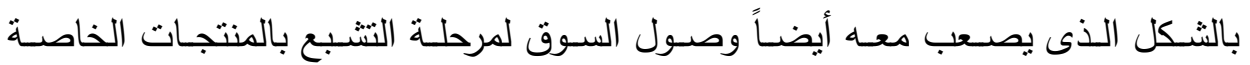
بالشركة.

فى مرحلة الاهتزاز وعلى الرغم من تباطؤ معدل نمو المبيعات نتيجة دخول العديد من

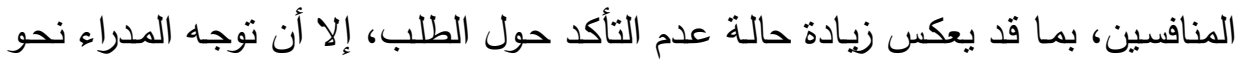
تقبل المخاطرة قد تجعلهم يتبنوا هيكل تكلفة أقل مرونة من خلال زيادة التكاليف الثابتة على حساب التكاليف المتغيرة، ولكن بدرجة أقل مقارنة بمرحلة الانخفاض والنمو، وذللك مُه

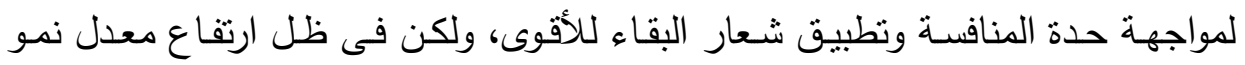
الناتج المحلى الإجمالى وزيـادة حجم الثـركة (كتغيرات ضـابطة) - والعكس صـحيح، وذلك إلى جانب قوة المركز المالى للشركة وتعدد أنشنطها. فى مرحلة النضـج وفى حال توجه المدراء نحو تقبل المخاطرة تزداد التكاليف الثابتة فى هيكل التكلفة فى حالـة زيـادة عدم التأكد حول الطلب نتيجـة تبنى استراتيجيات فعالـة لتعديل العلامـة التجارية وتحسين منتجات الثركة من حيث الجودة، لضمان البقاء فى لي السوق خاصة مع نزايد التهديدات من المنافسين المحتملين، ولكن فى ظل ارتفاع معدل نمو الناتج المحلى الإجمالى وزيادة حجم الثركة (كمتغيرات ضابطة) والعكس صحيح.

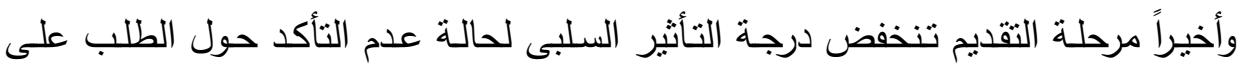
مرونـة هيكل التكلفة مقارنـة بباقى مراحل دورة حياة الثركة فى حالة توجه المدراء نحو 
تقبل المخاطرة، وبالتالى نزداد التكاليف الثابتة فى هيكل التكلفة ولكن ليس بنفس الدرجة فى باقى مراحل دورة حياة الثركة فى حالة زيادة حالة عدم التأكد حول الطلب، وذلك أملاً فى زيادة الطلب على منتجات الثركة والاستعداد لمرحلة النمو . ومن ثم وفى ضوء ما سبق يمكن استتناج أن اختلاف علاقة حالة عدم التأكد حول الطلب بمرونة هيكل التكلفة تتوقف على توجه المدراء نحو المخاطرة سواء من حيث تجنب المخاطرة أو الإقبال عليها وذلك خلال المراحل المختلفة لدورة حياة الثركات الصناعية محل الدراسـة؛ حيث تزداد درجة التأثير السلبى لحالة عدم التأكد حول الطلب على مرونـة هيكل التكلفة وفقاً للنتائج السابقة فى حالة توجـه مدراء الثركات الصناعية نحو الإقبال على تحمل المخاطرة مقارنة بتوجه المدراء نحو تجنب المخاطرة، وذلك خلد المراحل المختلفة لدورة حياة الشركات

الصناعية محل الدراسة وعلى اختلاف ترتيبها وفقاً لاختلاف توجه المدراء نحو المخاطرة. وبالتالى يمكن رفض الفرض الثانى للبحث والذى بنص على أنه: "لا يوجود اختلاف فى أثر لثراه توجـه المدراء نحو المخاطرة على العلاقة بين حالة عدم التأكد حول الطلب وهيكل التكلفة

خلال المراحل المختلفة لدورة حياة الشركات الصناعية العاملة فى بيئة الأعمال المصرية".

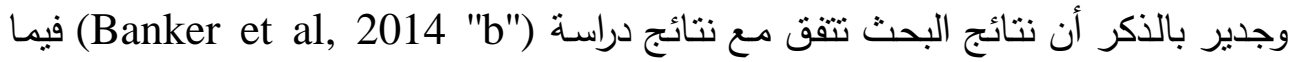
يخص نتائج الفرض الأول للبحث والخاص بوجود أثر سالب لحالة عدم التأكد حول الطلب على مرونـة هيكل التكلفة؛ ومن ثم كلما زادت حالة عدم التأكد حول الطلب تنخفض مرونـة هيكل التكلفة من خلال زيادة التكاليف الثابتة فى هيكل التكلفة على حساب التكاليف المتغيرة وذللك بالتطبيق على الشركات الصناعية، بينما تختلف نتائج البحث فيما يخص الفرض الأول مع نتائج دراسة (Kallapur and Eldenburg, 2005)؛ حيث توصلت هذه الدراسة إلى

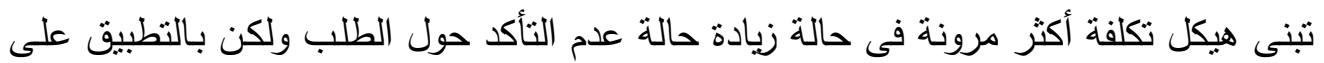
قطاع المستشفيات. ولكن قدمت نتائج الفرض الأول للبحث الحسالى دليلـ اختبـارى إضـافى مقارنـة بالدراسـات

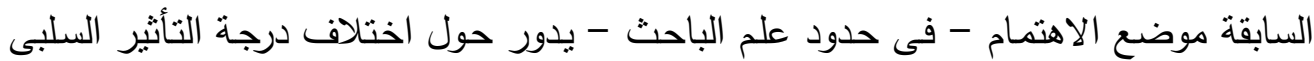
لحالة عدم التأكد حول الطلب على مرونـة هيكل التكلفة خلال المراحل المختلفة لدورة حياة الشركات الصناعية محل الدراسة. 
أما فيما يخص نتائج الفرض الثانى للبحث يتضح أنها تتفق مع ما توصلت إليه دراسة Bo (and Sterken, 2007؛ حيث توصلت إلى ارتباط انخفاض (ارتفاع) درجة نفور (كراهية)

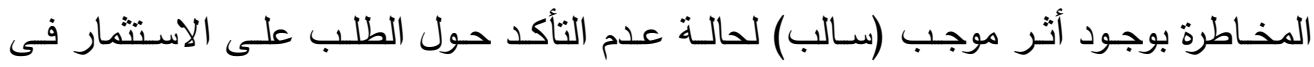
الأصـول الثابتة ومـن ثم زيـادة (انخفاض) التكـاليف الثابتـة وذلك فـى الثـركات ذات معامـل المخاطرة السالب (الموجب). بينما قدم البحث الحالى دليل اختبارى إضافى (فى حدود علم الباحث) حول اختلاف التأثثر السلبى لحالة عدم التأكد حول الطلب على مرونة هيكل التكلفة (وليس الاستثمار فى الأصول

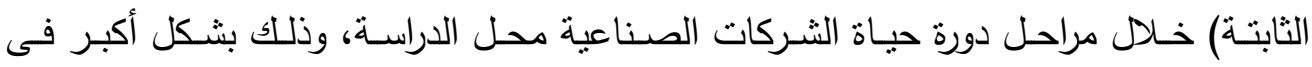
الثركات ذات معامل المخاطرة السـالب (RC-) - ممن يقبل مدرائها على تحمل المخاطرة، وذللك مقارنـة بالشـركات ذات معامل المخـاطرة الموجب (RC+) - مدـن يقبل مدرائها على تجنب المخاطرة، بما يعكس اختلاف أثز توجه المدراء نحو المخاطرة على العلاقة بين حالة عدم التأكد حول الطلب ومرونة هيكل التكلفة خلال مراحل دورة حياة الثركات الصناعية محل لهل

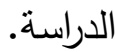

\section{رابعاً:حدود النتائج}

ينبغى التعامل مـع النتائج التى تم التوصل إليها فى هذا البحث بعد مناقشـة نتائج فروضهـ البحثية بحذر وذلك للأسباب الآتية: 1- تقتصر نتائج البحث على عينـة الثـركات الصـناعية محل الدراسـة التى تتنمى لقطـاع الصناعات التحويلية فقط، وبالتالى يصعب تعميم النتائج على غيرها من الثركات ذات الأنشطة المختلفة.

2- ترتبط نتائج البحث بالنمـاذج المستخدمة لقياس حالـة عدم التأكد حول الطلب ومرونـة هيكل التكلفة وفقاً لدراسة ("banker et al, 2014 "b). 3- تـرتبط نتـائج البحــث بـالنموذج المســتخدم للتعبيـر عـن مراحـل دورة حيـاة الثــركة

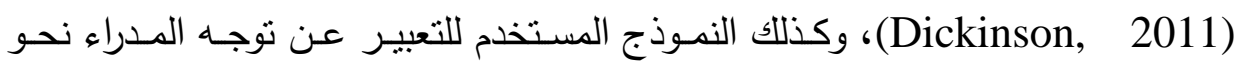
المخاطرة (Bo and Sterken, 2007). 4- ترتبط نتائج البحث بالفترة الزمنية المطبق عليها البحث وهى الفترة من عام 2010 حتى عام 2017. 


\section{القسم الرابع \\ الخلاصة والدراسات المستقبلية}

ناقش البحث الجدل القائم حول طبيعة العلاقة بين حالة عدم التأكد حول الطلب ومرونـة

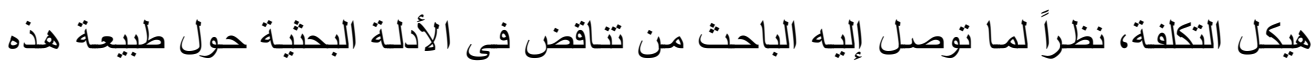
العلاقة؛ حيث توصلت دراسة ("Banker et al, 2014 'b") إلى أن زيادة حالة عدم التأكد حول الطلب تؤدى إلى تبنى هيكل تكلفة أقل مرونـة (بمعنى زيادة التكاليف الثابتة مقارنـة

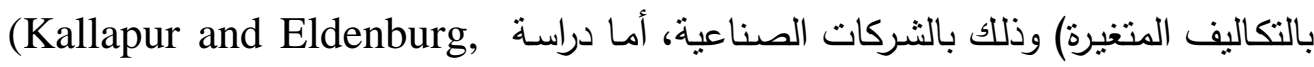
(2005 نوصلت إلى العكس وذللك بالتطبيق على قطاع المستشفيات.

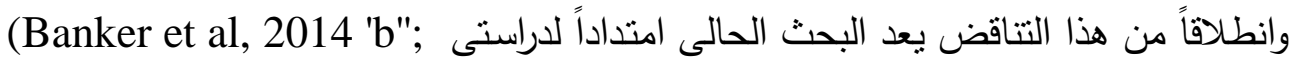
Kallapur and Eldenburg, 2005) ولكنه يختلف عنهما فى أن البحث الحالى اهتم بدراسة العلاقة بين حالة عدم التأكد حول الطلب ومرونة هيكل التكلفة خلال المراحل المختلفة

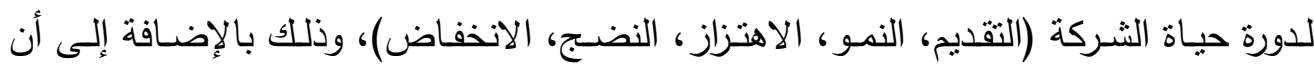

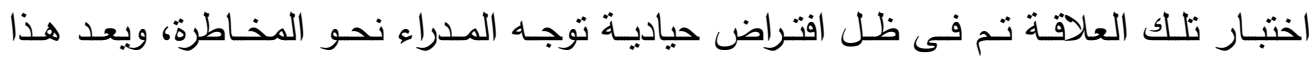
الافتراض غير واقعى من الناحية العملية. لذا تطرق البحث الحالى أيضاً لدراسـة أثر توجه المدراء نحو المخاطرة على طبيعة العلاقة بين

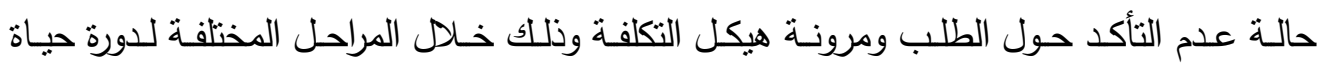
الثركة، للتعرف على طبيعة هذه العلاقة خلال المراحل المختلفة لدورة حياة الثركة سواء فى ظل توجه المدراء نحو تجنب المخاطرة أو الإقبال على تحمل المخاطرة. ومن ثم تم تطبيق البحث الحالى على عينـة مكونـة من (76 شركة) من الثركات الصناعية

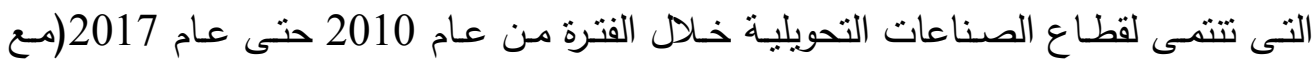
مراعاة أنه تم فقد 10 مشـاهدات لكل شركة بداية من عام 2000) لتقدير حالة عدم التأكد حول الطلب وتوجه المدراء نحو المخاطرة، وبالتالى تبدأ السلسلة الزمنية من عام 2000 حتى عام عام 2017، وبلـغ عدد المشـاهدات الإجمـالى (535 مشـاهدة) نتيجـة تحليل البيانـات الطوليـة بشكل غير متوازن (UnbalancedPanelData)، وذلك باستخدام برنامج التحليل الإحصائى

.(Eviews Version 10) 
كما تم استخدام نموذج الأثار الثابتة (FEM) (Fixed effects model)، أو ما يسمى

Least-squares dummy بـموذج المربعـات الصـغرى باسـتخدام المتغيـرات الوهميـة (LSDV) variable اختلاف فى العلاقة بين حالة عدم التأكد حول الطلب وهيكل التكلفة خلال المراحل المختلفة

للورة حياة الشركات الصناعية العاملة فى بيئة الأعمال المصرية". ولكن تم استخدام طريقة المربعات الصغرى المرجحة (Weighted Least Squares) (WLS) لأسباب تتعلق بضرورة إضافة متغيرات وهمية وتفاعلية متعددة لتقسيم المشاهدات وفقاً لدرجة توجـه المدراء نحو المخاطرة خـلال مراحل دورة حياة الثـركات، بمـا يهدد بانخفاض درجـات الحرية ويؤثر على كفاءة النتائج التى يتم التوصل إليها, وينص الفرض الثانى للبحث على أنه "لا يوجود اختلاف فى أثز توجه المدراء نحو المخاطرة على العلاقة بين حالة عدم التأكد حول الطلب وهيكل التكلفة خلال المراحل المختلفة لدورة حياة الشركات الصناعية العاملة فى بيئة

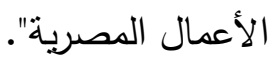

\section{وفى إطار اختبار الفرض الأول والثانى للبحث توصل الباحث للتتائج التالية:} 1- نوفير الدليل العلمى على أن زيادة (انخفاض) حالة عدم التأكد حول الطلب يصـاحبها

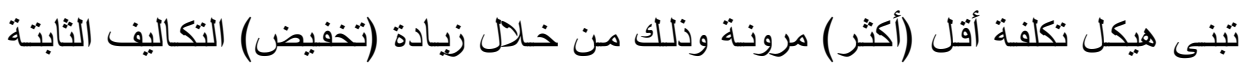
مقارنـة بالتكاليف المتغيرة، ولكن فى ظل ارتفاع (انخفاض) معدل نمو الناتج المحلى مردى ودلى الإجمالى وزيادة (انخفاض) حجم الشركات الصناعية محل الدراسة.

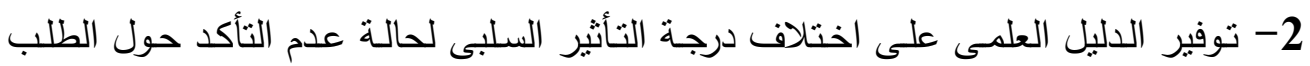
على مرونـة هيكل التكلفة خـلال المراحل المختلفة لدورة حياة الشركات الصناعية محل لهل

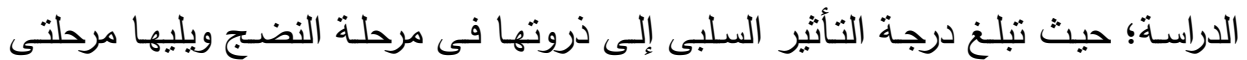

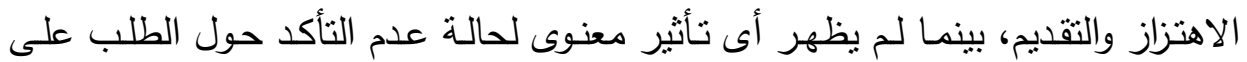
مرونة هيكل التكلفة فى مرحلتى النمو والانخفاض، وذللك فى ظل افتراض حيادية توجها المدراء نحو المخاطرة، ومعنوية التأثير السلبى لمعدل نمو الناتج المحلى الإجمالى وحجم مردم الثركة على مرونـة هيكل التكلفة فى المراحل المختلفة لدورة حياة الثـركات الصناعية

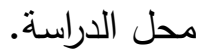


3- توفير الدليل العلمى على زيادة درجة التأثير السلبى لحالة عدم التأكد حول الطلب على مرونـة هيكل التكلفة فى حال توجه المدراء نحو تحمل المخاطرة بمقدار الضعف وذلك مقارنة بحال توجه المدراء نحو تجنب المخاطرة، ولكن دون الاهتمام بالمراحل المختلفة لدورة حياة الشركات الصناعية محل الدراسة. 4- توفير الدليل العلمى على اختلاف أثر توجه المدراء نحو المخاطرة على طبيعة العلاقة بين حالـة عدم التأكد حول الطلب ومرونـة هيكل التكلفة خـلال المراحل المختلفة لدورة حياة الثركات الصناعية محل الدراسة، حيث: - تزداد بصفة عامة درجة التأثير السلبى لحالة عدم التأكد حول الطلب على مرونـة هيكل التكلفة خلال المراحل المختلفة لدورة حياة الثركات الصناعية محل الدراسة فى حال نوجه

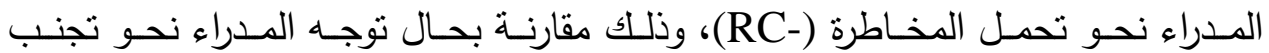

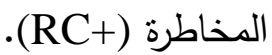

- تختلف درجة التأثير السلبى لحالة عدم التأكد حول الطلب على مرونـة هيكل التكلفة فى

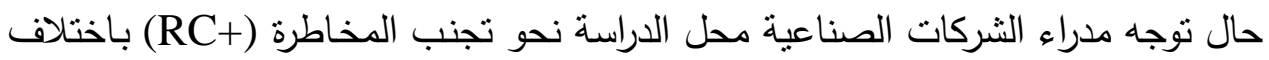
مراحل دورة حيـاة الثـركة؛ حيث تبلـغ ذروتهـا فـى مرحلـة النمـو (Gross)، يليهـا مرحلـة

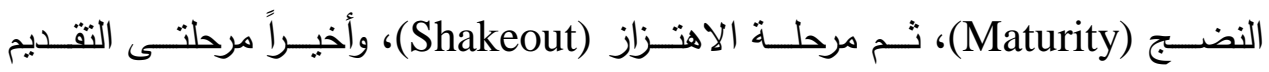
(Introduction)

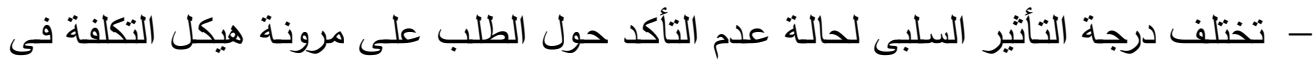
حال توجه مدراء الثركات الصناعية محل الدراسة نحو تحمل المخاطرة (RC) باختلاف مراحل دورة حيـاة الثـركة؛ حيث تبلـغ ذروتها فـى مرحلـة الانخفاض (Decline)، يليها

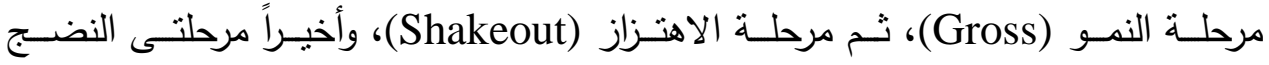
(Maturity) 


\section{الاراسات المستقبلية}

يقترح الباحث العديد من المجالات التى يمكن أن تشكل أساساً لبحوث ودراسـات مستقبلية

$$
\text { من أهمها: }
$$

1- البحث عن متغيرات أخرى قد تساهم فى تفسير العلاقة بين حالة عدم التأكد حول الطلب

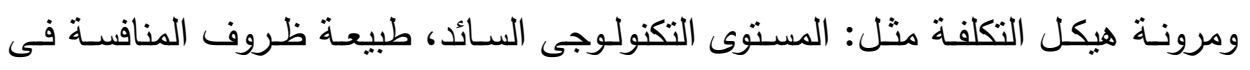

أسواق المنتجات.

2- تكرار نفس الدراسـة الحالية ولكن بالتطبيق على عينة من الشركات الصناعية والخدمية والتجارية.

3- - تكرار نفس الدراسة الحالية ولكن مع استخدام مقاييس أخرى لهيكل التكلفة وتوجه المدراء نحو المخاطرة وحالة عدم التأكد حول الطلب.

4- - دراسة أثر حالة عدم التأكد حول الطلب على إدارة الأرباح: دراسة اختبارية. 5- دراسة أثز حالة عدم التأكد حول الطلب على التكاليف اللزجة: دراسة اختبارية. 6- دراسة أثر توجه المدراء نحو المخاطرة على الأداء المالى للشركة: دراسة اختبارية. 


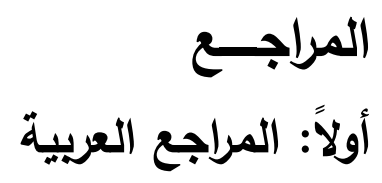

1-وزارة التجارة والصناعة، 2020/2016، "إستراتيجية وزارة التجارة والصناعة لتعزيز التتمية

$$
\text { الصناعية والتجارة الخارجية"، مناح على: }
$$

.http://www.mti.gov.eg/Arabic/Documents/strategy\% 2017.pdf

$$
\text { ثانياً: المراجع الأجنبية }
$$

1-Abel,A.B.,1983, "Optimal Investment under Uncertainty", AmeOrican Economic Review, Vol. 73 (1): 228-233.

2- Aboody, D., Levi, S., and Weiss, D., 2017, "Managerial Incentives, Options, and Cost-Structure Choices", Review of Accounting Studies, December: 1-30.

3- Anderson, M.C., and Lee, J.H., 2016, "Asymmetric Cost Behavior: A Life Cycle Analysis", Management Accounting Section (MAS) Research and Case Conference, University of Calgary.

4- Arya, A. and Glover, J., 2001, "Option Value to Waiting Created by a Control Problem" Journal of Accounting Research, Vol. 39 (3): 405-415.

5- Bagshaw, K. B., 2015, "Assessing the Capacity Strategic Options on Capacity Utilisation of Manufacturing Firms in Rivers State, Nigeria", International Journal of Business and Social Science, Vol. 6(10): 64-75.

6- Balakrishnan, R., Sivaramakrishnan, K. and Sprinkle G., 2008, "Managerial Accounting", Hoboken, NJ: Wiley.

7- Balakrishnan, R., Labor, E., and Soderstrom, N.S., 2014, "Cost Structure and Sticky Costs", Journal of Management Accounting Reasearch, Vol.26 (2): 91- 116.

8- Banker, R.D., Bardhan, I.R, and Chen, T.Y., 2008, "The Role of Manufacturing Practices in Mediating the Impact of Activity-Based Costing on Plant Performance", Accounting and Organziations and Society, Vol. 33(1): 1-19. 
9- Banker, R. D., and Byzalov, D., 2014 (a), "Asymmetric Cost Behavior", Journal of Management Accounting Research, Vol. 26(2): 43-79.

10- Banker, R.D., Byzalov, D., Dujowich, J.M.P., 2014 (b), “Demand Uncertainty and Cost Behavior", The Accounting Review, Vol. 89 (3): $839-865$.

11- Banker, R.C., Ciftci, M., and Mashruwala, R., 2006, "The Effect of Prior-Period Sales Changes on Cost Behavior", Available at: http://apps.olin.wustl.edu/workingpapers/ pdf/2006-08-003.pdf.

12- Baranoff, E., Brockett, P. L., and Kahane, Y., 2009, "Risk Management for Enterprises and Individuals", 1 ed, Saylor Foundation.

13- Barclay, M., and Smith, C. W., 2005, "The Capital Structure Puzzle: The Evidence Revisited", Journal of Applied Corporate Finance, Vol. 17 (1): 8 - 17.

14- Bo, H., and Sterken, E., 2007, "Attitude towards Risk, Uncertainty, and Fixed Investment", The North Americian Journal of Economics and Finance, Vol. 18 (1): 59-75.

15- Brierley, J.A., Cowton, C.J., and Drury, C., 2007, "Product Costing Practices in Different Manufacturing Industries: A British Survey”, International Journal of Management, Vol. 24 (4) 667 675.

16- Brigham, E. F., and Houston, J. F., 2007, "Fundamentals of Financial Management", $11^{\text {th }} \mathrm{ed}$, USA: South-Weston Part of the Thomson Corporation.

17- Brigham, E. F., and Ehrhardt, M. C., 2005, "Financial Management: Theory and Practice", $11^{\text {th }}$ ed, USA: South-Weston Part of the Thomson Corporation.

18- Caballero, R. J., 1991, "Competition and the Non-Robustness of the Investment-Uncertainty Relationship", American Economic Revi-ew, Vol. 81 (March): 279-286.

19- Chan, S.H., Gau, G.W., and Wang, K., 1995, "Stock Market Reaction to Capital Investment Decision: Evidence Business Reloc482 
ation", Journal of Financial and Quantitative Analysis, Vol. 30 (1): 81-100.

20- Chen, C., Lu, H., and Sougiannis, T., 2008, "Managerial Empire Building, Corporate Governance, and the Asymmetrical Behavior of Selling, General, and Administrative Costs", Working Paper, Unive-rsity of Illinois at Urbana-Champaign.

21- Chung, K. H., Wright, P., and Charoenwong, C., 1998, "Investment Opportunities and Market Reaction to Capital Expenditures", Journal of Banking and Finance, Vol. 22 (1): 1-60.

22- Concina, L., 2014, "Risk attitude and Economics", Foundation for an Industrial Safety Culuture, Toulouse, France, Free Available at: http://www.Foncsi.org.

23- Costa, W. B., Macedo, M A., Yokoyama, K. Y., and Almeida, J. E., 2017, "The Determinates of the Life Cycle Stages of Brazilian Public Companies: A Study Based on Financial Accounting Variables", BBR Brazilian Business Review, Vol. 4 (3): 304 - 320.

24- Dekkers, R., and Kanapathy, K., 2012, "Practices for Strategic Capacity Management in Malaysian Manufacturing Firms", Procedia-Social and Behavioral Sciences, Vol. 57: 466-476.

25-Deshmukh, S., Voght, S. E., 2005, "Investment, Cash Flow, and Corporate Hedging", Journal of Corporate Finance, Vol. 11(4): 628-644.

26- Dickinson, V., 2011, "Cash Flow Patterns as a Proxy for Firm Life Cycle", The Accounting Review, Vol. 86 (6): 1969-1994.

27- Driver, C., Imai, K., Temple, P., and Urga, G., 2002, "Contrasts Between Classes of Assets in Fixed Investments Panel Equations as A Way of Testing Real Option Theory", Available at:

http://citeseerx.ist.psu.edu/viewdoc/download?doi=10.1.1.202.1233\& rep $=$ rep $1 \&$ type $=$ pdf

28- Guan, B., Zhang, J., and Shang, Z., 2015, "The Analysis of Operating Leverage Effects Based on EBIT", International Conference on Applied Social Science: 1-55. 
29- Guilding, C., Drury, C., and Tayles, M., 2005 "An Empirical Investigation of the Importance of Cost- Plus Pricing", Managerial Auditing Journal, Vol. 20 (2): 125-137.

30- Guiso, L., and Parigi, G., 1999, "Investment and Demand Uncertainty", The Quarterly Journal of Economics, Vol. 114(1): 185-227.

31- Gujarati, D.N., 2009, "Basic Econometrics", $5^{\text {th }}$ ed, New York: McGraw-Hill/Irwin.

32- Habib, A., and Hasan, M. M., 2015, "Firm Life Cycle, Corporate Risk-Taking and Investor Sentiment", Accounting and Finance, Vol. 57 (2): 465 - 497.

33- Harris, C., 2014, "Fixed and Variable Costs: Theory and Practice in Electricity", 1 St Edition, Palgrave Macmillan Limited.

34- Hartman, R., 1972, "The Effect of Price and Cost Uncertainty on Investment", Journal of Economic Theory, Vol. 5 (2): 258-266.

35- Hartman, R. 1976, "Factors Demand with Output Price Uncertainty", American Economic Review, Vol. 66 (4): 675-682.

36- Harvett,C.M.,2013,"AStudy of Uncertainty and Risk Management Practice Relative to Perceived Project Complexity", A Thesis for the Degree of Doctor of Philosphy, Bond University.

37- Hillson, D., and Murray, W., 2007, "Understanding and Managing Risk Attitude", 2 edition, Aldershot, UK, Gower.

38- Holtewert, P., and Bauernhansl, T., 2016, "Increase of Capacity Flexibility in Manufacturing Systems by Substitution of Product Functions", Procedia CIRP, Vol. 57: 92-97.

39- Horngren, C.T., Datar, S.M. and Rajan, M.V., 2015, "Cost Accounting: A Mangerial Emphasis", $15^{\text {th }}$ Edition, Prentice Hall.

40- Horngren, C.T., Datar, S.M. and Rajan, M.V., 2006, "Cost Accounting: A Managerial Emphasis", Pearson Education Incorporation Upper.

41- Huang, M. G., Chang, P. L., and Chou, Y. C., 2008, "Demand Forecasting and Smoothing Capacity Planning for Products with 
High Random Demand Volatility, International Journal of Production Research, Vol. 46 (12): 3223-3239.

42- Ibrahim, A. S, and Ezat, A.N., 2017, "Sticky Cost Behavior: Evidence from Egypt", Journal of Accounting in Emerging Economies, Vol. 7(1): 16-34.

43- Indrawati, N. K., 2017, " Moderating Effects of Manager's Attitude toward Risk on Relationship between Demand Uncertainty and Fixed Investment Decision and the Effect on Firm Value", Australian Academy of Accounting and Finance Review, Vol. 3 (2): $72-84$.

44- Jacobs, F. R., Berry, W. L., Whybark, D. C., and Vollmann, T.E., 2011, "Manufacturing Planning and Control for Supply Chain Management", $1^{\text {st }}$, The Library of Congress, Mc Graw Hill.

45- Jensen, M., 1986, "The aAgency Costs of Free Cash Fows, Coporate Finance, and Takeovers", American Economic Review, Vol. 76 (2): $323-329$.

46- Julka, N., Baines, T., Tjahjono, B., Lendermann, P., and Vitanov, V., 2007, "A Review of Multi-Factor Capacity Expansion Models for Manufacturing Plants: Search for a Holistic Decision Process", International Journal of Production Economics, Vol. 106 (2): 607-621.

47- Kallapur, S., and Elenburg, L., 2005, "Uncertainty, Real Option, and Cost Behavior: Evidence from Washington State Hospitals", Journal of Accounting Research, Vol. 43(5): 735 - 752.

48- Kikolski, M., 2016, "Identification of Production bottlenecks with the Use of Plant Simulation Software",Economics and Management, Vol. 8 (4): 103-112.

49- Kiymaz, H., and Hodgin, R., 2003, "Enhancing Clarity and Competencess of Basic Financial Text Treatments on Operating Leverage", Journal of Economics and Finance Eduction, Vol.2 (1): $35-45$.

50- Knudsen, O. K., and Scandizzo, P. L., 2011, "Real Options and Project Evaluation: A Primer", Working Paper No. 72487, available at: 
http://documents.worldbank.org/curated/en/300761468275362646/pdf /624870WP0P08720June090201100PUBLIC0.pdf.

51-Lamminmaki, D., and Drury, C., 2001, "A Comparison of New Zealand and British Product-Costing Practices", The International Journal of Accounting, Vol. 36 (3): 329 - 347.

52-Leahy, J. V., and Whited, T. M., 1996, "The Effect of Uncertainty on Investments: Some Stylized Facts", Journal of Money, Credit, and Banking, Vol. 28 (1): 64-83.

53-Lee, S., and Park, S.B., 2014, "A Study on the Associated between Operating Leverage and Risk: The Case of the Airline Industry", International Journal of Economics, Vol. 6 (3): 120-125.

54-Leland, H. E., 1972, "Theory of the Firm Facing Uncertain Demand", American Economic Review, Vol. 62 (3): 278-291.

55-Lensink, R., Bo, H., and Sterken, E., 2001, "Investment, Capital Market Imperfections and Uncertainty: Theory and Empirical Results", Cheltenham, UK: Edward Elgar.

56-Levy, H., and Wiener, Z., 2013, "Prospect Theory and Utility Theory: Temporary Versus Permanent Attitude towards Risk", Available at: https://papers.ssrn.com/sol3/ papers.cfm?abstract_id$=2197750$.

57-Liu, M., 2008, "Accruals and Managerial Operating Decisions over the Firm Life-cycle", Working Paper, Pennsylvania State University.

58- Marks, R. N., 2007, "Operating Leverage", Working Paper, University of Chicago and NBER, Available at:https://pdfs.seman-ticscholar.org/2c99/b53b6682f6d30c08997527ae3a8b595d5979.-pdf.

59-Mcdonald, R. L. and Siegel, D. R, 1985, "Investment and the Valuation of Firms When There Is an Option to Shut Down" International Economic Review, Vol. 26 (2): 331-49.

60-Mcdonald, R. L. and Siegel, D. R, 1986, "The Value of Waiting to Invest” Quarterly Journal of Economics, Vol. 101 (4): 707-727.

61-Meunier, G., Ponssard, J. P., and Thomas, C., 2016, "Capacity Investment under Demand Uncertainty: The Role of Imports in the 
U.S Cement Industry", Journal of Economics and Management Strategy, Vol. 25(2): 455-486.

62-Nakamura, T., 1999, "Risk - Aversion and Uncertainty - Investment Relationship: A note", Journal of Economic Behavior and Organization, Vol. 38 (3): 357-363.

63-Nickell, S. J., 1978, "The Investment Decision of Firms", Cambridge, MA: Cambridge University Press.

64-Noreen, E., and Soderstrom, N., 1994, "Are Overhead Costs Strictly Proportional to Activity?: Evidence from Hospital Departments, Journal of Accounting and Economics, Vol.17 (1): 255-278.

65-Noreen, E., and Soderstrom, N., 1997, "The Accuracy of Proportional Cost Models: Evidence from Hospital Service Departments", Review of Accounting Studies, Vol. 2 (1): 89-114.

66-Nwaeze, E. T., 2004, "Replacement versus Adaptation Investments and Equity Value", Journal of Corporate Finance, Vol. 11(3): 523549.

67-Oberholzer, M., and Ziemerink, J., 2004 "Cost behaviour classification and cost behaviour structures of manufacturing companies", Meditari Accountancy Research, Vol. 12 (1):179-193.

68-Oler, D., and Picconi, M., 2010, "Implications of Insufficient and Excess Cash for Future Performance", Working Paper, Texas Tech University and Indiana University.

69-Olhager, J., Rudberg, M., and Wikner, J., 2001, "Long-Term Capacity Management Linking the Perspectives from Manufacturing Strategy and Sales and Opertions Planning", International Journal of Production Economics, Vol. 69: 215-225.

70-Pavlatos, O., 2011, "The Impact of Strategic Management Accounting and Cost Structure on ABC Systems in Hotels", Journal of Hospitality Financial Management, Vol. 19 (2): 52 - 73.

71-Raffi, F., and Swamidass, P.M., 1987, "Towards a Theory of Manufacturing Overhead Cost Behavior: A Conceptual and Empirical Analysis", Journal of Operations Management, Vol.7 (1,2): 121-137. 
72-Sandmo, A., 1971, "The Theory of the Competitive Firm Underprice Uncertainty", American Economic Review, Vol. 61 (1): 6573.

73-Schwartz, E., and Trigeorgis, L., 2001, "Real Options and Investment Under Uncertainty: Classical Reading and Recent Contributions", First edition, Library of Congress, Massachusetts Insititute of Technology.

74-Shapira, Z., 1995, "Risk Taking A Managerial Perspective", Russell Sage Foundation, New York, Library of Congress.

75-Toma, S. V., Chitita, M., and Sarpe, D., 2012, "Risk and Uncertainty", Procedia Economics and Finance, Vol. 3: 975-980.

76-Varila, M., Seppanen, M., and Heinonen, E., 2005, " Effects of Automation on Cost Accounting: A Case Study in Warehouse Logistics", $7^{\text {th }}$ Manufacturing Accounting Research Conference, Tampere, Finland, May 30- June 1: 1-15.

77-Via, N., and Perego, P., 2014, "Sticky Cost Behaviour: Evidence from Small and Medium Sized Companies", Accounting and Finance, Vol. 54 (3): 753-778.

78-Vorst, P., and Yohn,T. L., 2017, "Life Cycle Models and Forecasting Growth and Profitability", Available at:http://sydney.edu.au/business/_data/assets/pdf_file/0007/340945/meafa2018_yo hn.pdf.

79-Wesiss, D., 2010, “Cost Behavior and Analysts' Earnings Forecasts", The Accounting Review, Vol.85 (4): 1441 - 1471. 


\section{ملحـق البحث}

قائمة بأسماء الشركات محل البحث

\begin{tabular}{|c|c|c|c|}
\hline 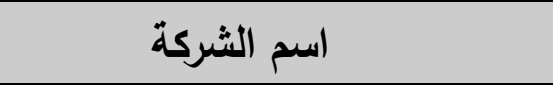 & b & اسم الثركة & b \\
\hline الاسكندرية للادوية والصناعات الكيماوية & 39 & الالتا للسكر & 1 \\
\hline ممفيس للادوية والصناعات الكيماوية & 40 & أجواء للصناعات الغذائية - مصر & 2 \\
\hline المالية والصناعية المصرية & 41 & العربية لمنتجات الألبان " آراب ديرى" & 3 \\
\hline القاهرة للادوية والصناعات الكيماوية & 42 & الثرقية الوطنية للأمن الغذائى & 4 \\
\hline كفر الزيات للمبيدات والكيماويات & 43 & مطاحن شرق الدلتا & 5 \\
\hline مصر للزيوت والصابون & 44 & مطاحن ومخابز شمال القاهرة & 6 \\
\hline غاز مصر & 45 & مطاحن مصر الوسطى & 7 \\
\hline الشروق الحديثة للطباعة والتظليف & 46 & مطاحن ومخابز جنوب القاهرة والجيزة & 8 \\
\hline رويكس لتصنيع البلاستيك & 47 & مطاحن وسط وغرب الدلتا & 9 \\
\hline الشرق الاوسط لصناعة الزجاج & 48 & المصرية لصناعة النشا والجلوكوز & 10 \\
\hline العز للسيراميك والبورسلين - الجوهرة & 49 & العامة للصوامع والتخزين & 11 \\
\hline العامة لمنتجات الخزف والصينى & 50 & مطاحن مصر العليا & 12 \\
\hline القومية للاسمنت & 51 & مطاحن ومخابز الأسكندرية & 13 \\
\hline العربية للخزف - اراسمكو & 52 & القاهرة للزيوت والصابون & 14 \\
\hline ليسيكو مصر & 53 & الاسكندرية للغزل والنسيج (سبينالكس) & 15 \\
\hline السويس للاسمنت & 54 & النيل لحليج الاقطان & 16 \\
\hline 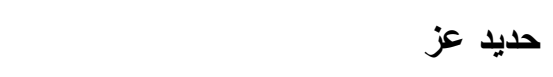 & 55 & جولان تكس للاصواف & 17 \\
\hline اسمنت بورتلاند طرة المصرية & 56 & العربية لطيج الاقطان & 18 \\
\hline جنوب الوادى للاسمنت & 57 & العربيــة ويولفـــارا للغـزل والنســيج - & 19 \\
\hline مصر بنى يوسف للاسمنت & 58 & النساجون الثرقيون للسجاد & 20 \\
\hline مصر للاسمنت - قنا & 59 & النصر للملابس والمنسوجات - كابو & 21 \\
\hline اسمنت سيناء & 60 & العامة لصناعة الورق - راكتا & 22 \\
\hline الالومنيوم العربية & 61 & السويس للاكياس & 23 \\
\hline
\end{tabular}




\begin{tabular}{|c|c|c|c|}
\hline العز الاخيلة للصلب - الاسكندرية & 62 & الورق للشرق الاوسط - سيمو & 24 \\
\hline الحديد والصلب المصرية & 63 & الاهرام للطباعة والتظليف & 25 \\
\hline اكرو مصر للشدات والسقلات المعدنية & 64 & الشرقية للاخان - ايسترن كومبانى & 26 \\
\hline مصر للالومنيوم & 65 & المصرية الدولية للصناعات الداوائية - & 27 \\
\hline الصناعات الهندسية المعمارية للانشاء ايكون & 66 & مينا فارم للادوية والصناعات الكيماوية & 28 \\
\hline مصر لصناعة التبريد والتكييف - ميراكو & 67 & الاسكندرية للزيوت المعدنية & 29 \\
\hline النصر لصناعة المحولات - الماكو & 68 & اكتوير فارما & 30 \\
\hline الكابلات الكهريائية المصرية & 69 & سيدى كرير للبتروكيماويات & 31 \\
\hline الاسكندرية لاسمنت بورتلاند & 70 & جلاكسو سميثكلاين & 32 \\
\hline الحديثة للمواد العازلة - مودرن (بيتومود) & 71 & ابو قير للاسمدة والصناعات الكيماوية & 33 \\
\hline العربية للصناعات الهندسية. & 72 & الصناعات الكيماوية المصرية - كيما & 34 \\
\hline 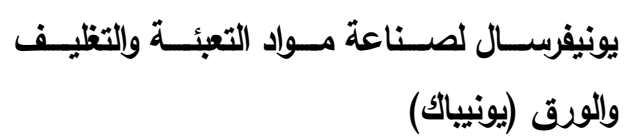 & 73 & مصر لصناعة الكيماويات & 35 \\
\hline اسيك للتعدين - اسكوم & 74 & الزيوت المستخلصة ومنتجاتها & 36 \\
\hline سماد مصر - ايجفريت & 75 & البويات والصناعات الكيماوية - باكين & 37 \\
\hline النيل للادوية والصناعات الكيماوية & 76 & العربية للادوية والصناعات الكيماوية & 38 \\
\hline
\end{tabular}

